\title{
How Radical are 'Radical' Photocatalysts? A Closed-Shell Meisenheimer Complex is Identified as a Super-reducing Photoreagent
}

\author{
Adam J. Rieth, Miguel I. Gonzalez, Bryan Kudisch, Matthew Nava, and Daniel G. Nocera* \\ ${ }^{a}$ Department of Chemistry and Chemical Biology, Harvard University, 12 Oxford Street, Cambridge, MA 02138, \\ USA.
}

\begin{abstract}
Super-reducing excited states have the potential to activate strong bonds, leading to unprecedented photoreactivity. Excited states of radical anions, accessed via reduction of a precatalyst followed by light absorption, have been proposed to drive photoredox transformations under super-reducing conditions. Here we investigate the radical anion of naphthalene monoimide as a photoreductant and find that the radical doublet excited state has a lifetime of $24 \mathrm{ps,} \mathrm{which} \mathrm{is} \mathrm{too} \mathrm{short} \mathrm{to} \mathrm{facilitate} \mathrm{photoredox} \mathrm{activity.}$ To account for the apparent photoreactivity of the radical anion, we identify an emissive two-electron reduced Meisenheimer complex of naphthalene monoimide, $[\mathrm{NMI}(\mathrm{H})]^{-}$. The singlet excited state of $[\mathrm{NMI}(\mathrm{H})]^{-}$is a potent reductant $\left(-3.08 \mathrm{~V}\right.$ vs $\left.\mathrm{Fc} / \mathrm{Fc}^{+}\right)$, is long-lived (20 ns), and its emission can be dynamically quenched by chloroarenes to drive a radical photochemistry, establishing that it is this emissive excited state that is competent for reported $\mathrm{C}-\mathrm{C}$ and $\mathrm{C}-\mathrm{P}$ coupling reactivity. These results provide a mechanistic basis for photoreactivity at highly reducing potentials via singlet excited state manifolds and lays out a clear path for the development of exceptionally reducing photoreagents derived from electron-rich closed-shell anions.
\end{abstract}

\section{INTRODUCTION}

Exploring the redox potential limits accessible by photoinduced single-electron transfer can unlock new reactivity and expand the range of processes amenable to photoredox chemistry and the design of attendant synthetic methods. Using standard photocatalysts with ground state highest occupied molecular orbital (HOMO) potentials near to or more oxidizing than that of the normal hydrogen electrode $(\mathrm{NHE}=0)$, bond activation energies using visible light have been practically limited to less than $\sim 2 \mathrm{~V}$ in either direction. ${ }^{1,2}$ Recently, these limits have been circumvented by shifting the ground state potential of the photocatalyst via redox processes prior to light absorption; oxidation of a precatalyst followed by light absorption generates strongly oxidizing excited states ${ }^{3-6}$ and reduction of a precatalyst followed by light absorption can generate super-reducing excited states. ${ }^{7-11}$ These two-photon or electrophotocatalytic processes dramatically expand the range of photo-accessible synthetic disconnections. ${ }^{7-11}$ Additionally, because the processes are photoactivated, they are selective for single electron transfer (SET) even in cases where direct electrolysis would result in over-oxidation or -reduction. ${ }^{7}$ Although the highly reducing nature of excited organic radical anions has long been recognized, ${ }^{17,12,13}$ the mechanism and energetics of a process driven by a doublet excited state is quizzical as internal conversion for such a $\Delta S=0$ nonradiative decay to a doublet ground state is exceptionally fast. Spectroscopic investigations of organic radicals have demonstrated nearly universally short excited-state lifetimes on the ps timescale, ${ }^{14-19}$ in one case even shorter than a single vibrational period ( $7 \mathrm{fs}$ ). ${ }^{20}$ The short lifetime of doublet excited states cannot support bimolecular processes of photoredox reactions as the lifetime $\left(\tau_{o}\right)$ of the active excited state should be longer than the average time between molecular encounters - that is $\tau_{\mathrm{o}} \geq 1 / k_{\mathrm{d}}$ [sub] where $k_{d}$ is the rate of diffusion (typically $\sim 10^{9}-10^{10} \mathrm{M}^{-1} \mathrm{~s}^{-1}$ ), and [sub] is the concentration of substrate. For a substrate concentration of 0.1 $\mathrm{M}$, an approximate lower bound for a SET process requiring diffusion is $\tau_{\mathrm{o}} \geq 1-10 \mathrm{~ns}$. Therefore, the measured excited state lifetimes of nearly all radical doublet species are orders of magnitude too short to result in productive photochemistry. Indeed, excited state spectral features with lifetimes longer than $1 \mathrm{~ns}$ measured for several presumptive radical anions ${ }^{21,22}$ were later shown to instead arise from longer-lived closed shell impurities. For instance, the radical anions of both 9,10dicyanoanthacene and anthraquinone were later found to contain the emissive byproducts cyanoanthrolate or bianthrolate, respectively. ${ }^{14-19,22}$ Therefore, there is an imperative to better understand the nature of super-reducing radical photoreagents. ${ }^{7,9,10}$ A proper mechanistic understanding of the origins of super-reducing photochemistry can facilitate their application in the design of photoredox methods, and expand the possibilities for bond activation via reductive SET. ${ }^{23}$

Here we show that for one recently reported photoelectrocatalyst, naphthlalene monoimide (NMI), ${ }^{7}$ the photoactive component is not a radical, but a two-electron reduced species. Using a combination of cyclic voltammetry, spectroelectrochemistry, and ultrafast spectroscopy, we 


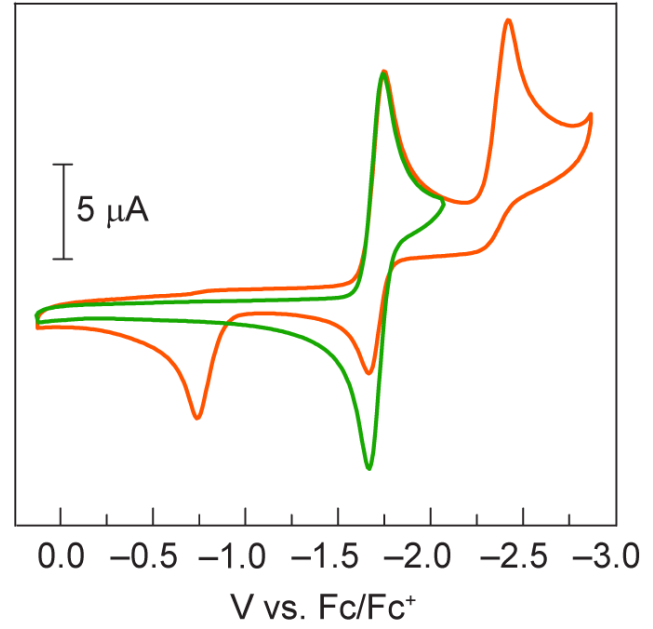

Figure 1. (A) Cyclic voltammograms of $1 \mathrm{mM}$ NMI in $0.1 \mathrm{M}$ $\mathrm{TBAPF}_{6}$ propylene carbonate solution, scanning at $50 \mathrm{mV} \mathrm{s}$ from 0.2 to $-2.0 \mathrm{~V}$ (green) and 0.2 to $-2.8 \mathrm{~V}$ (orange), using a glassy carbon working electrode, $\mathrm{Pt}$ mesh counter electrode, and leak-free $\mathrm{Ag} / \mathrm{AgCl}$ reference electrode.

demonstrate that two-electron reduction of NMI produces an emissive Meisenheimer complex, ${ }^{24,25}[\mathrm{NMI}(\mathrm{H})]^{-}[\mathrm{TBA}]^{+}$(TBA $=$ tetrabutylammonium), which has been isolated and crystallographically characterized. Time-resolved spectroscopy reveals that the lifetime of the doublet excited state of the radical anion $\left(\tau\left[{ }^{2} \mathrm{NMI}^{-}\right]^{*}\right)$ is $24 \mathrm{ps}$, which is too short to participate in photoredox chemistry. By contrast, the lifetime of the singlet excited state of the Meisenheimer complex $\left(\tau\left[{ }^{1} \mathrm{NMI}(\mathrm{H})^{-}\right]^{*}\right)$ is $20 \mathrm{~ns}$. This long fluorescent lifetime together with a $-3.08 \mathrm{~V}$ vs. $\mathrm{Fc} / \mathrm{Fc}^{+}$excited state energy gives rise to super-reducing chemistry. Indeed, the emissive excited state of the doubly reduced Meisenheimer complex is dynamically quenched by haloarene substrates, and leads to the previously observed $\mathrm{C}-\mathrm{C}$ and $\mathrm{C}-\mathrm{P}$ coupling reactivity. ${ }^{7}$ These results provide a clear mechanistic underpinning for super-reducing photoelectrocatalysis, laying out a path for the further development of powerfully reducing closed-shell anions as photoreagents for novel bond activation pathways.

\section{RESULTS}

Cyclic voltammetry (CV) of NMI in propylene carbonate containing $0.1 \mathrm{M}$ tetrabutylammonium hexafluorophosphate

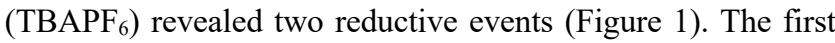
reduction wave occurs at $-1.7 \mathrm{~V}$ vs $\mathrm{Fc} / \mathrm{Fc}^{+}$and is fully reversible, so long as the sweep potential is limited to avoid the second reductive wave (Figure 1, green). The first reductive event corresponds to a single electron transfer to reversibly form the NMI radical anion, as previously observed. ${ }^{7,18}$ The second reductive feature is irreversible, at approximately -2.6 $\mathrm{V}$ (Figure 1, orange), and also corresponds to a one-electron process, coupled to a chemical step. The appearance of this irreversible reductive wave is accompanied by the emergence of an oxidative feature at $-0.7 \mathrm{~V}$, as well as a decrease in the peak height for reoxidation of the previously reversible feature at $-1.7 \mathrm{~V}$. Increasing the scan rate results in the formation of two distinct oxidation features near $-0.7 \mathrm{~V}$, as well as partial reversibility of the $-0.7 \mathrm{~V}$ feature upon reduction (Figure $\mathrm{S} 1$, $\mathrm{S} 2$ ). The cyclic voltammetry features are not altered after 10

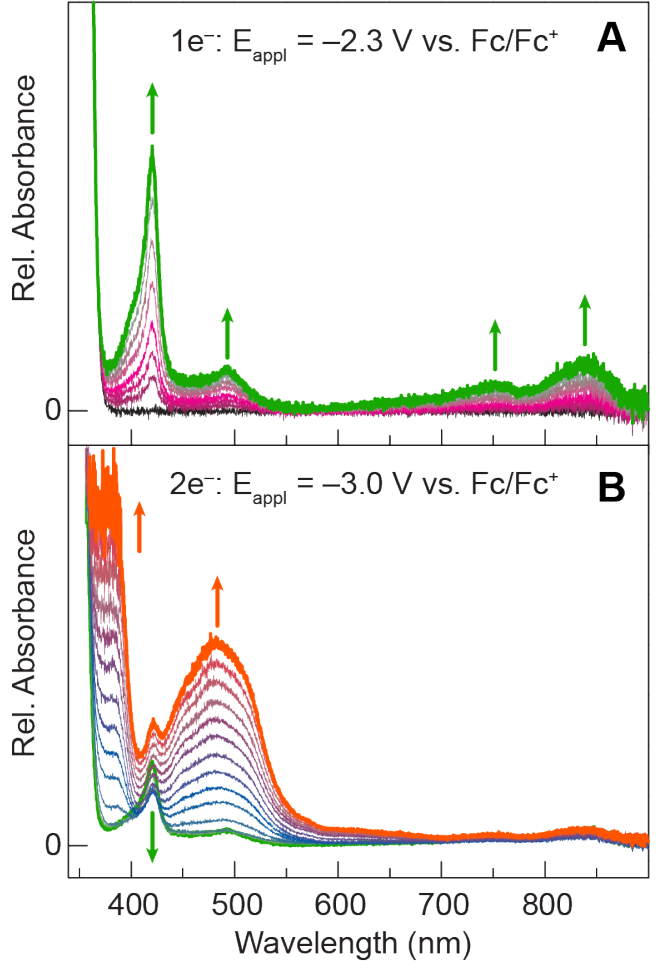

Figure 2. UV-visible spectroelectrochemistry of $1 \mathrm{mM}$ NMI in

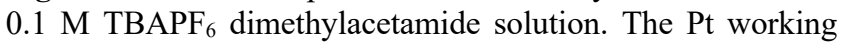
electrode was poised at the $1 \mathrm{e}^{-}$reducing potential of $\mathrm{E}_{\text {appl }}=-$ $2.3 \mathrm{~V}(\mathbf{A})$ and the $2 \mathrm{e}^{-}$reducing potential of $\mathrm{E}_{\mathrm{appl}}=-3.0 \mathrm{~V}(\mathbf{B})$.

cycles (Figure S3). After scanning past $-2.6 \mathrm{~V}$, the reversibility of the radical anion feature at $-1.7 \mathrm{~V}$ can be recovered when the scan is limited to $-2.0 \mathrm{~V}$ on the subsequent cycle (Figure S4).

Figure 2 shows spectroelectrochemistry data when the working electrode in a two-compartment $\mathrm{H}$-cell is polarized to $-2.3 \mathrm{~V}$ vs. $\mathrm{Fc} / \mathrm{Fc}^{+}$, which is sufficiently beyond the first wave to drive the one electron reduction of NMI. Prominent absorption features appear at 422 and $493 \mathrm{~nm}$, as well as weaker absorption signals at 750 and $850 \mathrm{~nm}$ (Figure 2A, green), all of which are characteristic of a naphthalene imide radical anion. ${ }^{18}$ Bulk electrolysis at $-2.3 \mathrm{~V}$ vs. $\mathrm{Fc} / \mathrm{Fc}^{+}$in a W-cell generated a bright lime green solution in the catholyte (Figure S5), with the same absorption features in Figure 2A. Examination of this electrolyzed solution by ultrafast transient absorption $\left(\lambda_{\mathrm{exc}}=\right.$ $420 \mathrm{~nm}$ ) revealed a bleach signal as well as an excited state absorption feature, both of which decay with a lifetime of $24 \mathrm{ps}$ (Figures 3A, 3B). This result is in agreement with previous measurements of rylene imide radical anion excited states. ${ }^{18}$

Figure 2B shows the spectroelectrochemistry of NMI when the applied potential in Figure $2 \mathrm{~A}$ is shifted more reducing, to $-3.0 \mathrm{~V}$, beyond the second reductive wave in CV. Strong absorption features at $385 \mathrm{~nm}$ and $490 \mathrm{~nm}$ grow in (Figure 2B, orange) with the concomitant disappearance of the NMI radical anion absorption features. Bulk electrolysis in a W-cell at -3.0 $\mathrm{V}$ vs. $\mathrm{Fc} / \mathrm{Fc}^{+}$generated a bright orange solution in the catholyte, with visible green emission at $\lambda_{\max }=550-600 \mathrm{~nm}$ (Figure 3C and Figure S5), just beyond the lowest energy absorption feature of the two-electron reduced NMI. A fluorescence excitation spectrum (Figure 3C, light orange dash) coincides with the absorption features of the doubly reduced NMI species, with the most intense emission arising from excitation of the 

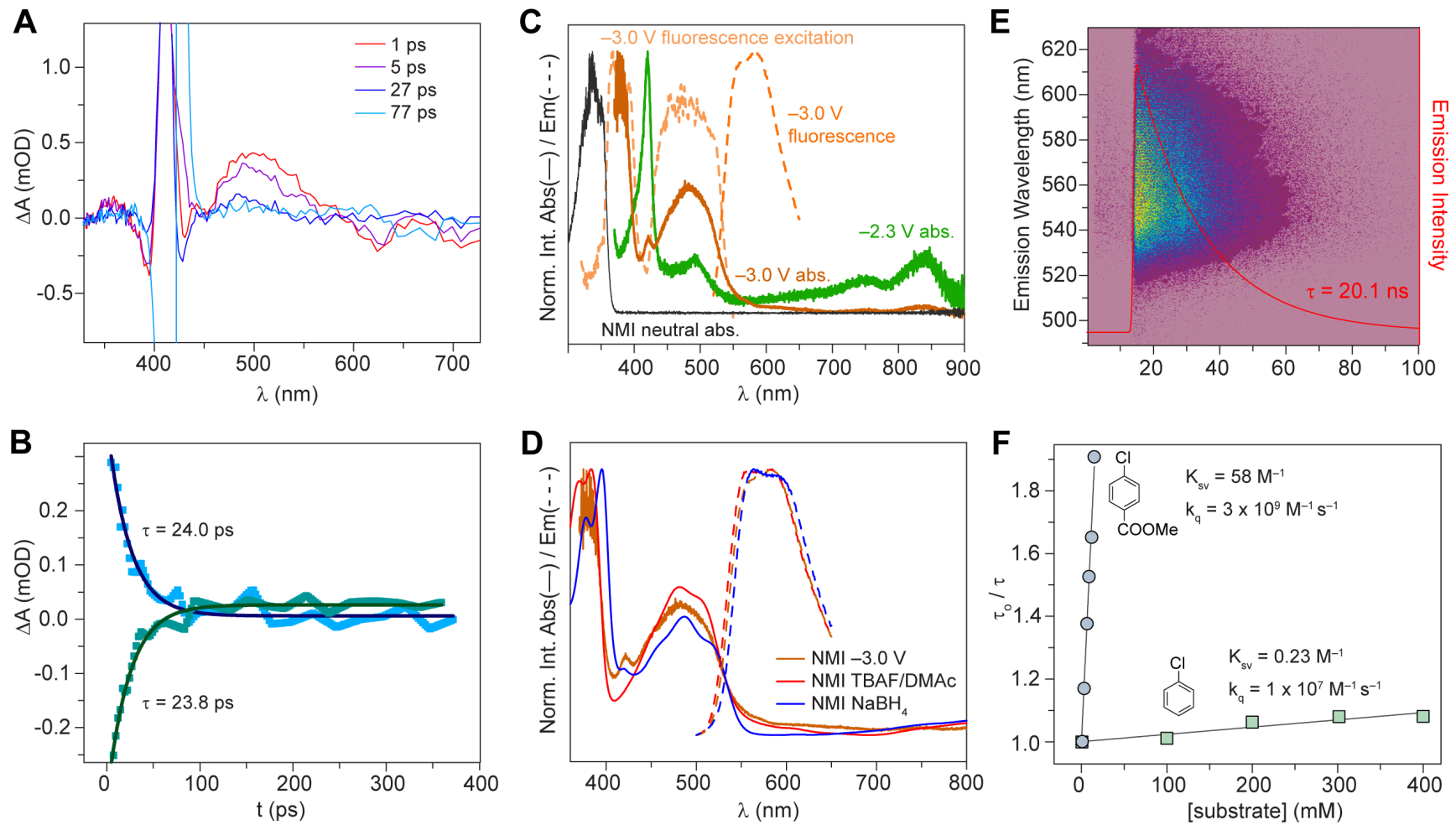

Figure 3. (A) Transient absorption spectra for NMI electrolyzed at $-2.3 \mathrm{~V}$ results in a transient absorption feature at $\lambda_{\max }=500 \mathrm{~nm}$ and a bleaching signal between 380 to $425 \mathrm{~nm}$; the bleach signal is interrupted by a sharp feature at $420 \mathrm{~nm}$ due to the excitation pump used to excite the most prominent absorptive feature of the NMI radical anion. (B) Single exponential decay fits (red lines) to the transient absorption data in panel $\mathbf{A}$ for the excited state absorption intensity averaged between $495-525 \mathrm{~nm}$ ( $\square$, light blue) and the bleach feature between 385-395 nm ( , sea green), both of which exhibit 24 ps lifetimes. (C) Normalized absorption spectra of NMI (black), NMI electrolyzed at $-2.3 \mathrm{~V}$ (one-electron reduced species, green), NMI electrolyzed at $-3 \mathrm{~V}$ (two-electron reduced species, burnt orange), overlayed with the normalized emission spectrum of the $-3.0 \mathrm{~V}$ electrolyzed sample (orange dash) and the excitation scan for the emission at $600 \mathrm{~nm}$ (light orange dash). (D) Normalized absorption (solid) and emission (dashed) spectra for NMI electrolyzed at $-3.0 \mathrm{~V} \mathrm{vs}$. Fc/Fc ${ }^{+}$(burnt orange), NMI treated with TBAF in DMAc (pink), and NMI treated with $\mathrm{NaBH}_{4}$ in DME (blue). (E) fs-pumped streak camera emission image ( $\lambda_{\text {exc }}$ $=480 \mathrm{~nm}$ ) for NMI treated with TBAF in DMAc. Colors represent photon counts (purple is low and red is high). The red line shows a monoexponential fit of data averaged in a 540-560 nm spectral window. (F) Dynamic Stern-Volmer quenching plots of solutions of NMI treated with TBAF in DMAc in the presence of 4-methylchlorobenzoate or chlorobenzene (fitted data presented in Figures S9 and S10).

absorption bands at $385 \mathrm{~nm}$ and $490 \mathrm{~nm}$. A lower-intensity emission with $\lambda_{\max }=550-600 \mathrm{~nm}$ is also observed for samples electrolyzed at $-2.3 \mathrm{~V}$, and its excitation spectrum also matches that of the two-electron reduced NMI (Figure S7). This result is consistent with the $\mathrm{CV}$ in Figure 1, which shows the onset of the second reduction occurs at $-2.3 \mathrm{~V}$. In view of the lowest energy absorption of the NMI radical anion, emission, if present, would be expected to occur beyond $850 \mathrm{~nm}$. However, no emission is observed arising from the NMI radical anion, even when excited at its peak absorption wavelength $\lambda_{\max }=420$ $\mathrm{nm}$ and the emission detection wavelength is scanned into the infrared spectral region ( $\lambda_{\text {det }}=800-1500 \mathrm{~nm}$, InGaAs detector) (Figure S8).

NMI may be reduced chemically using either fluoridemediated solvent oxidation with tetrabutylammonium fluoride (TBAF) in N,N'-dimethylacetamide (DMAc) or treatment with $\mathrm{NaBH}_{4}$ in dimethoxyethane (DME). For both reduction reactions, the absorption and emission spectra of the reduced product match those obtained for the electrochemically twoelectron reduced NMI (Figure 3D). Emission lifetime measurements were performed on NMI solutions in DMAc treated with TBAF using a fs-pumped streak camera (Figure $3 \mathrm{E})$. The data were averaged in the 540 to $560 \mathrm{~nm}$ window and fitted to a single exponential decay to furnish a lifetime of 20.1 ns (Figure 3E, red line).

Addition of chloroarene substrates to NMI treated with TBAF in DMAc resulted in dynamic quenching of the emission lifetime (Figures S9 and S10). Figure 3F shows well-behaved Stern-Volmer kinetics as measured by lifetime quenching. For methyl-4-chlorobenzoate the quenching rate constant is $k_{\mathrm{q}}=3 \times$ $10^{9} \mathrm{M}^{-1} \mathrm{~s}^{-1}$, and for the more challenging reduction of chlorobenzene, the quenching rate constant is reduced to $k_{\mathrm{q}}=$ $10^{7} \mathrm{M}^{-1} \mathrm{~s}^{-1}$.

Isolation of the doubly reduced, emissive NMI species proved possible via treatment of NMI with $\mathrm{NaBH}_{4}$ in dimethoxyethane. Anion exchange of the resulting product with tetrabutylammonium chloride resulted in a bright orange solid. ${ }^{1} \mathrm{H}$ and Heteronuclear Single Quantum Correlation Distortionless Enhancement by Polarization Transfer (HSQCDEPT) NMR experiments offered initial evidence of a hydridereduced naphthalene ring: the phase of the resonance near 4.1 ppm in ${ }^{1} \mathrm{H}$ NMR indicates a $\mathrm{CH}_{2}$ group, and not a $\mathrm{CH}$ or $\mathrm{CH}_{3}$ group (Figure S11). Experimental NMR spectra were consistent with ab initio structure and NMR chemical shift calculations of two NMI hydride addition isomers, ortho- and para-[NMI(H) $]^{-}$ (Tables S9-S10 for ${ }^{1} \mathrm{H}, \mathrm{S} 14-\mathrm{S} 15$ for ${ }^{13} \mathrm{C}$, and S18-S19, Figure 
A
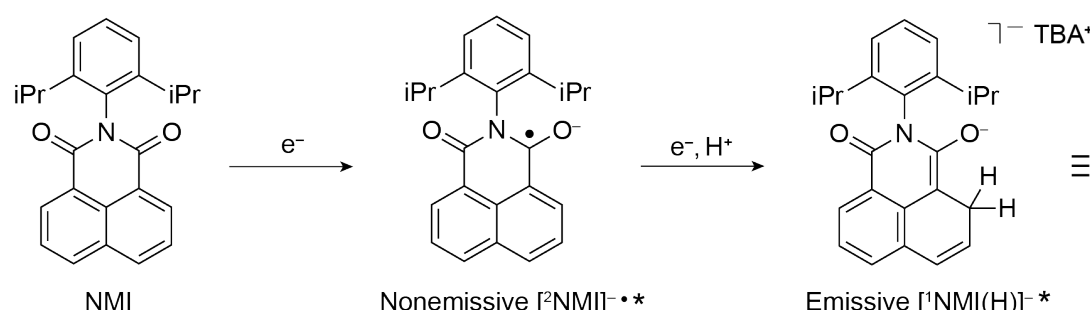

Nonemissive $\left[{ }^{2} \mathrm{NMI}\right]^{-\bullet *}$ $\tau=24 \mathrm{ps}$

Emissive $\left[{ }^{1} \mathrm{NMI}(\mathrm{H})\right]^{-*}$ $\tau=20 \mathrm{~ns}$

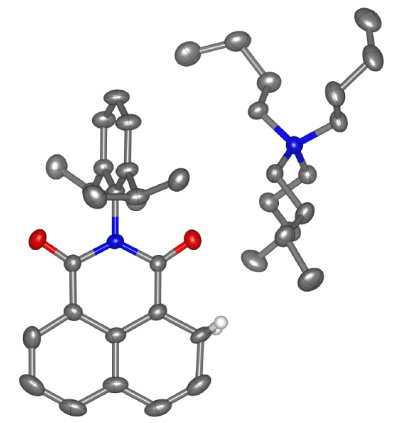

B

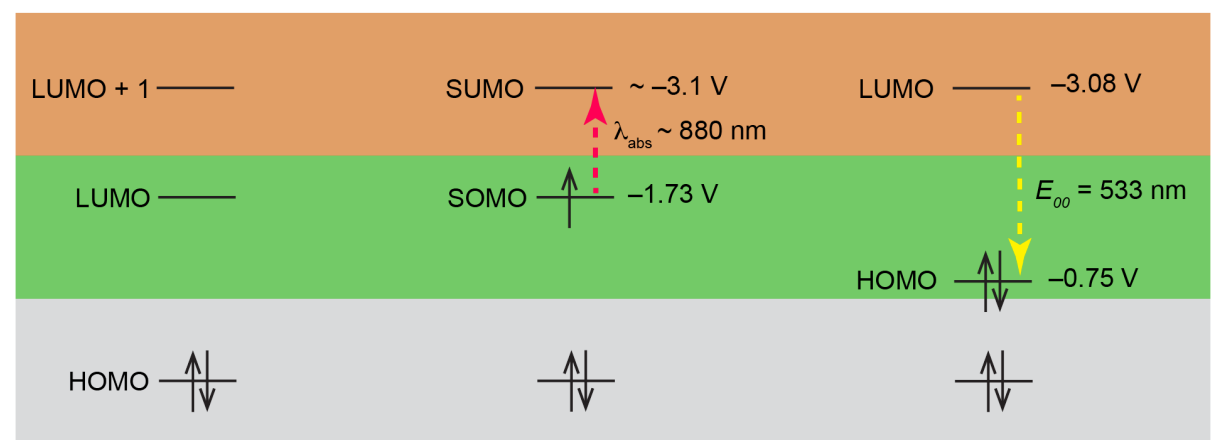

Figure 4. (A) Single-electron reduction of naphthalene monoimide (NMI) furnishes the radical anion with a doublet excited state $\left(\left[{ }^{2} \mathrm{NMI}^{\bullet}\right]^{*}\right)$ lifetime of $24 \mathrm{ps}$. A second electron transfer followed by protonation furnishes a two-electron reduced, emissive Meisenheimer complex with a singlet excited state $\left(\left[^{1} \mathrm{NMI}(\mathrm{H})^{-}\right]^{*}\right)$ lifetime of $20 \mathrm{~ns}$. Right: crystal structure of $[\mathrm{NMI}(\mathrm{H})]^{-}[\mathrm{TBA}]^{+}: \mathrm{C}$, gray; N, blue; O, red; H, white. H atoms except those on the $\mathrm{sp}^{3}$ carbon of the naphthalene ring are omitted and disorder is removed for clarity. Thermal ellipsoids shown at $50 \%$ probability. (B) Simplified energy level diagram of the NMI system; all potentials given vs. $\mathrm{Fc} / \mathrm{Fc}^{+}$. Energy levels for each species is aligned with the compounds in $\mathbf{A}$. SOMO = singly occupied molecular orbital. SUMO = singly unoccupied molecular orbital. Energetics of [NMI(H)] are assigned in Figure S21.

S20 for NMR peak assignments). Additional calculations revealed that the NMR data is inconsistent with two other conceivable isomers, meta- and carbo- $[\mathrm{NMI}(\mathrm{H})]^{-}$(Tables $\mathrm{S} 11-$ $\mathrm{S} 12$ for ${ }^{1} \mathrm{H}, \mathrm{S} 16-\mathrm{S} 17$ for ${ }^{13} \mathrm{C}$ ).

Recrystallization of the $\mathrm{NaBH}_{4}$-reduced NMI via slow diffusion of diethyl ether into a toluene solution of the product resulted in orange blade-like crystals suitable for single-crystal $\mathrm{X}$-ray diffraction analysis (Figure S12). Figure 4A shows the structure of the product, which corresponds to a reduced anionic NMI species with a charge-balancing $[\mathrm{TBA}]^{+}$countercation. A slight twist was evident in the imide ring, with a dihedral angle of $2.5^{\circ}$. Further examination of the structure revealed that the two carbon atoms at the 2- and 7-positions of the reduced naphthalene ring exhibited $\mathrm{C}-\mathrm{C}$ bond lengths that were longer than expected for $\mathrm{sp}^{2}$-hybridized carbon atoms. In addition, the residual electron density around these carbon atoms suggested the presence of both $\mathrm{C}\left(\mathrm{sp}^{3}\right) \mathrm{H}_{2}$ and $\mathrm{C}\left(\mathrm{sp}^{2}\right) \mathrm{H}$ hydrogen atoms. Accordingly, the structure was best refined with one $\mathrm{sp}^{3}$ hybridized carbon and one $\mathrm{sp}^{2}$ hybridized carbon disordered over the 2- and 7-positions. Consistent with the quinodal structure of a hydride-reduced Meisenheimer complex, the average carbonyl $\mathrm{C}-\mathrm{O}$ bond distances were lengthened by $0.035(6) \AA$ and the average $\mathrm{C}-\mathrm{C}$ bond distances between the carbonyl groups and the reduced naphthalene ring were shortened by $0.048(5) \AA$ with respect to the independently crystallized neutral NMI (Table S1). These relative changes in bond lengths are consistent with ab initio calculations for NMI and ortho-[NMI(H)]- (Figures S13 and S14, and Tables S3 and S4). Other structures of formal hydride addition products of NMI were also optimized, including para-, meta-, and carbo-
$[\mathrm{NMI}(\mathrm{H})]^{-}$, which did not match the crystallographic bond length changes (Figures S15-S17 and Tables S5-S7)

A cyclic voltammogram of the isolated $[\mathrm{NMI}(\mathrm{H})]^{-}[\mathrm{TBA}]^{+}$ reveals a prominent irreversible oxidative wave near $-0.7 \mathrm{~V}$ (Figure S6), matching the features observed upon the twoelectron reduction of the neutral NMI. Additionally, using $[\mathrm{NMI}(\mathrm{H})]^{-}[\mathrm{TBA}]^{+}$as a stoichiometric photoreagent, the reactivity previously reported to be due to the NMI radical anion is reproduced. ${ }^{7}$ Specifically, treatment of $[\mathrm{NMI}(\mathrm{H})]^{-}$ $[\mathrm{TBA}]^{+}$with stoichiometric methyl-4-chlorobenzoate in $\mathrm{C}_{6} \mathrm{D}_{6}$ resulted in no reaction in the dark (Figure S22). Upon $440 \mathrm{~nm}$ irradiation, the reductive homocoupling product dimethylbiphenyl-4,4'-dicarboxylate is observed as the major product, along with a smaller amount of the hydrodehalogenation product methyl benzoate (Figure S22). In the presence of excess $\mathrm{N}$-methyl pyrrole, the $\mathrm{C}-\mathrm{C}$ coupling product resulting from benzoate radical addition to $\mathrm{N}$-methyl pyrrole is also observed (Figure S23). In the presence of 5 equiv. triethylphosphite, the C-P coupling product methyl 4-(diethoxyphosphoryl)benzoate was obtained as the major product (Figures S24, S25).

\section{DISCUSSION}

Figure 4A summarizes the results of NMI redox chemistry and attendant excited state energetics and dynamics. NMI is reduced at $-1.73 \mathrm{~V}$ vs. $\mathrm{Fc} / \mathrm{Fc}^{+}$and when the voltammetry scan range is limited to less than $-2.3 \mathrm{~V}$, the one-electron wave is reversible, indicating the formation of a stable radical anion, $\mathrm{NMI}^{-}$(Figure 1, green). Bulk electrolysis of NMI at $-2.3 \mathrm{~V}$ vs. $\mathrm{Fc} / \mathrm{Fc}^{+}$yields the well-defined and characteristic absorption spectrum of $\mathrm{NMI}^{-}$shown in Figure $2 \mathrm{~A}$ (green trace). The 
absorption spectrum of solutions in the dark are indefinitely stable in the glovebox, allowing for the $\mathrm{NMI}^{-}$excited state properties to be examined upon its production by bulk electrolysis. The absence of emission from solutions of the radical anion is noteworthy, as the quantum yield for emission is:

$$
\Phi_{\mathrm{e}}=k_{\mathrm{r}} /\left(k_{\mathrm{r}}+k_{\mathrm{nr}}\right)
$$

where $k_{\mathrm{r}}$ is the rate of radiative relaxation and $k_{\mathrm{nr}}$ is the rate of nonradiative relaxation. The lack of emission is indicative of fast non-radiative decay subject to the condition that $k_{\mathrm{nr}}>k_{\mathrm{r}}$. This contention is verified by transient absorption spectroscopy (Figure 3A), which is able to capture the dynamics of the radical anion inasmuch as there is no emission signal available to monitor excited state decay kinetics. The bleaching signal as a result of ground state depletion $(\lambda=385-395 \mathrm{~nm})$ recovers with the same lifetime (24 ps) as the decay of the excited state absorption signal $(\lambda=495-525 \mathrm{~nm})$ of the NMI radical anion. A 24 ps lifetime of the radical anion excited state (Figure 3B) is too short to support bimolecular chemistry. Assuming an electron transfer rate constant at the diffusion limit of $10^{10} \mathrm{M}^{-1}$ $\mathrm{s}^{-1}$, at the concentrations that substrate has been employed for photoreactivity $(0.1 \mathrm{M})$, the chromophore will encounter a substrate molecule on average every $1 \mathrm{~ns}$. Therefore, with a lifetime of 24 ps, $\sim 42$ lifetimes of the excited state will pass between chromophore-substrate interactions, resulting in an excited state concentration of $\sim 10^{-19}$ times the original concentration of excited state. The passage of so many excited state lifetimes between chromophore-substrate collisions would give rise to a vanishingly small quantum yield that is too low to support observed photoredox conversion yields, which are achieved in a timescale of hours. In the absence of a viable photoredox chemistry of the radical anion, we sought to identify the species responsible for effecting the single-electron reductive chemistry of haloarenes, as such a photoreagent must possess potent reducing properties, which could be useful for a wide range of chemical conversions.

Extending the cathodic window of $\mathrm{CV}$ scans to more negative potential, a second wave is observed beyond the NMI radical anion (Figure 1, orange). The wave in Figure 1 is extremely informative. The cathodic current matches that observed for reduction of NMI to $\mathrm{NMI}^{-}$, thus indicating a oneelectron process. Moreover, the irreversibility of the second reductive wave is a characteristic of an EC process ${ }^{26}$ in which NMI radical anion undergoes a facile chemical reaction following the addition of an electron. The observation of a remnant amount of radical anion upon the anodic scan likely results from a limiting proton inventory needed for the chemical step of the EC process (vide infra). The anodic wave at $\mathrm{E}_{\mathrm{p}, \mathrm{a}}=-$ $0.65 \mathrm{~V}$ (orange trace) is associated with the product of the EC process of the NMI radical anion. At fast scan rates, the wave exhibits quasi-reversible behavior (Figure S2), indicative of a redox process associated with the product of the two-electron EC process of NMI.

Spectroelectrochemistry of NMI solutions under an applied voltage of $-3.0 \mathrm{~V}$ reveals the two-electron species may cleanly be generated and is stable in the absence of oxygen, as indicated by the permanence of the absorption spectrum (Figure 2B). Bulk electrolysis of the NMI solutions at $-3.0 \mathrm{~V}$ generates an orange solution with a pronounced emission band, $\lambda_{\text {em, max }}=563$ $\mathrm{nm}$ (Figure 3C). Excitation scans reveal that the fluorescence tracks the 385 and $490 \mathrm{~nm}$ absorption envelopes of the twoelectron reduced NMI species (Figure 3C). We note that the excitation spectrum in Figure $3 \mathrm{C}$ is the same as that recently assigned to an excitation spectrum of a purported quartet excited state of $\mathrm{NMI}^{-} \cdot{ }^{27}$ As the excitation spectrum is not that of the NMI radical anion, our result establishes that emission originates from the excited state of the two-electron reduced NMI species and not from either a spin-allowed or a spin forbidden excited state of the radical anion.

The cyclic voltammetry and spectroelectrochemistry results suggested that the doubly reduced NMI species generated from the EC process could be chemically generated and isolated. Treatment of NMI with $\mathrm{NaBH}_{4}$, followed by cation exchange, allowed for the isolation and crystallographic characterization of $[\mathrm{NMI}(\mathrm{H})]^{-}[\mathrm{TBA}]^{+}$(Figures 4 and S12). NMR characterization and comparison to DFT NMR shift calculations indicated the likely presence of two isomers, wherein the $\mathrm{sp}^{3}$ carbon on the naphthalene ring is either orthoor para- to the imide ring (Figures S11 and S20, Tables S18 and S19). Crystallographic refinement gave bond metrics consistent with the ortho- isomer (Table S1, Figure S12). Cyclic voltammetry of the isolated $[\mathrm{NMI}(\mathrm{H})]^{-}[\mathrm{TBA}]^{+}$revealed the same peaks as for neutral NMI, with a prominent initial oxidative wave at $-0.7 \mathrm{~V}$ vs. $\mathrm{Fc} / \mathrm{Fc}^{+}$(Figure S6). These results confirm the assignment of the two-electron reduced NMI observed in electrochemistry as the hydride-reduced species, $[\mathrm{NMI}(\mathrm{H})]^{-}$.

NMI may also be conveniently reduced by DMAc . Treatment of rylene imides with fluoride sources in some polar aprotic solvents was previously reported to result in one electron reduction, in the dark. ${ }^{32,33}$ The mechanism of this process has been debated in the literature, with initial reports suggesting direct fluoride oxidation ${ }^{32,28}$ later revised by reports of fluoride-mediated solvent oxidation, ${ }^{33}$ wherein a protoncoupled electron transfer (PCET) process involving solvent deprotonation and formation of bifluoride is concomitant with electron transfer from solvent to rylene imide. In the case of rylene bisimides, for which two-electron reductions are fully reversible, this process was demonstrated to terminate at one electron. $^{33,29}$ Here, for naphthalene monoimide, fluoride treatment in DMAc results in the formation of the two-electron reduced NMI, with absorption and emission spectra matching those of the doubly reduced species by spectroelectrochemistry. The same spectra are obtained for treatment of NMI with hydride transfer reagents such as $\mathrm{NaBH}_{4}$ (Figure 3D). We envision three plausible mechanisms for the generation of $[\mathrm{NMI}(\mathrm{H})]^{-}$by fluoride treatment of DMAc: solvent deprotonation followed by direct hydride transfer from solvent to NMI, solvent anion $\sigma$-addition to NMI followed by hydride elimination, or fluoride-mediated solvent oxidation to generate the NMI radical anion, followed by disproportionation. Other mechanisms involving nucleophilic fluoride addition to NMI, similar to that proposed in a recent publication, ${ }^{10}$ may also be operative.

Generation of $[\mathrm{NMI}(\mathrm{H})]^{-}$by TBAF in DMAc proved to be a convenient method to study the emissive lifetime and dynamic quenching with substrates. The lifetime of the emissive excited state of $[\mathrm{NMI}(\mathrm{H})]^{-}, 20 \mathrm{~ns}$, is just long enough to react in a useful fashion in solution limited by diffusion. With this lifetime, 
reactivity requires high substrate concentrations for efficient quenching. The high excited state reduction potential of $[\operatorname{NMI}(\mathrm{H})]^{-}$allows it to react with haloarenes. The two-electron reduced excited state species is dynamically quenched by aryl chlorides previously used as substrates for electrophotocatalytic $\mathrm{C}-\mathrm{C}$ and $\mathrm{C}-\mathrm{P}$ coupling reactions. We show that the fluorescence at $550 \mathrm{~nm}$ is quenched dynamically, indicating that substrate and excited state photocatalyst directly interact, providing an additional relaxation pathway for the photocatalyst which reduces its lifetime. The quenching rate for 4-methylchlorobenzoate, on the order of $10^{9} \mathrm{M}^{-1} \mathrm{~s}^{-1}$, is near the diffusion limit (Figures $3 \mathrm{~F}$ and S8). However, the substantially slower rate for chlorobenzene, on the order of $10^{7} \mathrm{M}^{-1} \mathrm{~s}^{-1}$ (Figures 3F and S9), indicates that this substrate is approaching the limit of redox potential for the excited state.

The reducing power of the $[\mathrm{NMI}(\mathrm{H})]^{-}$excited state, $[\mathrm{NMI}(\mathrm{H})]^{-*}$, may be determined from a Latimer diagram (Figure 21C). With properly assigned spectral properties, the overlap of the absorption and emission profiles of the twoelectron reduced species (Figure S21B) furnishes an $E_{00}$ value of $533 \mathrm{~nm}$, establishing an excited state energy of $2.33 \mathrm{eV}$. The reduction potential of the two-electron reduced NMI is approximated by the anodic wave at $-0.75 \mathrm{~V}$ vs. $\mathrm{Fc} / \mathrm{Fc}^{+}$in cyclic voltammetry (Figure S21A), furnishing a reduction potential of $\mathrm{E}\left([\mathrm{NMI}(\mathrm{H})]^{0 /-}=-3.08 \mathrm{~V}\right.$ vs $\mathrm{Fc}^{+} / \mathrm{Fc}$ (Figure 21C). The energetics of the $[\mathrm{NMI}(\mathrm{H})]^{-}$anion are summarized on the energy level diagram of Figure $4 \mathrm{~B}$ together with those of its NMI and NMI radical anion congeners.

As indicated by the Stern-Volmer quenching results and excited state redox potential, $[\mathrm{NMI}(\mathrm{H})]^{-*}$ is super-reducing, capable of supporting SET to haloarene substrates. Treatment of $[\mathrm{NMI}(\mathrm{H})]^{-}[\mathrm{TBA}]^{+}$with stoichiometric methyl-4chlorobenzoate in $\mathrm{C}_{6} \mathrm{D}_{6}$, along with $440 \mathrm{~nm}$ light and the radical traps N-methyl pyrrole or triethylphosphite resulted in $\mathrm{C}-\mathrm{C}$ and C-P coupled products (Figures S23-S25) that recapitulated the photon-mediated reactivity previously attributed to the NMI radical anion. Additionally, in the absence of a radical trap, irradiated solutions of methyl-4-chlorobenzoate and [NMI(H)] $[\mathrm{TBA}]^{+}$produced the aryl homocoupling product dimethylbiphenyl-4,4'-dicarboxylate, along with a smaller amount of the hydrodehalogenation product methyl benzoate (Figure S22). The biphenyl product is the plausible result of radical-radical coupling, which, in the absence of a transition metal catalyst, normally requires high radical concentrations.

The use of electrophotochemistry to generate NMI radical anion is not selective, as $[\mathrm{NMI}(\mathrm{H})]^{-}$may also be produced. The onset potential of the $\mathrm{EC}$ process is at $-2.3 \mathrm{~V}$ vs $\mathrm{Fc} / \mathrm{Fc}^{+}$. Consequently, the use of $-2.3 \mathrm{~V}$ in electrophotochemistry methods will result in a Nernstian production of $[\mathrm{NMI}(\mathrm{H})]^{-}$. The issue of non-selective production of the NMI radical anion is exacerbated by employing constant-current electrolysis, as has routinely been utilized to date, to generate the photoactive NMI species because the applied potential at the working electrode is uncontrolled. In a constant-current electrolysis, the working electrode is driven to a potential needed to maintain a constant current and thus will greatly exceed the onset potential of the EC process of the radical anion. Indeed, when the applied potential to the working electrode was controlled (not constantcurrent but constant potential) and set to a value slightly beyond the first reductive wave of NMI, product yields were substantially attenuated. ${ }^{7}$ In line with these results, we observe a small amount of fluorescence from a sample electrolyzed at $2.3 \mathrm{~V}$. The fluorescence excitation scan is not that of the NMI radical anion but matches that of the UV-vis spectrum of $[\mathrm{NMI}(\mathrm{H})]^{-}$(Figure S7). Thus, under constant current electrophotochemistry conditions, $[\mathrm{NMI}(\mathrm{H})]^{-}$is invariably formed and it is this species that is responsible for the observed photoreactivity.

Highly colored Meisenheimer complexes have a rich chemistry. ${ }^{24,25}$ They are key intermediates in $\mathrm{S}_{\mathrm{N}} \mathrm{Ar}$ chemistry, ${ }^{30}$ formed as $\sigma$-addition complexes of nucleophiles with arenes, and hydride Meisenheimer complexes have been implicated in biological metabolic pathways. ${ }^{31} \mathrm{We}$ demonstrate herein the utility of Meisenheimer complexes as super-reducing photocatalysts. Beyond the hydride $\sigma$-complex of NMI reported here, other nucleophiles could produce similar Meisenheimer adducts. Fluoride-mediated solvent oxidation may result in dimethylacetamidyl (from DMAc) or dimsyl (from DMSO) anion addition to NMI. ${ }^{32,33}$ Additionally, of possible relevance to several photochemical cycles invoking two-photon radical anion photocatalysis, a photon-mediated formation of a triethylamine (TEA) $\sigma$-complex may be envisioned wherein photooxidation of TEA followed by deprotonation produces a radical pair consisting of the NMI radical anion and the neutral TEA radical. A $\sigma$-complex formed from this radical pair is another possible photoactive Meisenheimer adduct. Moreover, the reduction potential for the $[\mathrm{NMI}(\mathrm{H})]^{-}$is $1 \mathrm{~V}$ positive of the reduction potential for the formation of the NMI radical anion, allowing for the possibility of $[\mathrm{NMI}(\mathrm{H})]^{-}$to function as a useful two-electron hydride transfer reagent. Accordingly, the development of Meisenheimer complexes may produce a palate of useful powerfully reducing one- and two-electron photoreagents.

The results reported herein for the NMI Meisenheimer complex may likely be generalized to organic transformations reported to be driven by radical anion excited states, as a preponderance of results demonstrate such doublet excited states to be too short-lived ${ }^{14-19}$ to participate in bimolecular reactions with substrates. For instance, hydrodehalogenation at potentials more reducing than $-2.0 \mathrm{~V}$ vs. saturated calomel electrode (SCE), initially proposed to be driven by the perylene diimide (PDI) radical anion excited state, ${ }^{34}$ is likely due to a closed-shell photoactive species that is formed by oxidative coupling between PDI and various substrates. ${ }^{35,36}$ Chloroarene electrophotoreductions have also been reported to result from a photoactive species that is proposed to be the radical anion of dicyanoanthracene. ${ }^{9} \quad$ However, the non-emissive dicyanoanthracene radical anion is frequently accompanied by emissive anthrolate or cyanoanthrolate impurities resulting from a bimolecular oxidation reaction of the neutral species. ${ }^{12,17,37}$ Such closed-shell anthrolate anions are known to be competent photocatalysts for very similar photoreductions of chloroarenes. ${ }^{38-40}$ In summary, the ultrafast relaxation resulting from internal conversion of doublet excited states to a doublet ground states suggests that synthetically useful photochemically active radical species would be extraordinary, as opposed to their reaction to produce closed shell species in which photoredox processes are driven from the more common singlet/triplet lowest energy excited state manifold. 


\section{CONCLUSIONS}

Spectro/electrochemical data combined with ultrafast transient absorption and emission spectroscopies demonstrates that the photoactive NMI species is a two-electron reduced singlet excited state $[\mathrm{NMI}(\mathrm{H})]^{-*}$, and not the excited state of the radical anion $\mathrm{NMI}^{\circ}$. The closed-shell electron rich photocatalyst results from two sequential one electron reductions of NMI, followed by a chemical step, which furnish a hydride. Whereas the short lifetime of 24 ps (Figures 3A, 3B) of the radical anion doublet excited state precludes intermolecular electron transfer, as imposed by diffusional limitations, the two-electron closed shell singlet excited state $[\mathrm{NMI}(\mathrm{H})]^{-*}$ possesses a lifetime of $20 \mathrm{~ns}$, which is typical of closed shell singlet excited states. This sufficiently long-lived excited state together with an exceptional excited state reduction potential bestows $[\mathrm{NMI}(\mathrm{H})]^{-}$with the properties to react with aryl halide substrates and effect $\mathrm{C}-\mathrm{C}$ and $\mathrm{C}-\mathrm{P}$ bond coupling, initiated by single electron transfer.

There are few excited state species with such super-reducing properties and sufficiently long lifetime to drive photoredox events. To this end, the $[\mathrm{NMI}(\mathrm{H})]^{-}$should find utility as a reagent for a variety of photochemical transformations that require the activation of strong bonds. Finally, the work described herein highlights that doublet excited states are generally too short-lived to support photoredox chemistry driven by electronically excited radical anions. We suspect that for systems in which radical anions have been proposed to drive photoredox chemistry, it may be prudent to reconsider the possibility of a more stable, closed shell, super-reducing species. Such re-evaluation will be useful for future elaboration of the role of super-reducing excited state species underpinning new synthetic methodologies.

\section{ASSOCIATED CONTENT}

\section{Supporting Information}

Experimental procedures, synthetic methods, characterization,

\section{REFERENCES}

(1) Shaw, M. H.; Twilton, J.; MacMillan, D. W. C. Photoredox Catalysis in Organic Chemistry. J. Org. Chem. 2016, 81, 6898-6926.

(2) Romero, N. A.; Nicewicz, D. A. Organic Photoredox Catalysis. Chem. Rev. 2016, 116, 10075-10166.

(3) Huang, H.; Lambert, T. H. Electrophotocatalytic SNAr Reactions of Unactivated Aryl Fluorides at Ambient Temperature and Without Base. Angew. Chem. Int. Ed. 2020, 59, 658-662.

(4) Huang, H.; Strater, Z. M.; Rauch, M.; Shee, J.; Sisto, T. J.; Nuckolls, C.; Lambert, T. H. Electrophotocatalysis with a Trisaminocyclopropenium Radical Dication. Angew. Chem. Int. Ed. 2019, 58, 13318-13322.

(5) Shen, T.; Lambert, T. H. Electrophotocatalytic Diamination of Vicinal C-H Bonds. Science 2021, 371, 620-626.

(6) Huang, H.; Strater, Z. M.; Lambert, T. H. Electrophotocatalytic $\mathrm{C}-\mathrm{H}$ Functionalization of Ethers with High Regioselectivity. J. Am. Chem. Soc. 2020, 142, 1698-1703.

(7) Cowper, N. G. W.; Chernowsky, C. P.; Williams, O. P.; Wickens, Z. K. Potent Reductants via Electron-Primed Photoredox Catalysis: Unlocking Aryl Chlorides for Radical Coupling. J. Am. Chem. Soc. 2020, 142, 2093-2099.

(8) MacKenzie, I. A.; Wang, L.; Onuska, N. P. R.; Williams, O. F.; Begam, K.; Moran, A. M.; Dunietz, B. D.; Nicewicz, D. A. Discovery crystallographic data, .cif structure files, Figures S1-S25, and Tables S1-S19. The Supporting Information is available free of charge on the ACS Publications website.

\section{AUTHOR INFORMATION}

\section{Corresponding Author}

Daniel G. Nocera - Department of Chemistry and Chemical Biology, Harvard University, 12 Oxford Street, Cambridge, MA 02138-2902; orcid.org/0000-0001-5055-320X; E-mail: dnocera@fas.harvard.edu.

\section{Authors}

Adam J. Rieth - Department of Chemistry and Chemical Biology, Harvard University, 12 Oxford Street, Cambridge, MA 02138-2902; orcid.org/0000-0002-9890-1346.

Miguel I. Gonzalez - Department of Chemistry and Chemical Biology, Harvard University, 12 Oxford Street, Cambridge, MA 02138-2902; orcid.org/0000-0003-4250-9035

Bryan Kudisch - Department of Chemistry and Chemical Biology, Harvard University, 12 Oxford Street, Cambridge, MA 02138-2902; orcid.org/0000-0003-3352-5383.

Matthew Nava - Department of Chemistry and Chemical Biology, Harvard University, 12 Oxford Street, Cambridge, MA 02138-2902; orcid.org/0000-0001-6575-1153

\section{Notes}

The authors declare no competing financial interests

\section{ACKNOWLEDGMENTS}

This work was supported by the National Science Foundation under grant CHE-1855531. M.I.G. acknowledges the Arnold and Mabel Beckman Foundation for an Arnold O. Beckman Postdoctoral Fellowship. NSF's ChemMatCARS Sector 15 is supported by the Divisions of Chemistry and Materials Research, National Science Foundation, under grant number CHE-1834750. Use of the Advanced Photon Source, an Office of Science User Facility operated for the U.S. Department of Energy (DOE) Office of Science by Argonne National Laboratory, was supported by the DOE under Contract No. DE-AC02-06CH1 1357.

and Characterization of an Acridine Radical Photoreductant. Nature 2020, 580 (7801), 76-80.

(9) Kim, H.; Kim, H.; Lambert, T. H.; Lin, S. Reductive Electrophotocatalysis: Merging Electricity and Light to Achieve Extreme Reduction Potentials. J. Am. Chem. Soc. 2020, 142, 20872092.

(10) Cole, J. P.; Chen, D.; Kudisch, M.; Pearson, R. M.; Lim, C.-H.; Miyake, G. M. Organocatalyzed Birch Reduction Driven by Visible Light. J. Am. Chem. Soc. 2020, 142, 13573-13581.

(11) Costentin, C.; Fortage, J.; Collomb, M.-N. Electrophotocatalysis: Cyclic Voltammetry as an Analytical Tool. $J$. Phys. Chem. Lett. 2020, 11, 6097-6104.

(12) Fox, M. A. The Photoexcited States of Organic Anions. Chem. Rev. 1979, 79, 253-273.

(13) Shukla, S. S.; Rusling, J. F. Photoelectrocatalytic Reduction of 4-Chlorobiphenyl Using Anion Radicals and Visible Light. J. Phys. Chem. 1985, 89, 3353-3358.

(14) Fujitsuka, M.; Kim, S. S.; Lu, C.; Tojo, S.; Majima, T. Intermolecular and Intramolecular Electron Transfer Processes from Excited Naphthalene Diimide Radical Anions. J. Phys. Chem. B 2015, $119,7275-7282$. 
(15) Fujitsuka, M.; Majima, T. Reaction Dynamics of Excited Radical Ions Revealed by Femtosecond Laser Flash Photolysis. J. Photochem. Photobiol. C Photochem. Rev. 2018, 35, 25-37.

(16) Fujita, M.; Ishida, A.; Majima, T.; Takamuku, S. Lifetimes of Radical Anions of Dicyanoanthracene, Phenazine, and Anthraquinone in the Excited State from the Selective Electron-Transfer Quenching. J. Phys. Chem. 1996, 100, 5382-5387.

(17) Breslin, D. T.; Fox, M. A. Excited-State Behavior of Thermally Stable Radical Ions. J. Phys. Chem. 1994, 98, 408-411.

(18) Gosztola, D.; Niemczyk, M. P.; Svec, W.; Lukas, A. S.; Wasielewski, M. R. Excited Doublet States of Electrochemically Generated Aromatic Imide and Diimide Radical Anions. J. Phys. Chem. A 2000, 104, 6545-6551.

(19) Gumy, J. C.; Vauthey, E. Investigation of the Excited-State Dynamics of Radical Ions in the Condensed Phase Using the Picosecond Transient Grating Technique. J. Phys. Chem. A 1997, 101, $8575-8580$.

(20) Zinchenko, K. S.; Ardana-Lamas, F.; Seidu, I.; Neville, S. P.; Van Der Veen, J.; Lanfaloni, V. U.; Schuurman, M. S.; Wörner, H. J. Sub-7-Femtosecond Conical-Intersection Dynamics Probed at the Carbon K-Edge. Science 2021, 371, 489-494.

(21) Eriksen, J.; Joergensen, K. A.; Linderberg, J.; Lund, H. Electron-Transfer Fluorescence Quenching of Radical Ions. Experimental Work and Theoretical Calculations. J. Am. Chem. Soc. 1984, 106, 5083-5087.

(22) Eriksen, J.; Lund, H.; Nyvad, A. I. Electron-Transfer Fluorescence Quenching of Radical Ions. Acta Chem. Scand. 1983, $37 b, 459-466$.

(23) Chakraborty, B.; Menezes, P. W.; Driess, M. Beyond $\mathrm{CO}_{2}$ Reduction: Vistas on Electrochemical Reduction of Heavy Non-Metal Oxides with Very Strong E-O Bonds $(\mathrm{E}=\mathrm{Si}, \mathrm{P}, \mathrm{S}) . \mathrm{J}$. Am. Chem. Soc. 2020, 142, 14772-14788.

(24) Meisenheimer, J. Ueber Reactionen Aromatischer Nitrokorper. Justus Liebig 1902, 323, 205-242.

(25) Jackson, C. J.; Gazzolo, F. H. On Certain Colored Substances Derived from Nitro Compounds. Third Paper. Proceedings of the American Academy of Arts and Sciences 1900, 35, 263-281.

(26) Savéant, J-M.; Costentin, C. Elements of Molecular and Biomolecular Electrochemistry. 2 ${ }^{\text {nd }}$ Ed. Wiley, Hoboken, NJ. 2019.

(27) Tian, X.; Karl, T. A.; Reiter, S.; Yakubov, S.; de Vivie-Riedle, R.; König, B.; Barham, J. P. Electro-mediated PhotoRedox Catalysis for Selective $\mathrm{C}\left(\mathrm{sp}^{3}\right)-\mathrm{O}$ Cleavages of Phosphinated Alcohols to Carbanions. Angew. Chemie Int. Ed. 2021. DOI: 10.1002/anie.202105895.
(28) Guha, S.; Saha, S. Fluoride Ion Sensing by an Anion- $\pi$ Interaction. J. Am. Chem. Soc. 2010, 132, 17674-17677.

(29) Wentz, H. C.; Skorupskii, G.; Bonfim, A. B.; Mancuso, J. L.; Hendon, C. H.; Oriel, E. H.; Sazama, G. T.; Campbell, M. G. Switchable Electrical Conductivity in a Three-Dimensional MetalOrganic Framework: Via Reversible Ligand n-Doping. Chem. Sci. 2020, 11, 1342-1346.

(30) Neumann, C. N.; Hooker, J. M.; Ritter, T. Concerted Nucleophilic Aromatic Substitution with ${ }^{19} \mathrm{~F}^{-}$and ${ }^{18} \mathrm{~F}^{-}$. Nature 2016, 534, 369-373.

(31) Lenke, H.; Knackmuss, H. J. Initial Hydrogenation during Catabolism of Picric Acid by Rhodococcus Erythropolis HL 24-2. Appl. Environ. Microbiol. 1992, 58, 2933-2937.

(32) Saha, S. Anion-Induced Electron Transfer. Acc. Chem. Res. 2018, 51, 2225-2236.

(33) Bélanger-Chabot, G.; Ali, A.; Gabbaï, F. P. On the Reaction of Naphthalene Diimides with Fluoride Ions: Acid/Base versus Redox Reactions. Angew. Chem. Int. Ed. 2017, 56, 9958-9961.

(34) Ghosh, I.; Ghosh, T.; Bardagi, J. I.; Konig, B. Reduction of Aryl Halides by Consecutive Visible Light-Induced Electron Transfer Processes. Science 2014, 346, 725-728.

(35) Marchini, M.; Gualandi, A.; Mengozzi, L.; Franchi, P.; Lucarini, M.; Cozzi, P. G.; Balzani, V.; Ceroni, P. Mechanistic Insights into Two-Photon-Driven Photocatalysis in Organic Synthesis. Phys. Chem. Chem. Phys. 2018, 20, 8071-8076.

(36) Zeman, C. J.; Kim, S.; Zhang, F.; Schanze, K. S. Direct Observation of the Reduction of Aryl Halides by a Photoexcited Perylene Diimide Radical Anion. J. Am. Chem. Soc. 2020, 142, 2204 2207.

(37) Janzen, E. G.; Rudy, B. C.; Lopp, I. G.; Happ, J. W. Chemiluminescent Oxygenation of 9,10-Dicyanoanthracene Radical Anion. Chem. Commun. 1970, 491-492.

(38) Schmalzbauer, M.; Marcon, M.; König, B. Excited State Anions in Organic Transformations. Angew. Chemie Int. Ed. 2021, 60, 62706292.

(39) Schmalzbauer, M.; Svejstrup, T. D.; Fricke, F.; Brandt, P.; Johansson, M. J.; Bergonzini, G.; König, B. Redox-Neutral Photocatalytic $\mathrm{C}-\mathrm{H}$ Carboxylation of Arenes and Styrenes with $\mathrm{CO}_{2}$. Chem 2020, 6, 2658-2672.

(40) Schmalzbauer, M.; Ghosh, I.; König, B. Utilising Excited State Organic Anions for Photoredox Catalysis: Activation of (Hetero)Aryl Chlorides by Visible Light-Absorbing 9-Anthrolate Anions. Faraday Discuss. 2019, 215, 364-378. 
Table of Contents

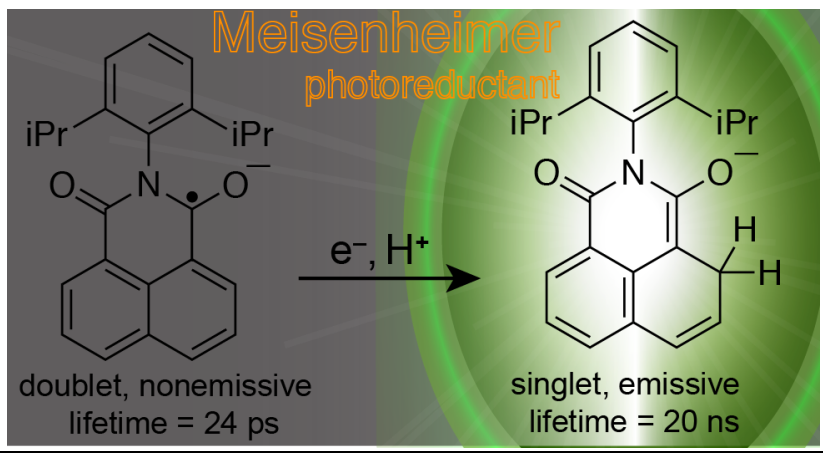




\title{
Supporting Information
}

\section{How radical are 'radical' photocatalysts? A closed-shell Meisenheimer complex is identified as a superreducing photoreagent}

\author{
Adam J. Rieth, Miguel I. Gonzalez, Bryan Kudisch, Matthew Nava, and Daniel G. \\ Nocera $^{*}$ \\ Department of Chemistry and Chemical Biology, Harvard University, 12 Oxford Street, Cambridge, \\ MA 02138 \\ * Corresponding author email: dnocera@fas.harvard.edu
}




\section{Table of Contents}

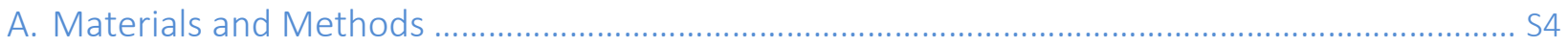

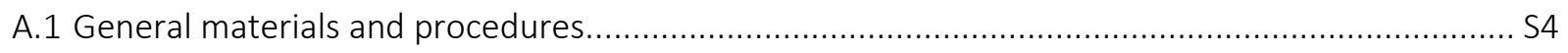

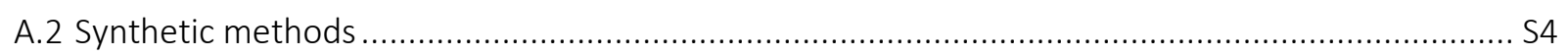

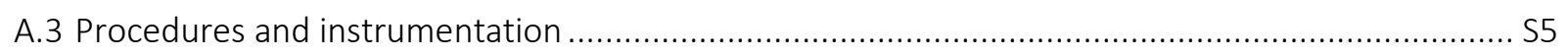

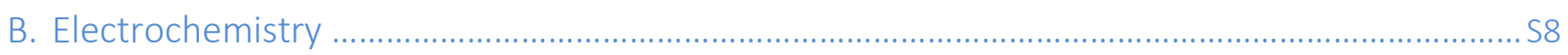

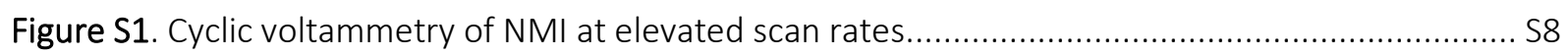

Figure S2. Scan rate dependance of peak currents in cyclic voltammetry of NMI ............................ S8

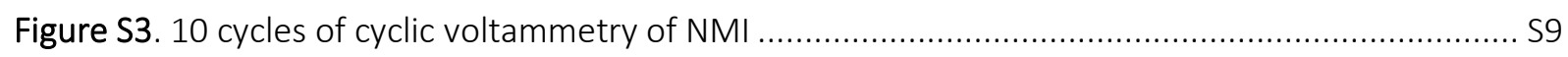

Figure S4. Potential window dependance of cyclic voltammetry of NMI ........................................... S9

Figure S5. Images of bulk electrolysis setups in a W-cell ................................................................ S10

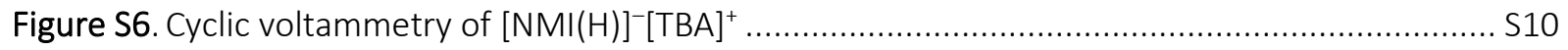

C. Steady-State and Time-Resolved Emission....................................................................... 11

Figure S7. Steady-state emission and excitation of electrolyzed and TBAF treated NMI samples ....... S11

Figure S8. Infrared emission and excitation of the radical anion of NMI electrolyzed at $-2.3 \mathrm{~V}$......... S11

Figure S9. Time-resolved emission lifetime fits for NMI treated with 4-methylchlorobenzoate .......... S12

Figure S10. Time-resolved emission lifetime fits for NMI treated with chlorobenzene ..................... S13

D. Nuclear Magnetic Resonance (NMR) Spectroscopy ......................................................... S14

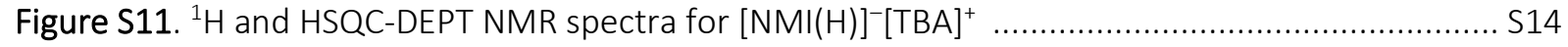

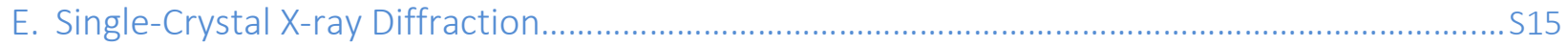

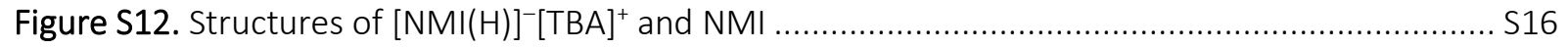

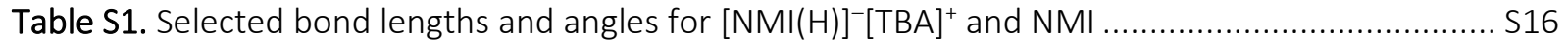

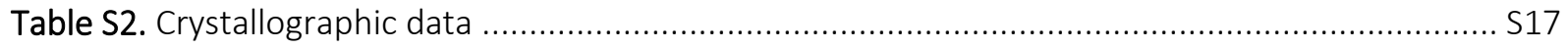

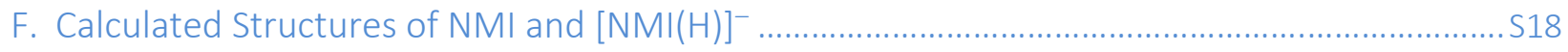

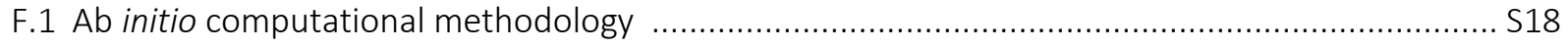

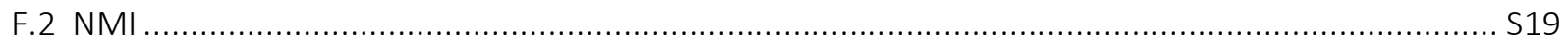

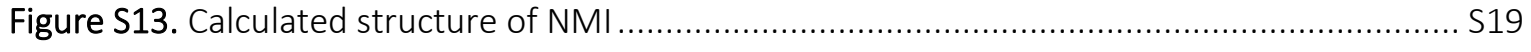

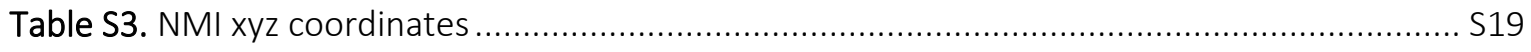

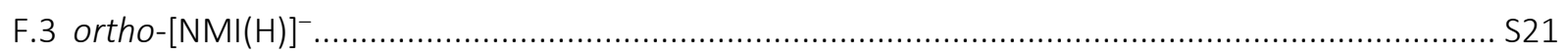

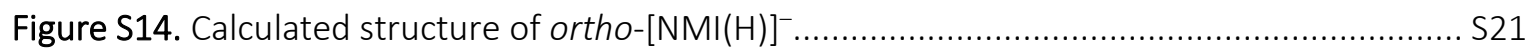

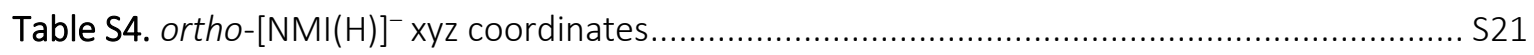

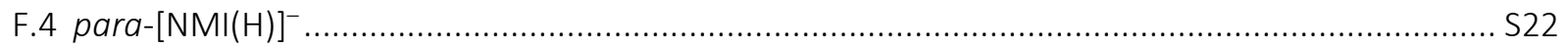

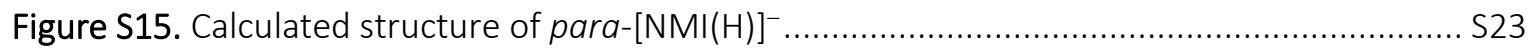

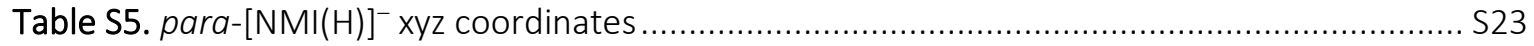

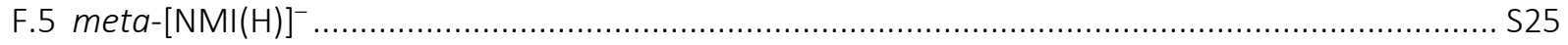




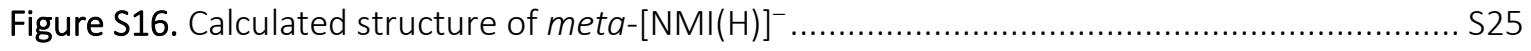

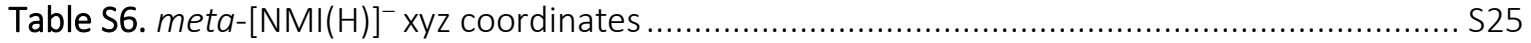

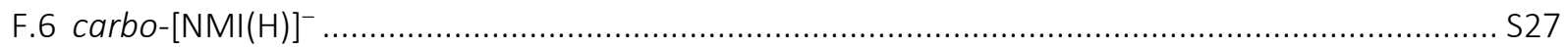

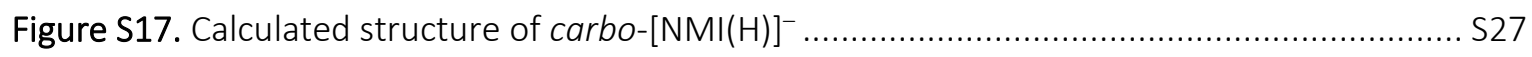

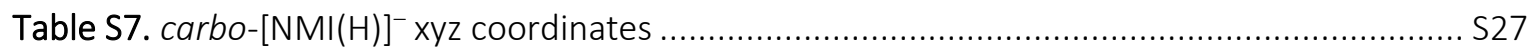

G. NMR Chemical Shift and Absolute Chemical Shielding Calculations .................................... S29

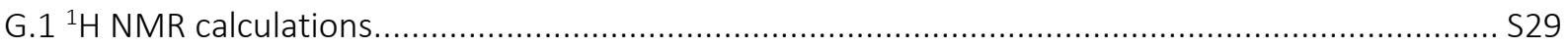

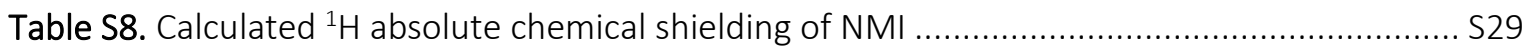

Figure S18. ${ }^{1} \mathrm{H}$ experimental shift versus absolute chemical shielding of NMI........................... S29

Table S9. Calculated ${ }^{1} \mathrm{H}$ absolute chemical shielding and predicted shift of ortho-[NMI(H)]- ....... S30

Table S10. Calculated ${ }^{1} \mathrm{H}$ absolute chemical shielding and predicted shift of para-[NMI(H)] $]^{-} \ldots \ldots . \mathrm{S} 30$

Table S11. Calculated ${ }^{1} \mathrm{H}$ absolute chemical shielding and predicted shift of meta-[NMI(H)]- $\ldots . . . \mathrm{S} 31$

Table S12. Calculated ${ }^{1} \mathrm{H}$ absolute chemical shielding and predicted shift of carbo- $[\mathrm{NMI}(\mathrm{H})]^{-} \ldots . \mathrm{S} 31$

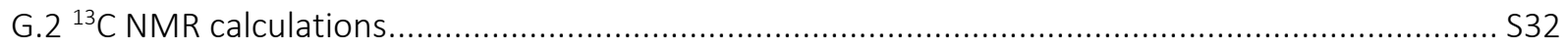

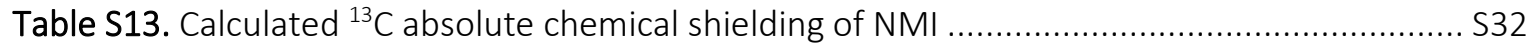

Figure S19. ${ }^{13} \mathrm{C}$ experimental shift versus absolute chemical shielding of $\mathrm{NMI} . . . \ldots \ldots \ldots \ldots \ldots \ldots \ldots \ldots . . . . . . . . . . . .333$

Table S14. Calculated ${ }^{13} \mathrm{C}$ absolute chemical shielding and predicted shift of ortho-[NMI $\left.(\mathrm{H})\right]^{-}$..... S33

Table S15. Calculated ${ }^{13} \mathrm{C}$ absolute chemical shielding and predicted shift of para-[NMI(H)] $]^{-}$..... S34

Table S16. Calculated ${ }^{13} \mathrm{C}$ absolute chemical shielding and predicted shift of meta-[NMI(H)] $]^{-}$.... S34

Table S17. Calculated ${ }^{13} \mathrm{C}$ absolute chemical shielding and predicted shift of carbo- $[\mathrm{NMI}(\mathrm{H})]^{-}$.... S34

G.3 Analysis of the experimental NMR spectra based on calculations ............................................ S35

Table S18. Calculated ${ }^{1} \mathrm{H}$ and ${ }^{13} \mathrm{C}$ shifts of hydridic positions for isomers of $[\mathrm{NMI}(\mathrm{H})]^{-} \ldots \ldots \ldots \ldots \ldots . . . . . . .535$

Table S19. Experimental ${ }^{1} \mathrm{H}$ and ${ }^{13} \mathrm{C}$ shifts of hydridic positions for isomers of $[\mathrm{NMI}(\mathrm{H})]^{-} \ldots \ldots \ldots \ldots . \mathrm{S} 35$

Figure S20. Tentative isomer assignment of the ${ }^{1} \mathrm{H}$ NMR spectrum ...................................... S36

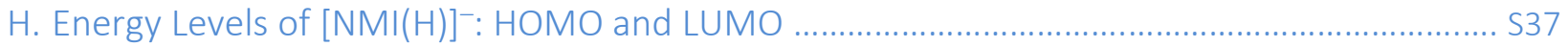

Figure S21. Assignment of $\mathrm{HOMO}$ and $E_{00}$ energies, and $-[\mathrm{NMI}(\mathrm{H})]^{-}$Latimer diagram ................ S37

I. Photoreactivity of $[\mathrm{NMI}(\mathrm{H})]^{-}[\mathrm{TBA}]^{+}$with methyl-4-chlorobenzoate ....................................S38

Figure S22. [NMI(H)] $]^{-}[\mathrm{TBA}]^{+}$and methyl-4-chlorobenzoate ${ }^{1} \mathrm{H}$ NMR spectra .......................... S39

Figure S23. [NMI(H)]-[TBA] $]^{+}$, methyl-4-chlorobenzoate, and N-methyl pyrrole ${ }^{1} \mathrm{H}$ NMR spectra .. S40

Figure S24. [NMI $(\mathrm{H})]^{-}[\mathrm{TBA}]^{+}$, methyl-4-chlorobenzoate, and triethylphosphite ${ }^{1} \mathrm{H}$ NMR spectra.. S41

Figure S25. [NMI(H)] $\left.]^{-[T B A}\right]^{+}$, methyl-4-chlorobenzoate, and triethylphosphite ${ }^{31} \mathrm{P}$ NMR spectra. S42

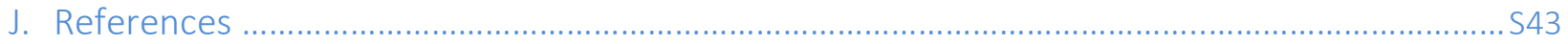




\section{A. Materials and Methods}

\section{A.1 General Materials and Procedures}

All reagents were purchased from commercial suppliers and used without further purification, unless otherwise noted. Solvents were purified by an argon purged solvent purification system and stored over activated 3-Å molecular sieves in a $\mathrm{N}_{2}$-filled glovebox, unless otherwise noted. Dimethylacetamide (DMAc) and propylene carbonate were purchased from Sigma Aldrich in Sure/Seal bottles and stored over activated $4-\AA \AA \AA$ molecular sieves in a $\mathrm{N}_{2}$-filled glovebox. All samples were prepared in a $\mathrm{N}_{2}$-filled glovebox.

\section{A.2 Synthetic Methods}

Naphthalene monoimide (NMI). NMI was synthesized as previously reported. ${ }^{1}$ Briefly, $6.73 \mathrm{~g}$ (34 $\mathrm{mmol}$ ) naphthalic anhydride was suspended in $100 \mathrm{~mL}$ propionic acid, then $19.0 \mathrm{~mL}$ (100 mmol) 2,6-diisopropylaniline was added. The mixture was stirred under nitrogen and heated to reflux overnight. After cooling to room temperature, $50 \mathrm{~mL}$ deionized water was added and solids were collected by filtration. The solids were washed with water, then hexanes, then dried at $50^{\circ} \mathrm{C}$. The solids were recrystallized from chloroform/hexanes to obtain white crystalline solids. A second recrystallization by slow diffusion of diethyl ether into dichloromethane was performed to obtain colorless plate crystals suitable for single-crystal X-ray diffraction.

Treatment with tetrabutylammonium fluoride (TBAF) in DMAc. Inside a $\mathrm{N}_{2}$-filled glovebox, NMI $(7.5 \mathrm{mg}$ ) was dissolved in $20 \mathrm{~mL}$ DMAc, then $0.2 \mathrm{~mL} 1 \mathrm{M}$ TBAF in tetrahydrofuran was added. The solution immediately turns orange and slowly darkens, with visible green emission.

Isolation of hydride-reduced [NMI(H)]-[TBA] +. Naphthalene monoimide (400 mg, 1.09 mmol) and $\mathrm{NaBH}_{4}(50 \mathrm{mg}, 1.31 \mathrm{mmol})$ were added to a $250 \mathrm{~mL}$ Schlenk flask with a stir bar and degassed by 5 vacuum/nitrogen cycles. The flask was then cooled in an ice water bath. Dimethoxyethane (DME) $(80 \mathrm{~mL}$ ) from an Ar-purged solvent purification system was then added to the flask via cannula transfer. The mixture was then stirred under nitrogen in the ice bath for 4 hours, over which time it slowly turned from clear to yellow to bright orange. The solution was allowed to warm to room temperature and stirred under nitrogen overnight. The solvent volume was 
reduced to $20 \mathrm{~mL}$ under vacuum, then the flask was sealed under vacuum and brought into a nitrogen-filled glovebox. Hexanes $(100 \mathrm{~mL})$ was added and the resulting bright yellow precipitate was collected by filtration. The solids were washed with diethyl ether and then suspended and stirred overnight in $80 \mathrm{~mL}$ benzene with $600 \mathrm{mg}$ tetrabutylammonium chloride (TBACl) (2.18 $\mathrm{mmol})$. The solids were removed by filtration. The filtrate solvent volume was reduced by half under vacuum, and then $100 \mathrm{~mL}$ diethyl ether was added, and the resulting bright orange precipitate was collected by filtration and washed with ether. Crystals suitable for single-crystal Xray diffraction were obtained by slow diffusion of diethyl ether into a toluene solution of the bright orange product.

\section{A.3 Procedures and Instrumentation}

UV-visible spectroscopy. Absorption spectroscopy was performed using a Varian Cary 5000 UVvis-NIR spectrometer

Electrochemistry and spectroelectrochemistry. Electrochemical experiments were performed using a CH Instruments 760D potentiostat in a nitrogen-filled glovebox. Cyclic voltammetry (CV) measurements were performed using a three-electrode setup with a glassy carbon or Platinum disk working electrode, a Pt mesh counter electrode, and a leak-free $\mathrm{Ag} / \mathrm{AgCl}$ reference electrode (Warner Instruments). Glassy carbon and platinum working electrodes were polished using 1- $\mu \mathrm{m}$ alumina powder on felt prior to use. After each CV, ferrocene (FC) was added and the CV was repeated to obtain an accurate non-aqueous reference. All compounds were dissolved in degassed propylene carbonate/0.1 M tetrabutylammonium hexafluorophosphate (electrochemical grade, Sigma Aldrich), which was stored on activated 4-A molecular sieves in the glovebox. Bulk electrolysis was performed in a W-cell with Pt wire working electrode and Pt mesh counter electrode with $1 \mathrm{mM} \mathrm{NMI}$ in the catholyte and $20 \mathrm{mM}$ triethylamine in the anolyte. Catholyte and anolyte compartments were stirred. Electrolysis was continued until the current was $10 \%$ of the initial value. For ultrafast transient absorption, the bulk-electrolyzed radical anion was diluted to an absorbance at $420 \mathrm{~nm}$ of 0.8 O.D.

Spectroelectrochemistry was performed using an OceanOptics USB400 spectrometer and DTmini-2-GS Deuterium/Halogen light source in an H-cell quartz cuvette using a Pt wire working electrode and a leak-free $\mathrm{Ag} / \mathrm{AgCl}$ reference electrode on the cuvette side, and a Pt mesh counter 
electrode on the opposite chamber, separated by a $1 \mathrm{~cm}^{2}$ glass frit. Approximately $20 \mathrm{mM}$ triethylamine was added to the counter electrode compartment.

Nuclear magnetic resonance (NMR). NMR experiments was performed in the Harvard University Department of Chemistry Laukien Purcell Instrumentation Facility using a Bruker AVANCE NEO 400 $\mathrm{MHz}$ spectrometer equipped with a broadband probe, or a JEOL ECZ400S $400 \mathrm{MHz}$ spectrometer equipped with a broadband probe.

Ultrafast transient absorption. The broadband femtosecond transient absorption setup is based on a previously reported single-shot probe-referenced design. ${ }^{2}$ The setup has been described in previous publications. A Ti:Sapphire regenerative amplifier (Coherent Libra-HE) provides $3 \mathrm{~W}$ fundamental pulses (800 nm, $\sim 50 \mathrm{fs}$ ) at $1 \mathrm{kHz}$. An OPerA SOLO (Coherent) is seeded with $2 \mathrm{~W}$ of the fundamental to provide pump pulses at $420 \mathrm{~nm}$. The pulse energy was set to $200 \mathrm{~nJ}$ using a variable neutral density filter. The pump pulses were subsequently aligned onto a $1.7 \mathrm{~m}$ computercontrolled, motorized translation stage (Aerotech ATS62150, U100 controller) equipped with a hollow retro-reflector (Newport) followed by an ultrabroadband polarizer and $\lambda / 2$ waveplate (Thorlabs) to produce linearly polarized pulses at magic angle $\left(54.7^{\circ}\right)$ with respect to the probe pulse. Alignment of the stage was confirmed immediately prior to the transient absorption experiments using a reference dye, $\mathrm{Ru}(\mathrm{bpy})_{3} \mathrm{Cl}_{2}$ in water, which when photoexcited under the same experimental conditions gave flat dynamics on the timescale investigated, in accordance with its excited state lifetime of greater than 7 ns.

Chirped white light pulses were generated by focusing a fraction ( $1 \mathrm{~mW}$ ) of the remaining fundamental laser output ( $\mathrm{f}=100 \mathrm{~mm}$, Thorlabs) into a $5 \mathrm{~mm}$ calcium fluoride $\left(\mathrm{CaF}_{2}\right)$ crystal that was continuously translated back-and-forth perpendicular to the input beam to avoid thermal damage. The generated pulses were reflectively collimated ( $f=50 \mathrm{~mm}$, Thorlabs) and aligned onto a $15 \mathrm{~mm}$ translation stage (PhysikInstrumente, M-111.DG, Mercury DC controller). A notch filter (EKSMA, VEI6053) removed the residual fundamental and the white light pulses were subsequently sent onto a broadband reflective neutral density filter (Thorlabs, NDUV04B) to generate probe (reflected) and reference (transmitted) pulses of approximately equal intensity. Pump, probe, and reference pulses were reflectively focused into the sample $(f=200 \mathrm{~mm})$ to yield Gaussian beams with diameters (full-width-half-maximum) of $70 \mu \mathrm{m}$ (pump) and $40 \mu \mathrm{m}$ (probe/reference). At the sample position, a $2 \mathrm{~mm}$ quartz cuvette with a screwcap that had been 
verified to be air-tight housed the sample for measurement. The solution was stirred using a magnetic stirrer to combat sample degradation. The transmitted probe and reference pulses were subsequently collimated reflectively $(f=200 \mathrm{~mm}$ ) before being send into a home-built fused-silica prism (OptoSigma, DPSQ-20-10H) spectrograph ( $f=250 \mathrm{~mm}$ ) equipped with two 16 bit, 512 pixel charge-coupled devices (Hamamatsu S7030-0906). Data acquisition was enabled by a custombuild interface board from Entwicklungsbüro Stresing. Differential normalized transmittance signals were collected on shot-to-shot basis with the pump chopped at $500 \mathrm{~Hz}$.

A single transient absorption trace consisted of 200 collected probe shots, resulting in 100 differential spectra, which were averaged for each time point. Data presented in this study was obtained by recording 7 transient absorption traces and averaging the results; rapid sample degradation precluded further averaging. Kinetic data (Figure 3B) were obtained by averaging the intensities of the time-dependent data over several wavelengths: from 385-395 nm for the bleach feature and from 495-525 nm for the excited state absorption feature.

Steady-state emission spectra. Emission spectra were obtained using a fluorometer (Photon Technology International (PTI), Model QM4) equipped with a $150 \mathrm{~W}$ Xe arc lamp excitation source and a photomultiplier tube (PMT) detector. Infrared spectra (Figure S7) were measured using a PTI InGaAs detector. Samples were prepared in $1 \mathrm{~cm}$ quartz cuvettes with threaded caps in the glovebox.

Time-resolved emission spectroscopy. Emission spectra with time resolution were collected using a Hamamatsu C4334 Streak Scope camera set perpendicular to the $480 \mathrm{~nm}$ excitation pulse, generated by a femtosecond noncollinear optical parametric amplifier (described above for transient absorption setup). For the streak scope, the blaze wavelength was $450 \mathrm{~nm}$, the grating was $100 \mathrm{~g} \mathrm{~mm}^{-1}$ the ruling was 100, the slit width was 100. The average of 5000 shots was used for each sample. There is no spectral correction for the streak camera, therefore the emission intensities appear slightly blue-shifted due to the blaze at $450 \mathrm{~nm}$, which is bluer than the measured emission from $550-600 \mathrm{~nm}$. The steady-state emission spectra are therefore a better representation of the emission intensities.

Dynamic Stern-Volmer quenching studies were carried out by measuring the lifetime $(\tau)$ by averaging the photon counts from $540-580 \mathrm{~nm}$ with excitation at $480 \mathrm{~nm}$. The quenching ratio 
$\left(\tau_{0} / \tau\right)$ and the Stern-Volmer constant $\left(K_{\mathrm{sv}}\right)$ were determined by the relation $\tau_{0} / \tau=1+$ $K_{\mathrm{sv}} \times$ [quencher], where $\tau_{\mathrm{o}}$ is the lifetime in the absence of quencher. The quenching rate $\left(k_{\mathrm{q}}\right)$ was determined by $k_{\mathrm{q}}=K_{\mathrm{sv}} / \tau_{\mathrm{o}}$. Samples were prepared in $1 \mathrm{~cm}^{2}$ quartz cuvettes with threaded caps in the glovebox.

Curve fitting was performed in OriginPro 9.0. Time-resolved emission data (Figures 3E, S8, S9) were fit according to a single exponential decay function $I(t)=I_{o} e^{-t / \tau_{o}}$.

\section{B. Electrochemistry}

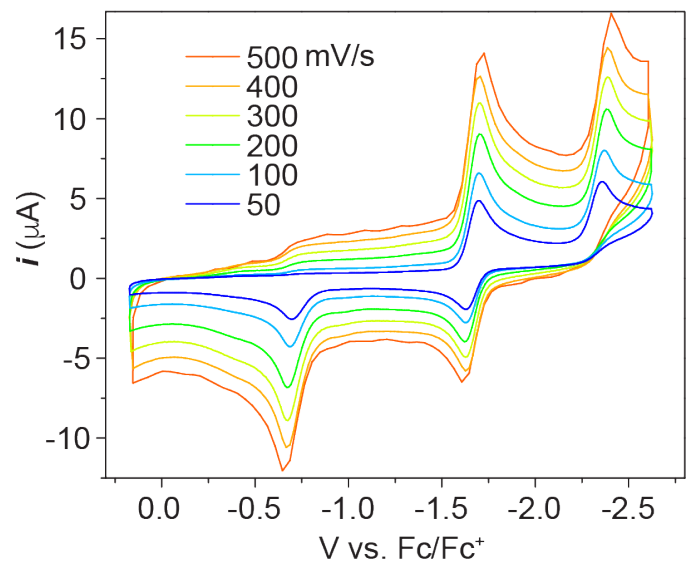

Figure S1. Cyclic voltammetry at scan rates from 50 to $500 \mathrm{mV} / \mathrm{s}$ of $1 \mathrm{mM} \mathrm{NMI}$ in $100 \mathrm{mM}$ TBAPF 6 propylene carbonate solution. Experiments were performed on a $1 \mathrm{~cm}^{2}$ glassy carbon working electrode, using a leakfree $\mathrm{Ag} / \mathrm{AgCl}$ reference electrode and a Pt mesh counter electrode in a $\mathrm{N}_{2}$-filled glovebox.
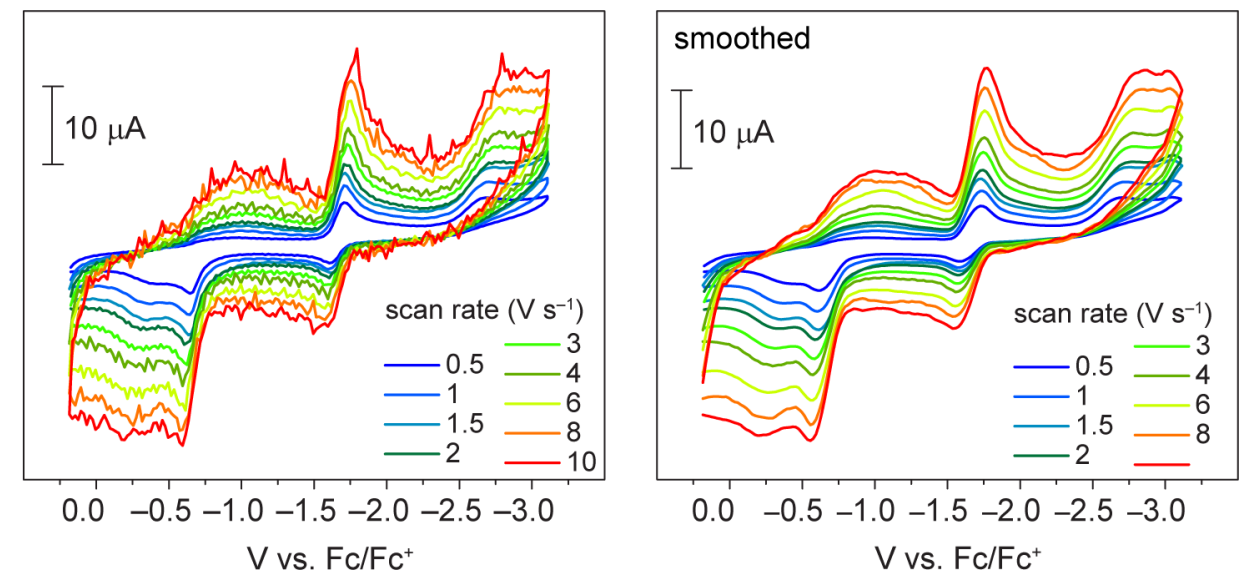

Figure S2. Cyclic voltammetry at elevated scan rates of $1 \mathrm{mM} \mathrm{NMI} \mathrm{in} 100 \mathrm{mM}$ TBAPF 6 propylene carbonate solution. Experiments were performed on a $0.5 \mathrm{~cm}^{2}$ Pt disk working electrode, using a leak-free $\mathrm{Ag} / \mathrm{AgCl}$ reference electrode and a Pt mesh counter electrode in a $\mathrm{N}_{2}$-filled glovebox. Left: raw data, Right: smoothed 


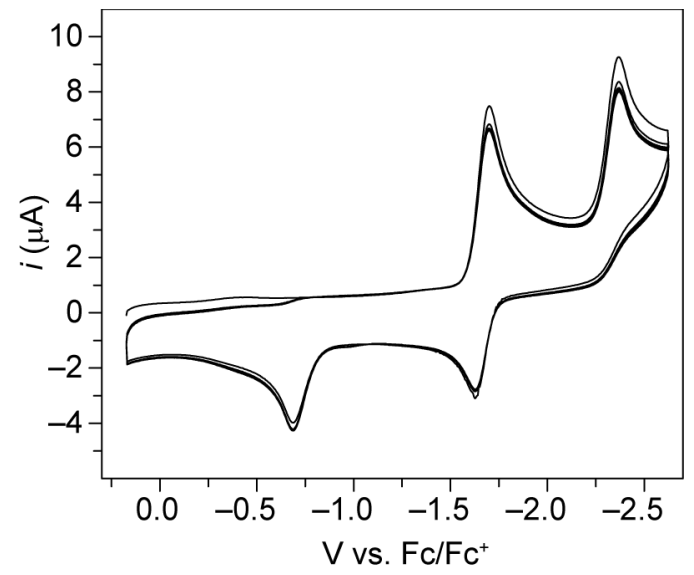

Figure S3. 10 cycles of cyclic voltammetry of $1 \mathrm{mM} \mathrm{NMI} \mathrm{in} 100$ mM TBAPF 6 propylene carbonate solution. The experiment was performed at $100 \mathrm{mV} \mathrm{s}^{-1}$ on a $1 \mathrm{~cm}^{2}$ glassy carbon working electrode, using a leak-free $\mathrm{Ag} / \mathrm{AgCl}$ reference electrode and a Pt mesh counter electrode in a nitrogen-filled glovebox.

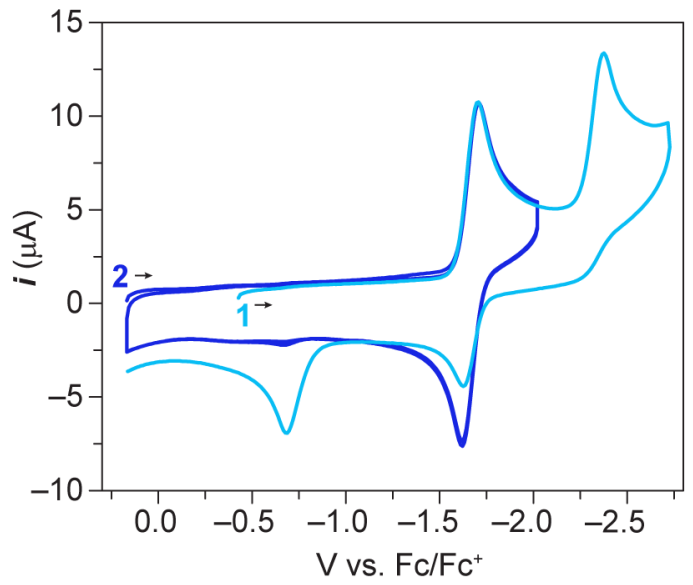

Figure S4. Cyclic voltammetry of $1 \mathrm{mM} \mathrm{NMI} \mathrm{in} 100 \mathrm{mM} \mathrm{TBAPF}_{6}$ propylene carbonate solution. After scanning past the second reductive feature on the first cycle (light blue), the sweep window was limited to $-2 \mathrm{~V}$ for the next 2 cycles (dark blue). The experiment was performed at $200 \mathrm{mV} \mathrm{s}^{-1}$ on a $1 \mathrm{~cm}^{2}$ glassy carbon working electrode, using a leak-free $\mathrm{Ag} / \mathrm{AgCl}$ reference electrode and a Pt mesh counter electrode in a nitrogenfilled glovebox. 


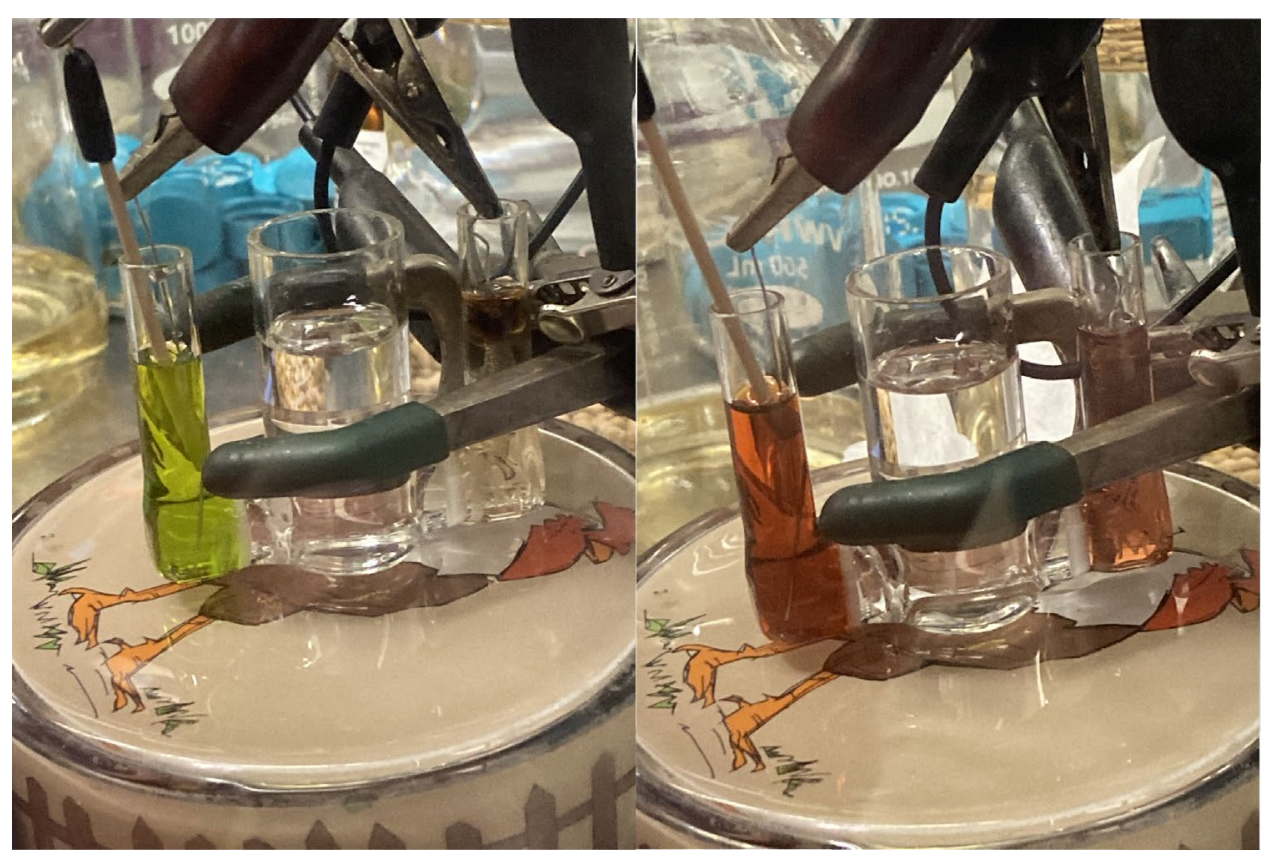

Figure S5. Setup for bulk electrolysis at $-2.3 \mathrm{~V}$ vs. $\mathrm{Fc} / \mathrm{Fc}^{+}$(left) and $-3 \mathrm{~V}$ vs. $\mathrm{Fc} / \mathrm{Fc}^{+}$(right) in a $\mathrm{W}$-cell inside a nitrogen-filled glovebox. TEA was used as a sacrificial reductant in the counter electrode compartment (right side of W-cell).

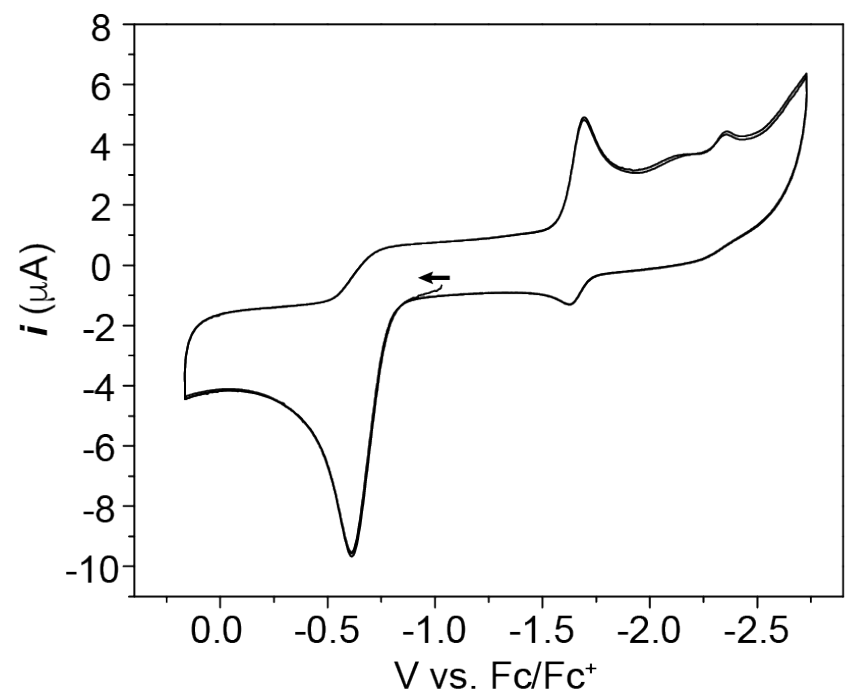

Figure S6. 3 cycles of cyclic voltammetry of $1 \mathrm{mM}[\mathrm{NMI}(\mathrm{H})]^{-}[\mathrm{TBA}]^{+}$in $100 \mathrm{mM}$ TBAPF$_{6}$ propylene carbonate solution. The experiment was performed at $100 \mathrm{mV} \mathrm{s}^{-1}$ on a $1 \mathrm{~cm}^{2}$ glassy carbon working electrode, using a leak-free $\mathrm{Ag} / \mathrm{AgCl}$ reference electrode and a Pt mesh counter electrode in a nitrogen-filled glovebox. 


\section{Steady-State and Time-Resolved Emission}
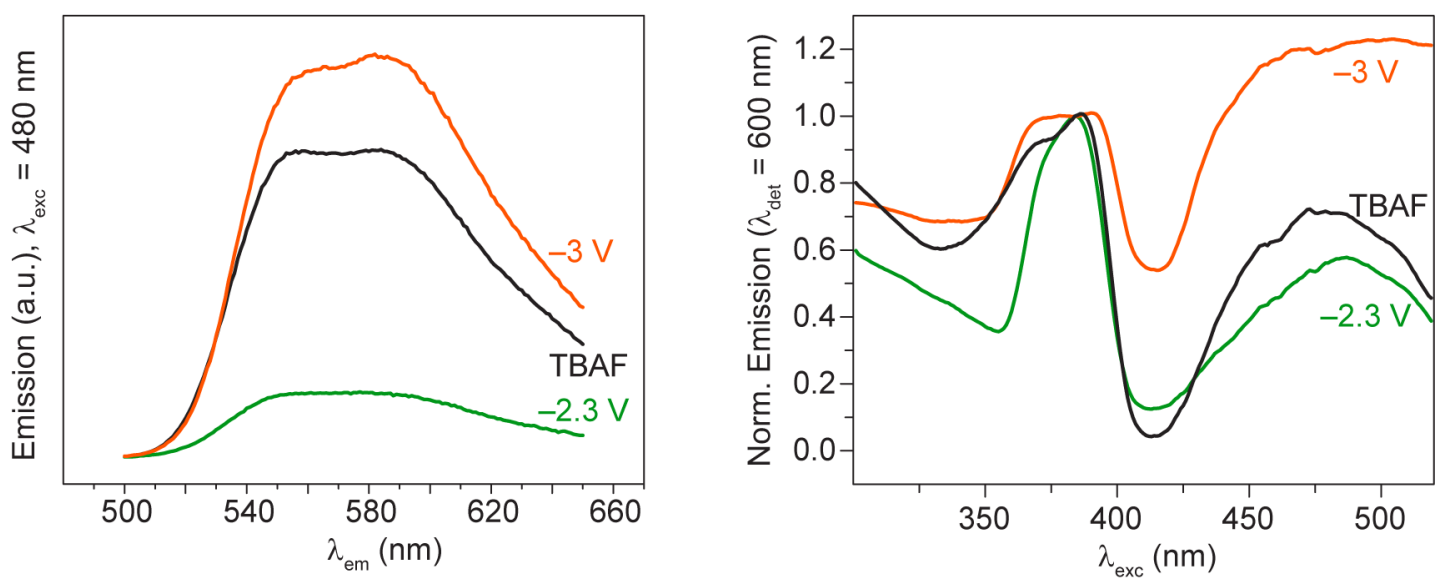

Figure S7. Emission (left) and excitation (right) spectra of NMI solutions electrolyzed at either -3.0 V (orange) or $-2.3 \mathrm{~V}$ (green) vs. Fc/Fc', compared with NMI treated with TBAF in DMAc (black). Grating corrections resulted in baseline deviations for excitation scans.
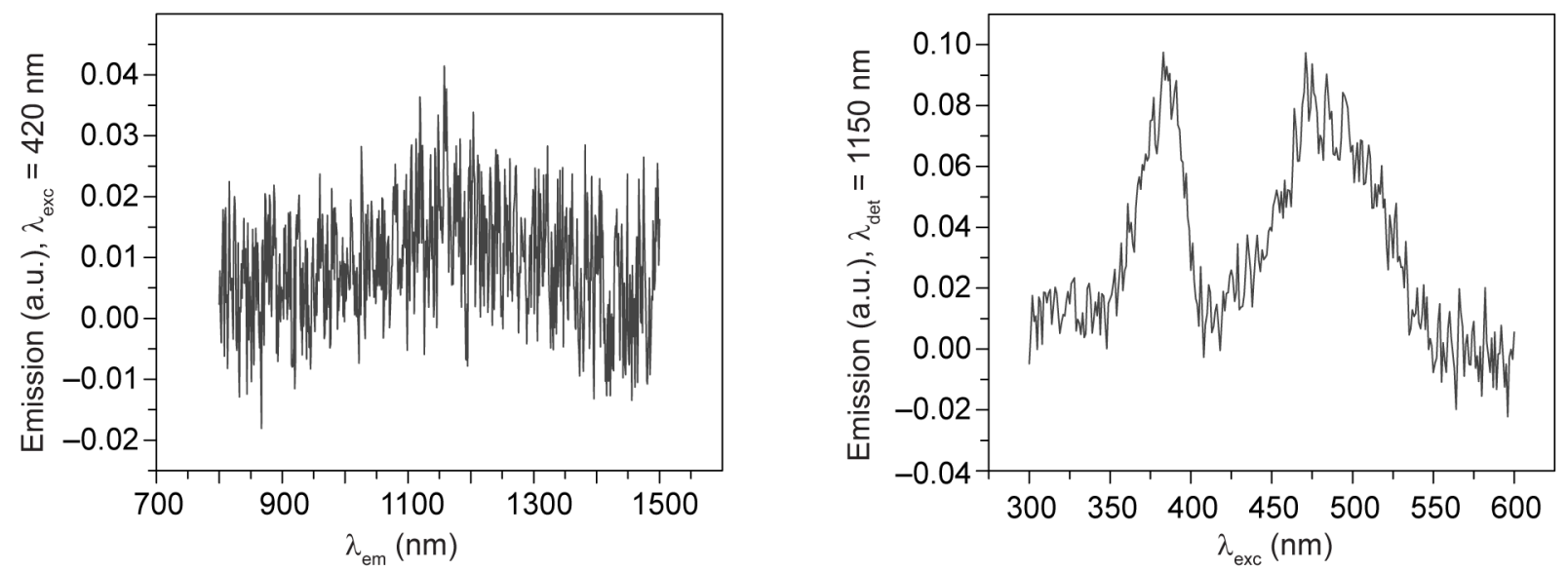

Figure S8. Infrared emission (left) and excitation (right) spectra of the NMI solution electrolyzed at or -2.3 $V$ vs. Fc/Fc'. Emission at $1150 \mathrm{~nm}$ is a second-order wavelength, at half the energy of the 550-600 $\mathrm{nm}$ emission in Figure S6, and therefore arises from the two-electron reduced NMI, with an excitation spectrum matching the absorbance of the 2-electron-reduced species. No emission could be detected originating from the NMI radical anion. 

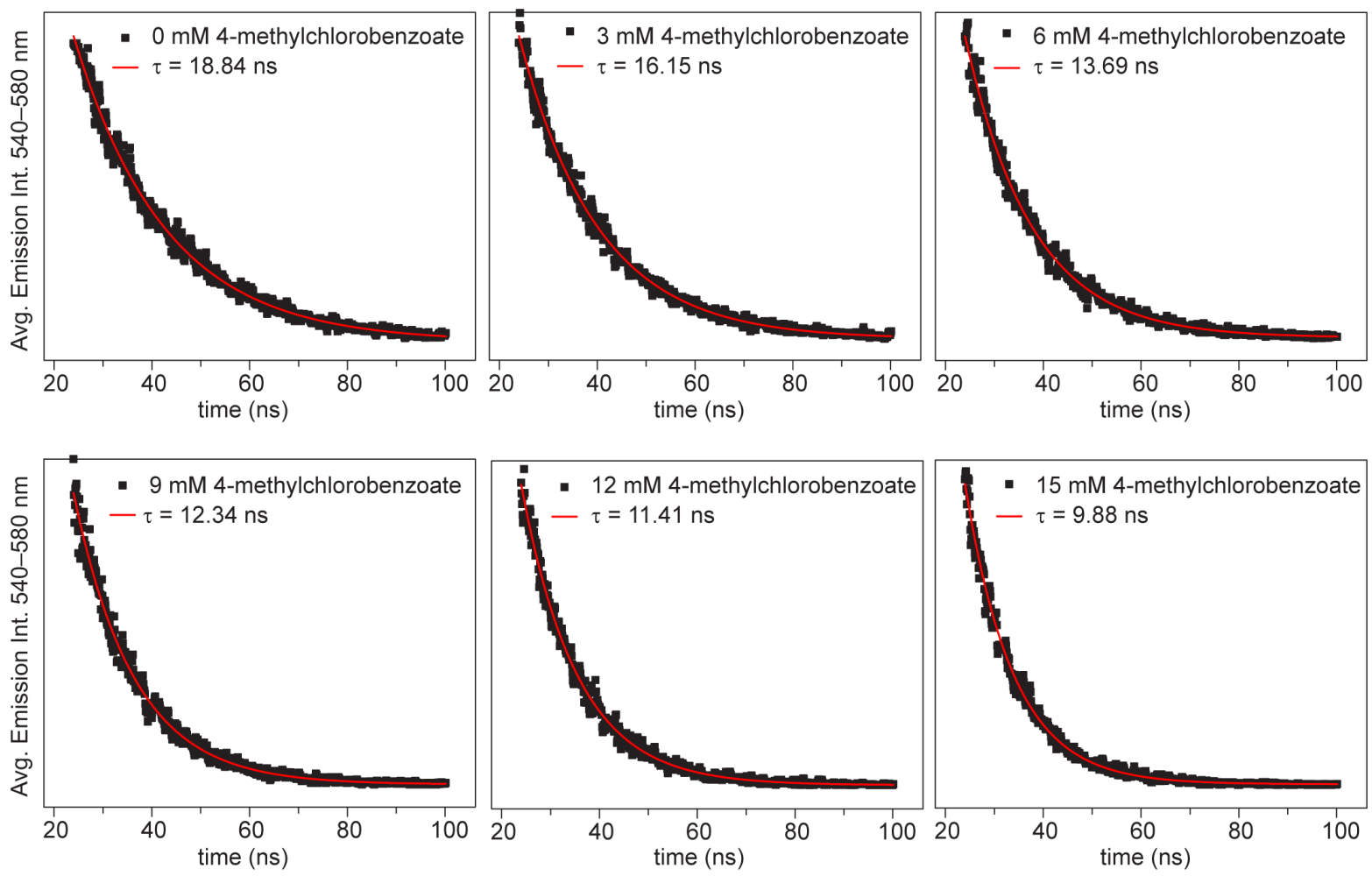

Figure S9. Time-resolved emission intensity $\left(\lambda_{\text {det }}=440-480 \mathrm{~nm}\right)$ with increasing concentration of 4methylchlorobenzoate. All samples are $0.1 \mathrm{mM} \mathrm{NMI}$ in $1 \mathrm{mM}$ TBAF in DMAc. Red lines are singleexponential decay fits to the data according to the equation $I(t)=I_{o} e^{-t / \tau}$. Stern-Volmer plot using this data presented in Figure 3F. 

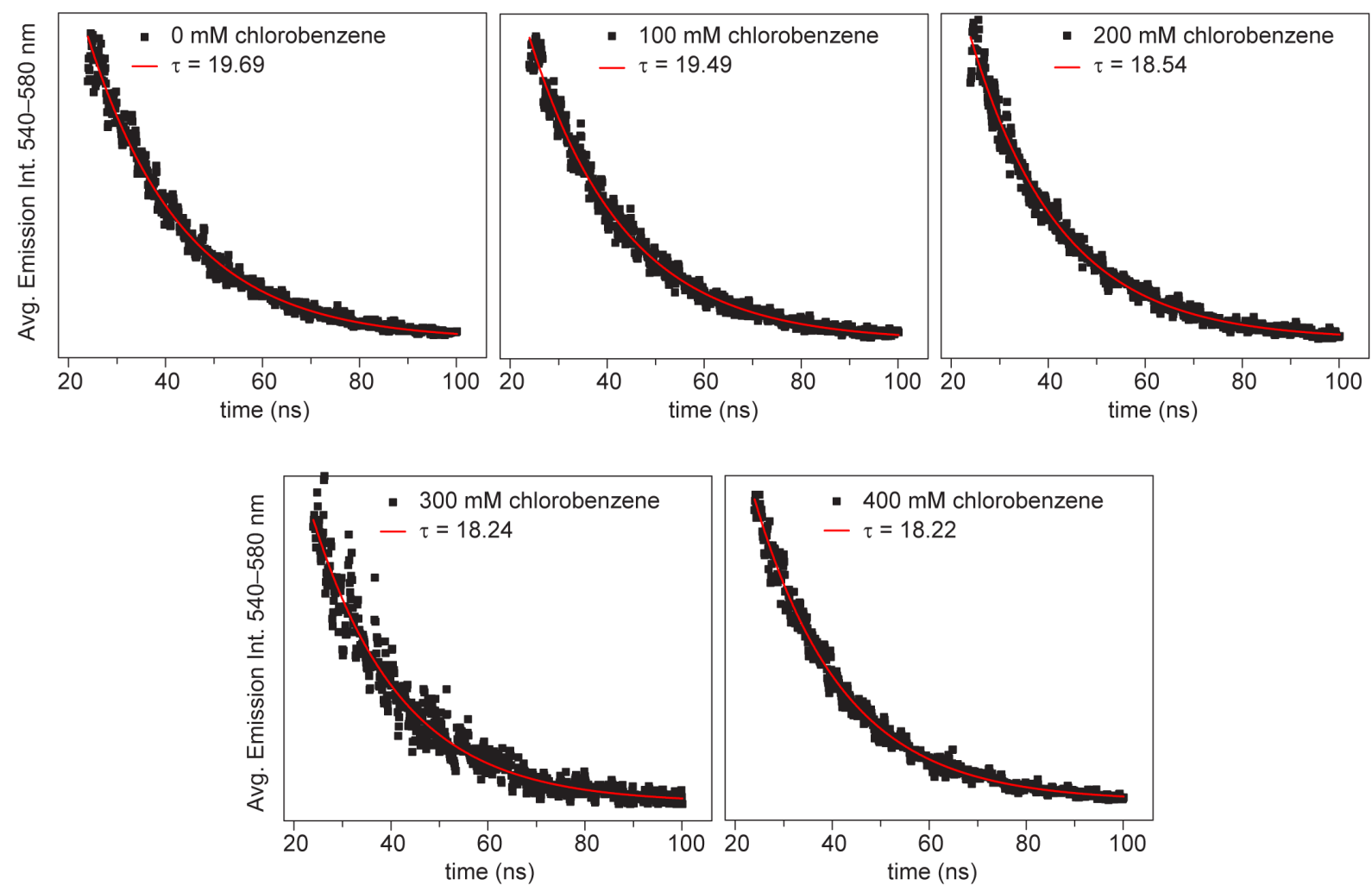

Figure S10. Time-resolved emission intensity $\left(\lambda_{\text {det }}=440-480 \mathrm{~nm}\right)$ with increasing concentration of chlorobenzene All samples are $0.1 \mathrm{mM} \mathrm{NMI}$ in $1 \mathrm{mM} \mathrm{TBAF}$ in DMAc. Red lines are single-exponential decay fits to the data according to the equation $I(t)=I_{o} e^{-t / \tau}$. Stern-Volmer plot using this data presented in Figure 3F. 


\section{NMR Spectroscopy}
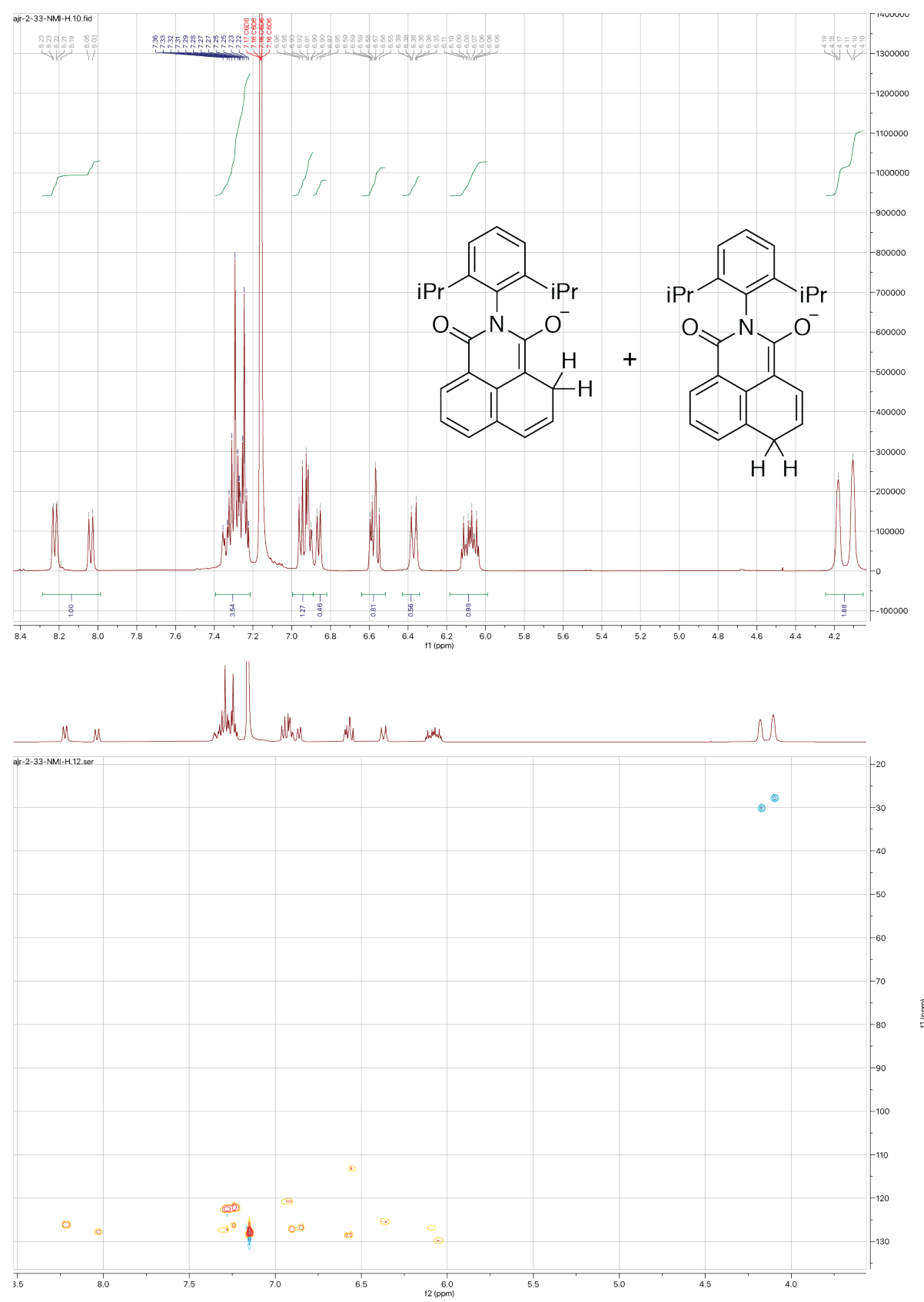

Figure S11. ${ }^{1} \mathrm{H}$ (top) and Heteronuclear Single Quantum Correlation - Distortionless Enhancement by Polarization Transfer (HSQC-DEPT) NMR spectra obtained in $\mathrm{C}_{6} \mathrm{D}_{6}$ for NMI treated with $\mathrm{NaBH}_{4}$ after anion exchange with $\mathrm{TBAPF}_{6}$. The y axis (f1) corresponds to the ${ }^{13} \mathrm{C}$ chemical shift of the carbon with attached protons at the ${ }^{1} \mathrm{H}$ chemical shift indicated in the $\mathrm{x}$-axis (f2). The phase is represented by color: blue colors indicate $\mathrm{CH}_{2}$ groups whereas red colors indicate $\mathrm{CH}$ or $\mathrm{CH}_{3}$ groups. Tentative peak assignments via density functional theory calculations are provided in section G. of this supporting information. 


\section{E. Single-Crystal X-ray Diffraction}

X-ray diffraction analysis was performed on single crystals coated with Paratone-N oil and mounted on a glass fiber for $[\mathrm{NMI}(\mathrm{H})]^{-}[\mathrm{TBA}]^{+}$and a MiTeGen loop for NMI. Crystals were frozen at $100 \mathrm{~K}$ by Oxford Cryosystems Cryostreams during the experiments. Data for $[\mathrm{NMI}(\mathrm{H})]^{-}[\mathrm{TBA}]^{+}$were collected at ChemMatCARS at the Advanced Photon Source at Argonne National Laboratory using synchrotron radiation $(\lambda=0.41328 \AA$ ) on a Huber three-circle diffractometer equipped with a Pilatus $1 \mathrm{M}(\mathrm{CdTe})$ detector, while data for the neutral NMI were collected at the Harvard Department of Chemistry and Chemical Biology X-ray Laboratory on a Bruker D8 Venture diffractometer equipped with a Bruker PHOTON100 CMOS detector. Raw data were integrated and corrected for Lorentz and polarization effects using Bruker AXS SAINT software. ${ }^{3}$ Absorption corrections were applied using SADABS. ${ }^{4}$ Space group assignments were determined by examination of systematic absences, E-statistics, and successive refinement of the structures. Both structures were solved by intrinsic phasing using SHELXT. ${ }^{5}$ All structures were refined using SHELXL ${ }^{6}$ operated in the OLEX $2^{7}$ interface. No significant crystal decay was observed during data collection.

During initial refinement of the structure of $[\mathrm{NMI}(\mathrm{H})]^{-}[\mathrm{TBA}]^{+}$, the two carbon atoms on the 2- and 7-positions of the reduced naphthalene ring were found to have longer $\mathrm{C}-\mathrm{C}$ bond distances than those expected for $\mathrm{sp}^{2}$ hybridized carbon atoms. Residual electron density close to these carbon atoms suggested the presence of both $\mathrm{C}\left(\mathrm{sp}^{3}\right) \mathrm{H}_{2}$ and $\mathrm{C}\left(\mathrm{sp}^{2}\right) \mathrm{H}$ hydrogen atoms. Based on these observations and characterization by NMR spectroscopy, the structure was assigned as a twoelectron reduced Meisenheimer complex with one $\mathrm{sp}^{3}$ hybridized carbon atom and one $\mathrm{sp}^{2}$ hybridized carbon atom disordered over two positions. The final refinement gave a value for $R_{1}$ that was $0.13 \%$ lower compared to a model that did not account for the disorder and $0.15 \%$ lower compared to a model that assigned the two carbon atoms as $\mathrm{C}\left(\mathrm{sp}^{2}\right) \mathrm{H}$ groups.

Thermal parameters for both structures were refined anisotropically for all non-hydrogen atoms. For the structure of $[\mathrm{NMI}(\mathrm{H})]^{-}[\mathrm{TBA}]^{+}$, disorder of the carbon atoms on the reduced naphthalene ring required displacement parameter restraints (SIMU and RIGU), while disorder of two carbon atoms of the tetrabutylammonium counteraction required both displacement parameter restraints (SIMU and RIGU) and distance restraints (DFIX). Hydrogen atoms in both structures were placed in ideal positions and refined using a riding model for all structures. 

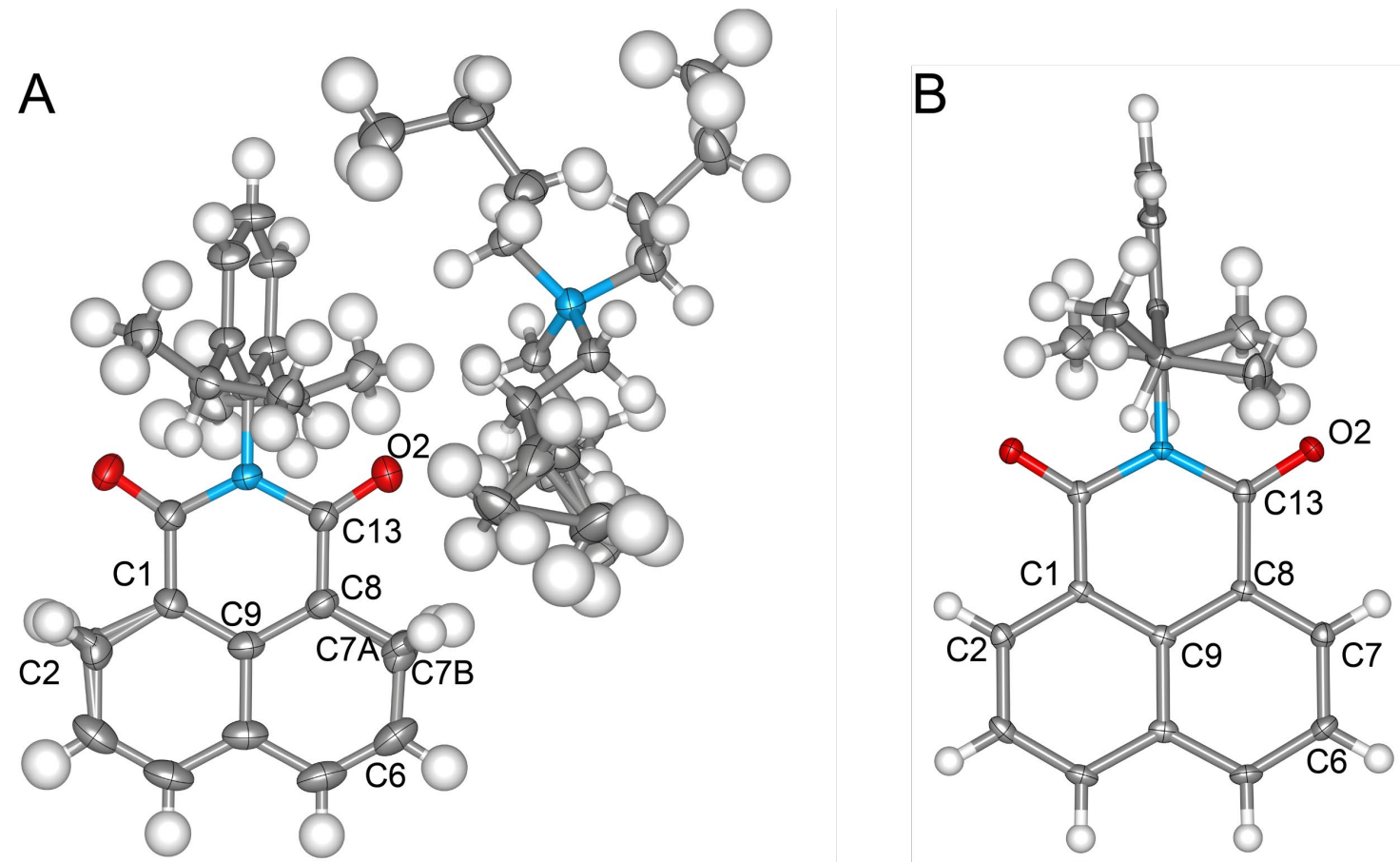

Figure S12. (A) Atomic displacement parameter plot for the solid-state structure of $[\mathrm{NMI}(\mathrm{H})]^{-}[\mathrm{TBA}]^{+}$at 100 K drawn at 50\% probability level as determined by single-crystal X-ray diffraction. The carbon atoms at the 2- and 7-positions of the reduced naphthalene ring correspond to one $\mathrm{sp}^{2}$ hybridized carbon atom and one $\mathrm{sp}^{3}$ hybridized carbon atom disorder over the two positions (relative occupancy of 42(3):58(3)). Two carbon atoms on the TBA countercation are also disordered over two positions (relative occupancy of 83.8(9):16.2(9)). (B) Atomic displacement parameter plot for the solid-state structure of NMI at $100 \mathrm{~K}$ drawn at 50\% probability level as determined by single-crystal X-ray diffraction. Red, blue, gray, and white ellipsoids represent $\mathrm{O}, \mathrm{N}, \mathrm{C}$, and $\mathrm{H}$ atoms, respectively.

Table S1. Selected bond lengths and angles for [NMI(H)]-

\begin{tabular}{lcl}
\hline Compound & {$[\mathrm{NMI}(\mathrm{H})]^{-[\mathrm{TBA}]^{+}}$} & \multicolumn{1}{c}{$\mathrm{NMI}$} \\
\hline $\mathrm{C} 9-\mathrm{C} 8$ & $1.411(3) \AA$ & $1.4182(19) \AA$ \\
$\mathrm{C} 8-\mathrm{C7}(\mathrm{A})\left(58 \%\right.$ occ. $\left.[\mathrm{NMI}(\mathrm{H})]^{-}\right)$ & $1.456(15) \AA$ & $1.374(3) \AA$ \\
C8-C7B $\left(42 \%\right.$ occ. $\left.[\mathrm{NMI}(\mathrm{H})]^{-}\right)$ & $1.51(3) \AA$ & - \\
C7(A)-C6 & $1.484(15) \AA$ & $1.402(3) \AA$ \\
C7B-C6 & $1.38(3) \AA$ & - \\
C8-C13 & $1.428(3) \AA$ & $1.479(2) \AA$ \\
C13-O2 & $1.253(2) \AA$ & $1.2158(18) \AA$ \\
Omega(C13-C8-C9-C1) & $2.5(3)^{\circ}$ & $0.37(2)^{\circ}$ \\
\hline
\end{tabular}


Table S2. Crystallographic data for [NMI(H)] $]^{-}$.

\begin{tabular}{|c|c|c|}
\hline Compound & {$[\mathrm{NMI}(\mathrm{H})]^{-}[\mathrm{TBA}]^{+}$} & $\mathrm{NMI}$ \\
\hline Formula & $\mathrm{C}_{40} \mathrm{H}_{60} \mathrm{~N}_{2} \mathrm{O}_{2}$ & $\mathrm{C}_{24} \mathrm{H}_{23} \mathrm{NO}_{2}$ \\
\hline$T(K)$ & $100(2)$ & $100(2)$ \\
\hline Crystal System & Monoclinic & Monoclinic \\
\hline Space Group & $\mathrm{Cc}$ & $C 2 / c$ \\
\hline$a(\AA)$ & $17.7475(13)$ & $14.4954(12)$ \\
\hline$b(\AA)$ & $11.9924(9)$ & $9.3527(8)$ \\
\hline$c(\AA)$ & $17.5891(12)$ & $27.510(2)$ \\
\hline$\alpha\left(^{\circ}\right)$ & 90 & 90 \\
\hline$B\left(1^{\circ}\right)$ & $96.0850(15)$ & $97.815(3)$ \\
\hline$\gamma\left(\left(^{\circ}\right)\right.$ & 90 & 90 \\
\hline$V\left(\AA^{3}\right)$ & $3722.5(5)$ & $3672.0(5)$ \\
\hline Z & 4 & 8 \\
\hline Radiation & Synchrotron & Mo Ka \\
\hline$\lambda(\AA)$ & 0.41328 & 0.71073 \\
\hline $2 \Theta$ Range for Data Collection $\left({ }^{\circ}\right)$ & 2.388 to 35.51 & 5.208 to 51.422 \\
\hline Completeness to $2 \theta$ & $98.4 \%\left(2 \Theta=28.714^{\circ}\right)$ & $95.2 \%\left(2 \Theta=50.484^{\circ}\right)$ \\
\hline Data / Restraints / Parameters & $11716 / 135 / 444$ & $3335 / 0 / 248$ \\
\hline Goodness of Fit on $F^{2}$ & 1.052 & 1.074 \\
\hline $\mathrm{R}_{1}^{\mathrm{a}}$ & 0.0455 & 0.0395 \\
\hline$w R_{2}^{b}(1>2 \sigma(I))$ & 0.1272 & 0.0871 \\
\hline$R_{1}^{a}$ (all data) & 0.0522 & 0.0544 \\
\hline$w R_{2}^{b}$ (all data) & 0.1304 & 0.0940 \\
\hline Largest Diff. Peak and Hole (e $\AA^{-3}$ ) & 0.334 and -0.152 & 0.172 and -0.214 \\
\hline
\end{tabular}

${ }^{a} R_{1}=\Sigma|| F_{0}|-| F_{\mathrm{c}}|| / \Sigma\left|F_{\mathrm{o}}\right| \cdot{ }^{b} w R_{2}=\left\{\Sigma\left[w\left(F_{\mathrm{o}}^{2}-F_{\mathrm{c}}{ }^{2}\right)^{2}\right] / \Sigma\left[w\left(F_{\mathrm{o}}^{2}\right)^{2}\right]\right\}^{1 / 2}$. 


\section{F. Calculated Structures of NMI and $[\mathrm{NMI}(\mathrm{H})]^{-}$}

\section{F.1. Ab initio Computational Methodology}

Geometry optimizations were performed using the program Gaussian $09^{8}$ at the B3LYP/6$311 G+(d, p)^{9-13}$ level of theory with model benzene solvation using the Polarizable Continuum Model (PCM) with the integral equation formalism variant (IEFPCM). Frequency calculations were performed to ensure all structures were at global minima. Four possible isomers of [NMI(H)]- were considered as possible species to correspond to the ${ }^{1} \mathrm{H}$ and ${ }^{13} \mathrm{C}$ NMR signals observed as a result of the reaction of NMI with a hydride source: hydride addition to the naphthalene ring producing either an ortho (ortho- $\left.[\mathrm{NMI}(\mathrm{H})]^{-}\right)$, meta $\left(\right.$meta- $\left.[\mathrm{NMI}(\mathrm{H})]^{-}\right)$or a para isomer (para- $\left.[\mathrm{NMI}(\mathrm{H})]^{-}\right)$, or to a carboxamide carbon (carbo-[NMI $\left.(\mathrm{H})]^{-}\right)$. The coordinates of the optimized structures of these species are deposited in the appendix of this supplementary material and were then used to perform an NMR calculation with the program Gaussian 09 using the GIAO method ${ }^{14-18}$ with the same level of theory and implicit solvent as for the geometry optimizations. These calculations were performed using Gaussian 09 with the following keywords: nmr=giao b3lyp/6-311+g(d,p) scrf=(iefpcm,solvent=benzene). A plot of the experimental vs. calculated absolute chemical shielding was constructed using the parent NMI as a calibration standard. 
F.2. NMI

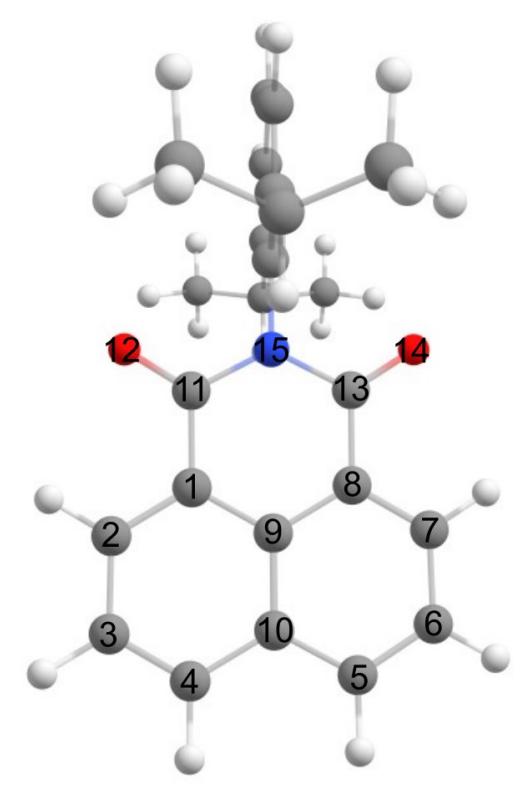

Figure S13. Calculated structure of $\mathrm{NMI}$ at the at the B3LYP/6-311G+(d,p) level of theory. Selected interatomic distances $(\AA)$ : C1-C2 1.383, C2-C3 1.408, C3-C4 1.378, C4-C10 1.418, C9-C10 1.427, C9C1 1.416, C1-C11 1.483, C11-012 1.218.

Table S3. NMI xyz coordinates optimized at the B3LYP/6-311G+(d,p) level of theory used for GIAO NMR calculations.

\begin{tabular}{|l|r|r|r|}
\hline Atom & $x$ & $y$ & $z$ \\
\hline C7 & -2.56240000 & -0.09370000 & 2.42400000 \\
\cline { 1 - 1 } C8 & -1.86560000 & -0.04780000 & 1.23060000 \\
\hline C9 & -2.56520000 & -0.00010000 & 0.00000000 \\
\hline C10 & -3.99210000 & -0.00010000 & 0.00000000 \\
\hline C6 & -4.67180000 & -0.04820000 & 1.24370000 \\
\hline H7 & -3.97080000 & -0.09390000 & 2.42890000 \\
\hline C4 & -2.00640000 & -0.12940000 & 3.35250000 \\
\hline H5 & -1.86560000 & 0.04760000 & -1.23070000 \\
\hline H6 & -4.67180000 & 0.04810000 & -1.24380000 \\
\hline C3 & -5.75650000 & -0.04850000 & 1.24860000 \\
\hline C2 & -4.50070000 & -0.13030000 & 3.37320000 \\
\hline H4 & -3.97080000 & 0.09380000 & -2.42900000 \\
\hline
\end{tabular}




\begin{tabular}{|c|c|c|c|}
\hline $\mathrm{H} 3$ & -4.50070000 & 0.13020000 & -3.37330000 \\
\hline $\mathrm{H} 2$ & -2.00640000 & 0.12920000 & -3.35260000 \\
\hline $\mathrm{C} 13$ & -0.38300000 & -0.04850000 & 1.24920000 \\
\hline C11 & -0.38300000 & 0.04830000 & -1.24930000 \\
\hline $\mathrm{O} 14$ & 0.26390000 & -0.08870000 & 2.28040000 \\
\hline $\mathrm{O} 12$ & 0.26390000 & 0.08830000 & -2.28050000 \\
\hline N15 & 0.26590000 & -0.00010000 & 0.00000000 \\
\hline $\mathrm{C} 16$ & 1.72140000 & 0.00000000 & 0.00000000 \\
\hline $\mathrm{C} 17$ & 2.39700000 & 1.23080000 & 0.03440000 \\
\hline $\mathrm{C} 18$ & 2.39720000 & -1.23050000 & -0.03440000 \\
\hline C19 & 3.79470000 & 1.20350000 & 0.03360000 \\
\hline $\mathrm{C} 20$ & 3.79490000 & -1.20300000 & -0.03380000 \\
\hline $\mathrm{C} 21$ & 4.48920000 & 0.00030000 & -0.00020000 \\
\hline $\mathrm{H} 19$ & 4.34670000 & 2.13620000 & 0.05920000 \\
\hline $\mathrm{H} 2 \mathrm{O}$ & 4.34710000 & -2.13560000 & -0.05950000 \\
\hline $\mathrm{H} 21$ & 5.57380000 & 0.00040000 & -0.00030000 \\
\hline $\mathrm{C} 22$ & 1.67000000 & -2.56960000 & -0.06830000 \\
\hline $\mathrm{H} 22$ & 0.59610000 & -2.37270000 & -0.07380000 \\
\hline $\mathrm{C} 23$ & 1.66960000 & 2.56970000 & 0.06840000 \\
\hline $\mathrm{H} 23$ & 0.59570000 & 2.37270000 & 0.07370000 \\
\hline $\mathrm{C} 24$ & 1.98980000 & -3.35750000 & -1.35260000 \\
\hline $\mathrm{H} 24 \mathrm{a}$ & 1.75210000 & -2.77180000 & -2.24360000 \\
\hline $\mathrm{H} 24 \mathrm{~b}$ & 3.04790000 & -3.63090000 & -1.40070000 \\
\hline $\mathrm{H} 24 \mathrm{c}$ & 1.40620000 & -4.28250000 & -1.38400000 \\
\hline $\mathrm{C} 25$ & 1.96900000 & -3.40650000 & 1.19000000 \\
\hline $\mathrm{H} 25 \mathrm{a}$ & 1.71600000 & -2.85480000 & 2.09830000 \\
\hline $\mathrm{H} 25 \mathrm{~b}$ & 1.38620000 & -4.33240000 & 1.17660000 \\
\hline $\mathrm{H} 25 \mathrm{c}$ & 3.02670000 & -3.68020000 & 1.24460000 \\
\hline $\mathrm{C} 26$ & 1.96870000 & 3.40690000 & -1.18960000 \\
\hline $\mathrm{H} 26 \mathrm{a}$ & 3.02630000 & 3.68090000 & -1.24390000 \\
\hline $\mathrm{H} 26 \mathrm{~b}$ & 1.71600000 & 2.85550000 & -2.09810000 \\
\hline $\mathrm{H} 26 \mathrm{c}$ & 1.38560000 & 4.33280000 & -1.17610000 \\
\hline $\mathrm{C} 27$ & 1.98900000 & 3.35730000 & 1.35300000 \\
\hline $\mathrm{H} 27 \mathrm{a}$ & 1.40540000 & 4.28230000 & 1.38450000 \\
\hline $\mathrm{H} 27 \mathrm{~b}$ & 1.75100000 & 2.77140000 & 2.24380000 \\
\hline $\mathrm{H} 27 \mathrm{c}$ & 3.04700000 & 3.63070000 & 1.40150000 \\
\hline
\end{tabular}




\section{F.3. ortho-[NMI(H)]-}

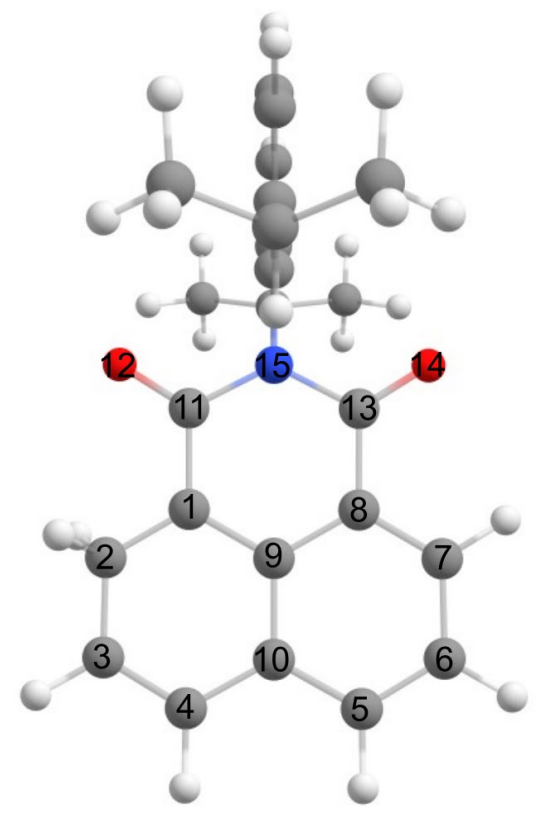

Figure S14. Calculated structure of ortho-[NMI(H)] $]^{-}$at the at the B3LYP/6-311G+(d,p) level of theory. Selected interatomic distances $(\AA)$ : C1-C2 1.514, C2-C3 1.503, C3-C4 1.342, C4-C10 1.458, C10-C5 1.384, C5-C6 1.411, C6-C7 1.383, C7-C8 1.407, C8-C9 1.427, C9-C10 1.443, C9-C1 1.405, C1-C11 1.412, C11-012 1.249, C13-014 1.241.

Table S4. Coordinates of ortho-[NMI(H)] $]^{-}$optimized at the B3LYP/6-311G+(d,p) level of theory used for GIAO NMR calculations.

\begin{tabular}{|l|c|c|c|}
\hline Atom & \multicolumn{1}{|c|}{$\boldsymbol{x}$} & $\boldsymbol{y}$ & $\mathbf{z}$ \\
\hline C7 & -2.51930000 & -0.06000000 & 2.49980000 \\
\hline C8 & -1.80970000 & -0.03110000 & 1.28460000 \\
\hline C9 & -2.50370000 & -0.00570000 & 0.03740000 \\
\hline C10 & -3.94570000 & -0.00260000 & 0.07890000 \\
\hline C5 & -4.60480000 & -0.03070000 & 1.29550000 \\
\hline C6 & -3.90200000 & -0.06190000 & 2.51870000 \\
\hline H7 & -1.94530000 & -0.07900000 & 3.41930000 \\
\hline C1 & -1.81660000 & 0.01980000 & -1.18730000 \\
\hline H5 & -4.66200000 & 0.03810000 & -1.19050000 \\
\hline H6 & -5.69210000 & -0.02710000 & 1.30130000 \\
\hline C3 & -4.44240000 & -0.08300000 & 3.45860000 \\
\hline C2 & -4.03280000 & 0.06010000 & -2.37520000 \\
\hline
\end{tabular}




\begin{tabular}{|c|c|c|c|}
\hline $\mathrm{H} 4$ & -5.74890000 & 0.05440000 & -1.15190000 \\
\hline H3 & -4.61810000 & 0.09330000 & -3.29110000 \\
\hline $\mathrm{H} 2$ & -2.24220000 & -0.83860000 & -3.12690000 \\
\hline $\mathrm{C} 13$ & -0.35440000 & -0.02680000 & 1.30890000 \\
\hline C11 & -0.40510000 & 0.02440000 & -1.21490000 \\
\hline $\mathrm{O} 14$ & 0.32710000 & -0.04600000 & 2.34610000 \\
\hline 012 & 0.29610000 & 0.04430000 & -2.24880000 \\
\hline N15 & 0.26800000 & 0.00100000 & 0.05610000 \\
\hline C16 & 1.71350000 & 0.00220000 & 0.03080000 \\
\hline C17 & 2.39890000 & 1.22930000 & 0.04350000 \\
\hline $\mathrm{C} 18$ & 2.40030000 & -1.22300000 & -0.01020000 \\
\hline C19 & 3.79660000 & 1.20700000 & 0.01410000 \\
\hline C20 & 3.79810000 & -1.19780000 & -0.03600000 \\
\hline $\mathrm{C} 21$ & 4.49450000 & 0.00520000 & -0.02390000 \\
\hline H19 & 4.34690000 & 2.14210000 & 0.01690000 \\
\hline $\mathrm{H} 2 \mathrm{O}$ & 4.34920000 & -2.13190000 & -0.06730000 \\
\hline $\mathrm{H} 21$ & 5.57980000 & 0.00620000 & -0.04470000 \\
\hline $\mathrm{C} 22$ & 1.66810000 & -2.55870000 & -0.04290000 \\
\hline $\mathrm{H} 22$ & 0.59840000 & -2.34960000 & -0.00560000 \\
\hline C23 & 1.66160000 & 2.56260000 & 0.05820000 \\
\hline $\mathrm{H} 23$ & 0.59930000 & 2.34950000 & 0.18480000 \\
\hline C24 & 1.93720000 & -3.31450000 & -1.35780000 \\
\hline $\mathrm{H} 24 \mathrm{a}$ & 1.66940000 & -2.69810000 & -2.21900000 \\
\hline $\mathrm{H} 24 \mathrm{~b}$ & 2.99230000 & -3.59240000 & -1.45130000 \\
\hline $\mathrm{H} 24 \mathrm{c}$ & 1.34520000 & -4.23500000 & -1.39590000 \\
\hline $\mathrm{C} 25$ & 2.00460000 & -3.42640000 & 1.18380000 \\
\hline $\mathrm{H} 25 \mathrm{a}$ & 1.77340000 & -2.89540000 & 2.11000000 \\
\hline $\mathrm{H} 25 \mathrm{~b}$ & 1.42110000 & -4.35280000 & 1.16610000 \\
\hline $\mathrm{H} 25 \mathrm{c}$ & 3.06430000 & -3.70100000 & 1.20360000 \\
\hline $\mathrm{C} 26$ & 1.81860000 & 3.29820000 & -1.28600000 \\
\hline $\mathrm{H} 26 \mathrm{a}$ & 2.86400000 & 3.56520000 & -1.47350000 \\
\hline $\mathrm{H} 26 \mathrm{~b}$ & 1.47280000 & 2.66770000 & -2.10790000 \\
\hline $\mathrm{H} 26 \mathrm{c}$ & 1.23060000 & 4.22220000 & -1.28660000 \\
\hline $\mathrm{C} 27$ & 2.09080000 & 3.45120000 & 1.23950000 \\
\hline $\mathrm{H} 27 \mathrm{a}$ & 1.48710000 & 4.36410000 & 1.26500000 \\
\hline $\mathrm{H} 27 \mathrm{~b}$ & 1.95780000 & 2.92760000 & 2.18910000 \\
\hline $\mathrm{H} 27 \mathrm{c}$ & 3.14060000 & 3.75130000 & 1.16050000 \\
\hline $\mathrm{H} 2 \mathrm{~b}$ & -2.20710000 & 0.89110000 & -3.12750000 \\
\hline
\end{tabular}




\section{F.4. para-[NMI(H)]-}

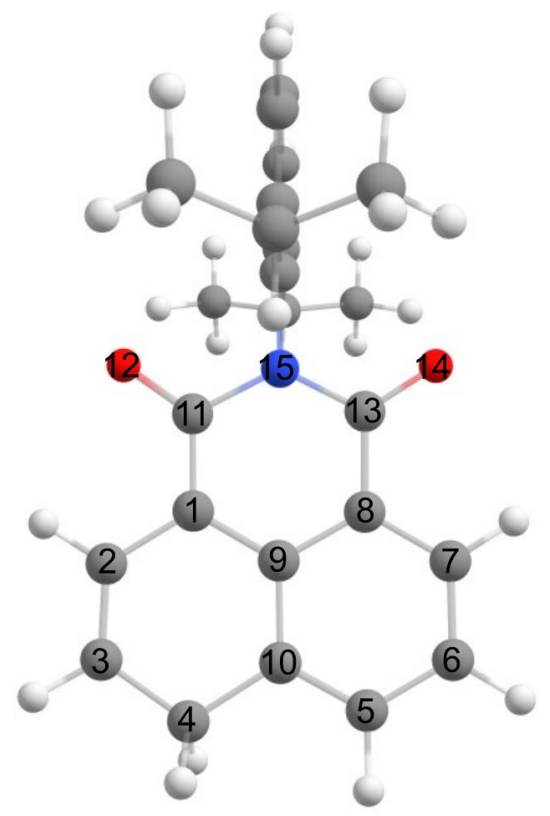

Figure S15. Calculated structure of para- $[\mathrm{NMI}(\mathrm{H})]^{-}$at the at the $\mathrm{B} 3 \mathrm{LYP} / 6-311 \mathrm{G}+(\mathrm{d}, \mathrm{p})$ level of theory. Selected interatomic distances $(\AA)$ : C1-C2 1.450, C2-C3 1.345, C3-C4 1.508, C4-C10 1.524, C10-C5 1.384, C5-C6 1.409, C6-C7 1.381, C7-C8 1.407, C8-C9 1.420, C9-C10 1.431, C9-C1 1.426, C1-C11 1.412, C11-012 1.254, C13-014 1.242.

Table S5. Coordinates of para-[NMI(H)]- optimized at the B3LYP/6-311G+(d,p) level of theory used for GIAO NMR calculations.

\begin{tabular}{|l|c|c|r|}
\hline Atom & $x$ & $y$ & $z$ \\
\hline C7 & -2.58280000 & 0.00170000 & -2.44500000 \\
\hline C8 & -1.81450000 & 0.00090000 & -1.21480000 \\
\hline C9 & -2.51160000 & 0.00010000 & 0.02880000 \\
\hline C10 & -3.94210000 & 0.00000000 & 0.06970000 \\
\hline C5 & -4.76200000 & 0.00130000 & -1.21500000 \\
\hline C6 & -3.92760000 & 0.00180000 & -2.47100000 \\
\hline H7 & -2.02310000 & 0.00210000 & -3.37440000 \\
\cline { 1 - 1 } C1 & -1.80230000 & -0.00090000 & 1.25900000 \\
\hline H5 & -4.58240000 & -0.00100000 & 1.29680000 \\
\hline H6 & -5.43620000 & 0.87050000 & -1.21520000 \\
\hline C3 & -4.45720000 & 0.00230000 & -3.41890000 \\
\hline C2 & -3.87050000 & -0.00200000 & 2.51280000 \\
\hline
\end{tabular}




\begin{tabular}{|c|c|c|c|}
\hline $\mathrm{H} 4$ & -5.66890000 & -0.00110000 & 1.32220000 \\
\hline H3 & -4.40580000 & -0.00290000 & 3.45550000 \\
\hline $\mathrm{H} 2$ & -1.91220000 & -0.00270000 & 3.40320000 \\
\hline $\mathrm{C} 13$ & -0.40330000 & 0.00090000 & -1.25800000 \\
\hline C11 & -0.34050000 & -0.00080000 & 1.25960000 \\
\hline $\mathrm{O} 14$ & 0.30580000 & 0.00160000 & -2.29200000 \\
\hline $\mathrm{O} 12$ & 0.34010000 & -0.00150000 & 2.29910000 \\
\hline N15 & 0.27690000 & 0.00000000 & 0.01210000 \\
\hline C16 & 1.72550000 & 0.00000000 & -0.01240000 \\
\hline C17 & 2.41000000 & -1.22910000 & -0.02220000 \\
\hline $\mathrm{C} 18$ & 2.41000000 & 1.22910000 & -0.02090000 \\
\hline C19 & 3.80890000 & -1.20370000 & -0.04170000 \\
\hline $\mathrm{C} 20$ & 3.80900000 & 1.20370000 & -0.04030000 \\
\hline C21 & 4.50590000 & 0.00000000 & -0.05100000 \\
\hline $\mathrm{H} 19$ & 4.36090000 & -2.13720000 & -0.04920000 \\
\hline $\mathrm{H} 2 \mathrm{O}$ & 4.36100000 & 2.13710000 & -0.04680000 \\
\hline $\mathrm{H} 21$ & 5.59060000 & -0.00010000 & -0.06610000 \\
\hline $\mathrm{C} 22$ & 1.68260000 & 2.56920000 & -0.00460000 \\
\hline $\mathrm{H} 22$ & 0.61040000 & 2.36680000 & -0.01550000 \\
\hline $\mathrm{C} 23$ & 1.68250000 & -2.56920000 & -0.00730000 \\
\hline $\mathrm{H} 23$ & 0.61030000 & -2.36670000 & -0.01840000 \\
\hline $\mathrm{C} 24$ & 1.98650000 & 3.36380000 & 1.28020000 \\
\hline $\mathrm{H} 24 \mathrm{a}$ & 1.73350000 & 2.78460000 & 2.17130000 \\
\hline $\mathrm{H} 24 \mathrm{~b}$ & 3.04510000 & 3.63440000 & 1.34040000 \\
\hline $\mathrm{H} 24 \mathrm{c}$ & 1.40470000 & 4.29040000 & 1.29920000 \\
\hline $\mathrm{C} 25$ & 2.00030000 & 3.41080000 & -1.25520000 \\
\hline $\mathrm{H} 25 \mathrm{a}$ & 1.75610000 & 2.86640000 & -2.17040000 \\
\hline $\mathrm{H} 25 \mathrm{~b}$ & 1.41770000 & 4.33690000 & -1.24480000 \\
\hline $\mathrm{H} 25 \mathrm{c}$ & 3.05860000 & 3.68530000 & -1.29570000 \\
\hline $\mathrm{C} 26$ & 1.98600000 & -3.36480000 & 1.27700000 \\
\hline $\mathrm{H} 26 \mathrm{a}$ & 3.04450000 & -3.63550000 & 1.33730000 \\
\hline $\mathrm{H} 26 \mathrm{~b}$ & 1.73270000 & -2.78620000 & 2.16850000 \\
\hline $\mathrm{H} 26 \mathrm{c}$ & 1.40410000 & -4.29140000 & 1.29510000 \\
\hline $\mathrm{C27}$ & 2.00050000 & -3.40980000 & -1.25840000 \\
\hline $\mathrm{H} 27 \mathrm{a}$ & 1.41780000 & -4.33600000 & -1.24880000 \\
\hline $\mathrm{H} 27 \mathrm{~b}$ & 1.75660000 & -2.86480000 & -2.17330000 \\
\hline $\mathrm{H} 27 \mathrm{c}$ & 3.05880000 & -3.68440000 & -1.29890000 \\
\hline $\mathrm{H} 4 \mathrm{~b}$ & -5.43710000 & -0.86720000 & -1.21630000 \\
\hline
\end{tabular}




\section{F.5. meta-[NMI(H)]-}

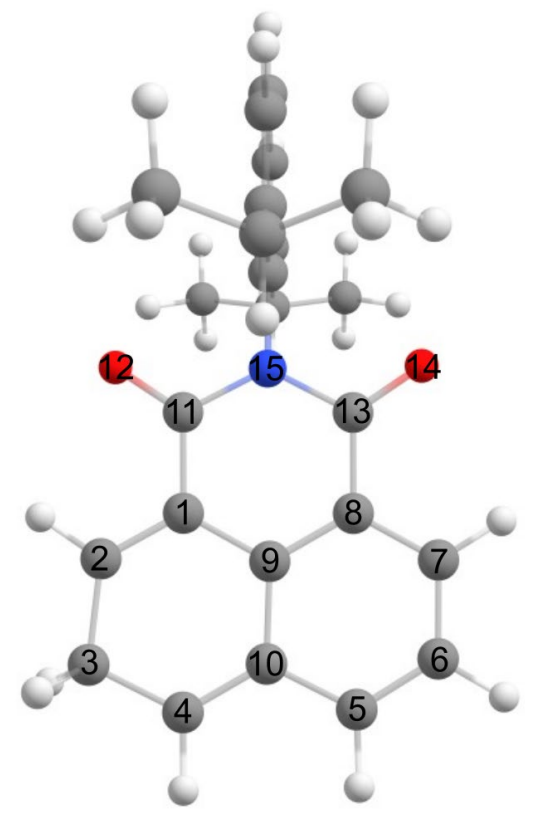

Figure S16. Calculated structure of meta-[NMI(H)] $]^{-}$at the at the B3LYP/6-311G+(d,p) level of theory. Selected interatomic distances $(\AA)$ : C1-C2 1.360, C2-C3 1.504, C3-C4 1.513, C4-C10 1.375, C10-C5 1.448, C5-C6 1.377, C6-C7 1.409, C7-C8 1.404, C8-C9 1.400, C9-C10 1.459, C9-C1 1.440, C1-C11 1.482, C11-012 1.225, C13-014 1.224.

Table S6. Coordinates of meta-[NMI(H)]- optimized at the B3LYP/6-311G+(d,p) level of theory used for GIAO NMR calculations.

\begin{tabular}{|l|c|c|c|}
\hline Atom & $x$ & $y$ & $z$ \\
\hline C7 & 2.52270000 & -0.10620000 & -2.38110000 \\
\hline C8 & 1.85450000 & -0.05250000 & -1.19790000 \\
\hline C9 & 2.53520000 & -0.02040000 & 0.07090000 \\
\hline C10 & 3.99370000 & 0.01300000 & 0.03900000 \\
\hline C5 & 4.68510000 & -0.03390000 & -1.14920000 \\
\hline C6 & 4.01920000 & -0.20320000 & -2.49700000 \\
\hline H7 & 1.93390000 & -0.10400000 & -3.29320000 \\
\hline C4 & 1.83190000 & 0.02520000 & 1.28110000 \\
\hline H5 & 4.62520000 & 0.10750000 & 1.33890000 \\
\hline H6 & 5.77130000 & 0.00650000 & -1.12600000 \\
\hline C3 & 4.37130000 & 0.54490000 & -3.23280000 \\
\hline C2 & 3.89940000 & 0.14320000 & 2.50910000 \\
\hline
\end{tabular}




\begin{tabular}{|c|c|c|c|}
\hline $\mathrm{H} 4$ & 5.71070000 & 0.14610000 & 1.37780000 \\
\hline H3 & 4.43140000 & 0.20650000 & 3.45540000 \\
\hline $\mathrm{H} 2$ & 1.92100000 & 0.12160000 & 3.43680000 \\
\hline C13 & 0.37320000 & -0.01300000 & -1.23850000 \\
\hline $\mathrm{C} 11$ & 0.35910000 & 0.00560000 & 1.27170000 \\
\hline 014 & -0.29030000 & 0.00120000 & -2.26820000 \\
\hline 012 & -0.33720000 & 0.00510000 & 2.27890000 \\
\hline N15 & -0.28360000 & -0.00350000 & 0.00580000 \\
\hline $\mathrm{C} 16$ & -1.73340000 & 0.00230000 & -0.00530000 \\
\hline C17 & -2.41080000 & 1.23270000 & -0.04580000 \\
\hline C18 & -2.42070000 & -1.22300000 & 0.01960000 \\
\hline C19 & -3.80880000 & 1.21250000 & -0.06460000 \\
\hline $\mathrm{C} 20$ & -3.81850000 & -1.19270000 & 0.00180000 \\
\hline $\mathrm{C} 21$ & -4.50980000 & 0.01250000 & -0.04120000 \\
\hline $\mathrm{H} 19$ & -4.35600000 & 2.14850000 & -0.09680000 \\
\hline $\mathrm{H} 20$ & -4.37330000 & -2.12450000 & 0.02070000 \\
\hline $\mathrm{H} 21$ & -5.59480000 & 0.01650000 & -0.05560000 \\
\hline $\mathrm{C} 22$ & -1.69560000 & -2.56260000 & 0.06540000 \\
\hline $\mathrm{H} 22$ & -0.62320000 & -2.36330000 & 0.06670000 \\
\hline $\mathrm{C} 23$ & -1.67510000 & 2.56690000 & -0.07020000 \\
\hline $\mathrm{H} 23$ & -0.60460000 & 2.35960000 & -0.04360000 \\
\hline $\mathrm{C} 24$ & -2.01410000 & -3.33480000 & 1.35940000 \\
\hline $\mathrm{H} 24 \mathrm{a}$ & -1.77260000 & -2.73550000 & 2.24010000 \\
\hline $\mathrm{H} 24 \mathrm{~b}$ & -3.07300000 & -3.60730000 & 1.41240000 \\
\hline $\mathrm{H} 24 \mathrm{c}$ & -1.42890000 & -4.25870000 & 1.40310000 \\
\hline $\mathrm{C} 25$ & -1.99510000 & -3.41360000 & -1.18290000 \\
\hline $\mathrm{H} 25 \mathrm{a}$ & -1.73360000 & -2.87400000 & -2.09610000 \\
\hline $\mathrm{H} 25 \mathrm{~b}$ & -1.41530000 & -4.34160000 & -1.15690000 \\
\hline $\mathrm{H} 25 \mathrm{c}$ & -3.05440000 & -3.68350000 & -1.23960000 \\
\hline $\mathrm{C} 26$ & -2.00030000 & 3.41730000 & 1.17210000 \\
\hline $\mathrm{H} 26 \mathrm{a}$ & -3.05800000 & 3.69770000 & 1.20040000 \\
\hline $\mathrm{H} 26 \mathrm{~b}$ & -1.76900000 & 2.87230000 & 2.09000000 \\
\hline $\mathrm{H} 26 \mathrm{c}$ & -1.41030000 & 4.33920000 & 1.16490000 \\
\hline $\mathrm{C} 27$ & -1.95430000 & 3.34410000 & -1.37030000 \\
\hline $\mathrm{H} 27 \mathrm{a}$ & -1.35990000 & 4.26270000 & -1.39760000 \\
\hline $\mathrm{H} 27 \mathrm{~b}$ & -1.69680000 & 2.74380000 & -2.24600000 \\
\hline $\mathrm{H} 27 \mathrm{c}$ & -3.00900000 & 3.62640000 & -1.44900000 \\
\hline $\mathrm{H} 3 \mathrm{~b}$ & 4.27660000 & -1.17070000 & -2.98320000 \\
\hline
\end{tabular}


F.6. $\operatorname{carbo}-[\mathrm{NMI}(\mathrm{H})]^{-}$

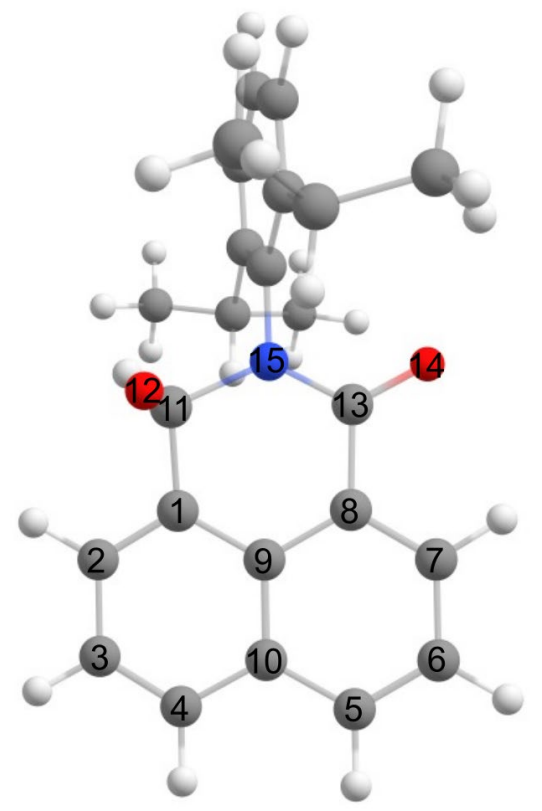

Figure S17. Calculated structure of carbo-[NMI(H)] $]^{-}$at the at the B3LYP/6-311G+(d,p) level of theory. Selected interatomic distances $(\AA)$ : C1-C2 1.380, C2-C3 1.413, C3-C4 1.377, C4-C10 1.419, C10-C5 1.419, C5-C6 1.376, C6-C7 1.411, C7-C8 1.380, C8-C9 1.424, C9-C10 1.432, C9-C1 1.419, C1-C11 1.531, C11-012 1.305, C13-O14 1.241, C2-C1-C11-012 79.5․

Table S7. Coordinates of carbo-[NMI $(\mathrm{H})]^{-}$optimized at the B3LYP/6-311G+(d,p) level of theory used for GIAO NMR calculations.

\begin{tabular}{|l|c|c|c|}
\hline Atom & $\mathbf{x}$ & $\mathrm{y}$ & $\mathbf{z}$ \\
\hline C7 & 2.61870000 & 1.10360000 & -2.12290000 \\
\hline C8 & 1.87620000 & 0.42440000 & -1.17910000 \\
\hline C9 & 2.53680000 & -0.14650000 & -0.06080000 \\
\hline C10 & 3.96510000 & -0.09560000 & 0.02870000 \\
\hline C5 & 4.69080000 & 0.59200000 & -0.97880000 \\
\hline C6 & 4.02470000 & 1.19630000 & -2.02080000 \\
\hline H7 & 2.11290000 & 1.54040000 & -2.97830000 \\
\hline C1 & 1.79330000 & -0.75600000 & 0.98970000 \\
\hline C4 & 4.60420000 & -0.72630000 & 1.12780000 \\
\hline H5 & 5.77330000 & 0.63760000 & -0.91130000 \\
\hline H6 & 4.58160000 & 1.73270000 & -2.78260000 \\
\hline C3 & 3.86510000 & -1.35810000 & 2.10200000 \\
\hline
\end{tabular}




\begin{tabular}{|c|c|c|c|}
\hline $\mathrm{H} 4$ & 5.68800000 & -0.69960000 & 1.18970000 \\
\hline H3 & 4.36370000 & -1.84140000 & 2.93560000 \\
\hline $\mathrm{H} 2$ & 1.86580000 & -1.80250000 & 2.83280000 \\
\hline $\mathrm{C} 13$ & 0.39630000 & 0.13770000 & -1.44540000 \\
\hline C11 & 0.29390000 & -0.66010000 & 1.04150000 \\
\hline $\mathrm{O} 14$ & 0.21730000 & -0.88370000 & -2.23750000 \\
\hline $\mathrm{O} 12$ & -0.31650000 & -1.06010000 & 2.04590000 \\
\hline N15 & -0.30150000 & -0.05690000 & -0.01240000 \\
\hline C16 & -1.71830000 & 0.15710000 & 0.01500000 \\
\hline C17 & -2.19110000 & 1.46030000 & 0.28410000 \\
\hline $\mathrm{C} 18$ & -2.61790000 & -0.89530000 & -0.26000000 \\
\hline C19 & -3.57020000 & 1.69210000 & 0.27480000 \\
\hline $\mathrm{C} 20$ & -3.98850000 & -0.61430000 & -0.25250000 \\
\hline $\mathrm{C} 21$ & -4.46740000 & 0.66460000 & 0.00850000 \\
\hline $\mathrm{H} 19$ & -3.94740000 & 2.68790000 & 0.48370000 \\
\hline $\mathrm{H} 2 \mathrm{O}$ & -4.69420000 & -1.41260000 & -0.45670000 \\
\hline $\mathrm{H} 21$ & -5.53520000 & 0.85910000 & 0.00520000 \\
\hline $\mathrm{C} 22$ & -2.15030000 & -2.31890000 & -0.53610000 \\
\hline $\mathrm{H} 22$ & -1.06450000 & -2.29300000 & -0.61580000 \\
\hline $\mathrm{C} 23$ & -1.24100000 & 2.60390000 & 0.62450000 \\
\hline $\mathrm{H} 23$ & -0.22540000 & 2.23560000 & 0.47400000 \\
\hline $\mathrm{C} 24$ & -2.54130000 & -3.26490000 & 0.61610000 \\
\hline $\mathrm{H} 24 \mathrm{a}$ & -2.14360000 & -2.90420000 & 1.56700000 \\
\hline $\mathrm{H} 24 \mathrm{~b}$ & -3.63000000 & -3.35410000 & 0.70740000 \\
\hline $\mathrm{H} 24 \mathrm{c}$ & -2.14010000 & -4.26790000 & 0.43360000 \\
\hline $\mathrm{C} 25$ & -2.67040000 & -2.84530000 & -1.88560000 \\
\hline H25a & -2.34970000 & -2.19150000 & -2.69890000 \\
\hline $\mathrm{H} 25 \mathrm{~b}$ & -2.26540000 & -3.84440000 & -2.07710000 \\
\hline $\mathrm{H} 25 \mathrm{c}$ & -3.76330000 & -2.92220000 & -1.90370000 \\
\hline $\mathrm{C} 26$ & -1.36810000 & 3.00860000 & 2.10630000 \\
\hline $\mathrm{H} 26 \mathrm{a}$ & -2.36360000 & 3.40970000 & 2.32370000 \\
\hline $\mathrm{H} 26 \mathrm{~b}$ & -1.20120000 & 2.15080000 & 2.76230000 \\
\hline $\mathrm{H} 26 \mathrm{c}$ & -0.63290000 & 3.78030000 & 2.35820000 \\
\hline $\mathrm{C} 27$ & -1.43070000 & 3.82200000 & -0.29710000 \\
\hline $\mathrm{H} 27 \mathrm{a}$ & -0.68450000 & 4.59030000 & -0.06970000 \\
\hline $\mathrm{H} 27 \mathrm{~b}$ & -1.31910000 & 3.54190000 & -1.34780000 \\
\hline $\mathrm{H} 27 \mathrm{c}$ & -2.41940000 & 4.27510000 & -0.17360000 \\
\hline $\mathrm{H} 11$ & -0.09120000 & 1.08940000 & -1.76530000 \\
\hline
\end{tabular}




\section{G. NMR Chemical Shift and Absolute Chemical Shielding Calculations}

\section{G.1. ${ }^{1} \mathrm{H}$ NMR Calculations}

To provide an accurate NMR prediction, an experimental chemical shift ( $\delta$ ) vs. absolute chemical shielding $(\sigma)$ plot was generated using the parent $\mathrm{NMI}$ as a calibration standard to minimize errors due to basis set effects. Linear regression between absolute chemical shielding $(\sigma)$ and experimental shift $(\delta)$ yielded $\sigma=-1.1319 * \delta+32.287$. This relationship was used to predict the ${ }^{1} \mathrm{H}$ NMR experimental chemical shifts of the ortho, meta, para and carbo hydride addition isomers of NMI. Due to the poor solubility of NMI in benzene, the only the protons of the isopropyl group, and ortho and para hydrogens of the naphthalene ring were included in the experimental fit. The atom numbering scheme used below is taken from Figure S12; hydrogen atom identity is based upon carbon atom attachment.

Table S8. Calculated absolute chemical shielding $\sigma$ vs. experimental ${ }^{1} \mathrm{H}$ NMR chemical shift $\delta$ of $\mathrm{NMI}$ in benzene- $d_{6}(\mathrm{ppm})$. iPr $=$ isopropyl.

\begin{tabular}{|c|c|c|}
\hline Entry & Experimental Chemical Shift $(\delta)$ & Calculated Shielding $(\sigma)$ \\
\hline $\mathrm{iPr} \mathrm{CH}_{3}$ & 1.2 & 30.8 \\
\hline iPr CH & 2.96 & 29.19 \\
\hline Naphthalene para $\mathrm{H}$ & 7.45 & 23.43 \\
\hline Naphthalene orthoH & 8.56 & 22.90 \\
\hline
\end{tabular}

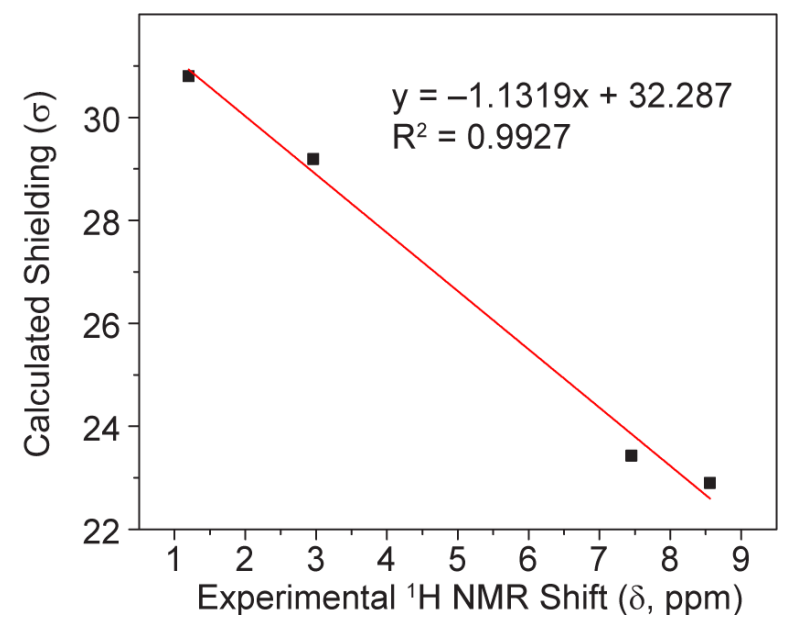

Figure S18. Experimental ${ }^{1} \mathrm{H}$ NMR chemical shifts $(\delta)$ vs. calculated absolute chemical shielding $(\sigma)$ of NMI. 
Table S9. Calculated absolute chemical shielding $\sigma$ vs. predicted ${ }^{1} \mathrm{H}$ NMR chemical shift $\delta$ of ortho-[NMI(H)] ${ }^{-}$ in benzene- $d_{6}(\mathrm{ppm})$. iPr = isopropyl.

\begin{tabular}{|l|c|c|}
\hline Entry & Calculated Shielding $(\sigma)$ & Predicted $(\delta)$ \\
\hline $\mathrm{iPr} \mathrm{CH}_{3} \times 12$ & 30.87 & 1.25 \\
\hline $\mathrm{iPr} \mathrm{CH} \times 2$ & 29.14 & 2.78 \\
\hline $\mathrm{C}(2)-H \times 2$ & 27.93 & 3.85 \\
\hline $\mathrm{C}(3)-H$ & 26.03 & 5.53 \\
\hline $\mathrm{C}(6)-H$ & 25.82 & 5.71 \\
\hline $\mathrm{C}(4)-H$ & 25.61 & 5.90 \\
\hline $\mathrm{C}(5)-H$ & 25.48 & 6.01 \\
\hline $\operatorname{PhiPr}_{2} \mathrm{C}-H \times 2$ & 24.75 & 6.66 \\
\hline $\operatorname{PhiPr}_{2} \mathrm{C}-H \times 1$ & 24.60 & 6.79 \\
\hline $\mathrm{C}(7)-H$ & 24.11 & 7.22 \\
\hline
\end{tabular}

Table S10. Calculated absolute chemical shielding $\sigma$ vs. predicted ${ }^{1} \mathrm{H}$ NMR chemical shift $\delta$ of para-[NMI(H)] ${ }^{-}$ in benzene- $d_{6}(\mathrm{ppm})$. iPr $=$ isopropyl.

\begin{tabular}{|l|c|c|}
\hline Entry & Calculated Shielding $(\sigma)$ & Predicted $(\delta)$ \\
\hline$i \operatorname{Pr} \mathrm{CH}_{3} \times 12$ & 30.90 & 1.23 \\
\hline $\mathrm{iPr} \mathrm{CH} \times 2$ & 29.10 & 2.82 \\
\hline $\mathrm{C}(4)-H \times 2$ & 27.90 & 4.05 \\
\hline $\mathrm{C}(3)-H$ & 27.16 & 4.53 \\
\hline $\mathrm{C}(6)-H$ & 25.40 & 6.08 \\
\hline $\mathrm{C}(5)-H$ & 25.05 & 6.39 \\
\hline $\mathrm{C}(2)-H$ & 24.85 & 6.57 \\
\hline $\operatorname{PhiPr}_{2} \mathrm{C}-H \times 2$ & 24.77 & 6.64 \\
\hline $\operatorname{PhiPr}_{2} \mathrm{C}-H \times 1$ & 24.62 & 6.77 \\
\hline $\mathrm{C}(7)-H$ & 24.00 & 7.32 \\
\hline
\end{tabular}


Table S11. Calculated absolute chemical shielding $\sigma$ vs. predicted ${ }^{1} \mathrm{H}$ NMR chemical shift $\delta$ of meta$[\mathrm{NMI}(\mathrm{H})]^{-}$in benzene- $d_{6}(\mathrm{ppm}) . \mathrm{iPr}=$ isopropyl, avg = protons are not strictly chemically equivalent but are averaged.

\begin{tabular}{|l|c|c|}
\hline Entry & Calculated Shielding $(\sigma)$ & Predicted $(\delta)$ \\
\hline iPr CH$H_{3} \times 12$ & 30.90 & 1.23 \\
\hline $\mathrm{C}(4)-H$ & 29.57 & 2.40 \\
\hline $\mathrm{iPr} \mathrm{CH}$ 2 & 29.24 & 2.69 \\
\hline $\mathrm{C}(7)-H$ & 27.05 & 4.62 \\
\hline $\mathrm{C}(5)-H$ & 26.95 & 4.72 \\
\hline $\mathrm{C}(6)-H$ & 26.47 & 5.14 \\
\hline $\mathrm{C}(2)-H$ & 26.04 & 5.52 \\
\hline $\mathrm{C}(3)-H$ (avg) & 25.80 & 5.73 \\
\hline $\operatorname{PhiPr}_{2} \mathrm{C}-H \times 2$ & 24.78 & 6.63 \\
\hline $\operatorname{PhiPr}_{2} \mathrm{C}-H \times 1$ & 24.59 & 6.80 \\
\hline
\end{tabular}

Table S12. Calculated absolute chemical shielding $\sigma$ vs. predicted ${ }^{1} \mathrm{H}$ NMR chemical shift $\delta$ of carbo$[\mathrm{NMI}(\mathrm{H})]^{-}$in benzene- $d_{6}(\mathrm{ppm}) . \mathrm{iPr}=$ isopropyl, avg = protons are not strictly chemically equivalent but are averaged.

\begin{tabular}{|l|c|c|}
\hline Entry & Calculated Shielding $(\sigma)$ & Predicted $(\delta)$ \\
\hline iPr $\mathrm{CH}_{3} \times 12$ (avg) & 30.83 & 1.29 \\
\hline $\mathrm{iPr} \mathrm{CH}$ & 28.57 & 3.28 \\
\hline $\mathrm{iPr} \mathrm{CH}$ & 27.80 & 3.96 \\
\hline $\mathrm{PhiPr}_{2} \mathrm{C}-H$ & 24.73 & 6.68 \\
\hline $\mathrm{PhiPr}_{2} \mathrm{C}-H$ & 24.64 & 6.76 \\
\hline $\mathrm{PhiPr}_{2} \mathrm{C}-H$ & 24.62 & 6.77 \\
\hline $\mathrm{C}(11)-H$ & 24.57 & 6.81 \\
\hline $\mathrm{C}(3)-H$ & 24.37 & 6.99 \\
\hline $\mathrm{C}(2)-H$ & 24.35 & 7.01 \\
\hline $\mathrm{C}(6)-H$ & 24.32 & 7.04 \\
\hline $\mathrm{C}(4)-H$ & 24.18 & 7.16 \\
\hline $\mathrm{C}(5)-H$ & 23.91 & 7.40 \\
\hline $\mathrm{C}(7)-H$ & 23.22 & 8.01 \\
\hline
\end{tabular}




\section{G.2. ${ }^{13} \mathrm{C}$ NMR Calculations}

To provide an accurate NMR prediction, an experimental chemical shift $(\delta)$ vs. absolute chemical shielding $(\sigma)$ plot was generated using the parent $\mathrm{NMI}$ as a calibration standard to minimize errors due to basis set effects. Linear regression between absolute chemical shielding $(\sigma)$ and experimental shift $(\delta)$ yielded $\sigma=-1.0284 * \delta+180.73$. This relationship was used to predict the ${ }^{13} \mathrm{C}$ NMR experimental chemical shifts of the ortho, meta, para and carbo hydride addition isomers of NMI. Due to the poor solubility of $\mathrm{NMI}$ in benzene, the experimental ${ }^{13} \mathrm{C}$ shifts of $\mathrm{NMI}$ were taken from a ${ }^{13} \mathrm{C}$ spectrum acquired in chloroform. The atom numbering scheme used below is taken from Figure S12.

Table S13. Calculated absolute chemical shielding $\sigma$ vs. experimental ${ }^{13} \mathrm{C}$ NMR chemical shift $\delta$ of $\mathrm{NMI}$ in chloroform- $d(\mathrm{ppm})$. iPr = isopropyl.

\begin{tabular}{|c|c|c|}
\hline Entry & Experimental Chemical Shift $(\delta)$ & Calculated Shielding $(\sigma)$ \\
\hline ¡Pr Cof $\mathrm{CH}_{3}$ & 24.13 & 157.93 \\
\hline iPr C of $\mathrm{CH}$ & 29.26 & 148.21 \\
\hline$C(1)+C(8)$ & 122.91 & 54.34 \\
\hline $\mathrm{PhiPr}_{2} \mathrm{C}$ of $\mathrm{Ph} \mathrm{C}-\mathrm{H} \times 2$ & 124.16 & 54.10 \\
\hline$C(3)+C(6)$ & 127.18 & 51.18 \\
\hline $\mathrm{PhiPr}_{2} \mathrm{C}$ of $\mathrm{Ph} \mathrm{C}-H \times 1$ & 129.63 & 48.76 \\
\hline$C(9)$ or $C(10)$ & 128.96 & 48.19 \\
\hline$C(9)$ or $C(10)$ & 130.99 & 46.03 \\
\hline$C(2)+C(7)$ & 131.88 & 45.48 \\
\hline$C 4)+C(5)$ & 134.32 & 43.03 \\
\hline $\mathrm{PhiPr}_{2} \mathrm{C}$ & 131.98 & 42.9 \\
\hline $\mathrm{PhiPr}_{2} \mathrm{C}$ of $\mathrm{C}-\mathrm{iPr}$ & 145.81 & 28.16 \\
\hline$C(11)+C(13)$ & 164.32 & 12.36 \\
\hline
\end{tabular}




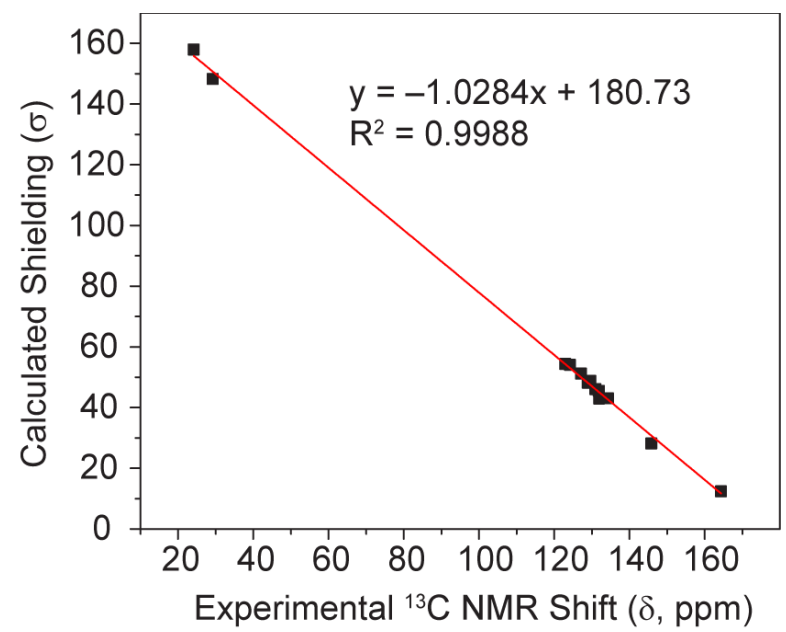

Figure S19. Experimental ${ }^{13} \mathrm{C}$ NMR chemical shifts $(\delta)$ vs. calculated absolute chemical shielding $(\sigma)$ of NMI.

Table S14. Selected calculated absolute chemical shielding $\sigma$ vs. predicted ${ }^{13} \mathrm{C}$ NMR chemical shifts $\delta$ of ortho- $[\mathrm{NMI}(\mathrm{H})]^{-}$in benzene- $d_{\sigma}(\mathrm{ppm})$.

\begin{tabular}{|c|c|c|}
\hline Entry & Calculated Shift $(\sigma)$ & Predicted $(\delta)$ \\
\hline C2 & 148.58 & 31.26 \\
\hline C6 & 68.27 & 109.35 \\
\hline C5 & 58.27 & 119.08 \\
\hline C7 & 49.05 & 128.04 \\
\hline C4 & 48.76 & 128.33 \\
\hline C3 & 48.33 & 128.74 \\
\hline C11 & 16.33 & 159.86 \\
\hline C13 & 13.18 & 162.93 \\
\hline
\end{tabular}

Table S15. Selected calculated absolute chemical shielding $\sigma$ vs. predicted ${ }^{13} \mathrm{C}$ NMR chemical shifts $\delta$ of $\operatorname{para}-[\mathrm{NMI}(\mathrm{H})]^{-}$in benzene- $d_{6}(\mathrm{ppm})$.

\begin{tabular}{|l|c|c|}
\hline Entry & Calculated Shielding $(\sigma)$ & Predicted $(\delta)$ \\
\hline C4 & 146.30 & 33.48 \\
\hline C3 & 73.00 & 104.76 \\
\hline C6 & 63.80 & 113.70 \\
\hline C7 & 51.61 & 125.55 \\
\hline C2 & 49.00 & 128.09 \\
\hline C5 & 48.88 & 128.21 \\
\hline C11 & 17.58 & 158.64 \\
\hline C13 & 12.01 & 164.06 \\
\hline
\end{tabular}


Table S16. Selected calculated absolute chemical shielding $\sigma$ vs. predicted ${ }^{13} \mathrm{C}$ NMR chemical shifts $\delta$ of meta-[NMI(H)]- in benzene- $d_{6}(\mathrm{ppm})$.

\begin{tabular}{|l|c|c|}
\hline Entry & Calculated Shielding $(\boldsymbol{\sigma})$ & Predicted $(\boldsymbol{\delta})$ \\
\hline C3 & 138.66 & 40.91 \\
\hline C4 & 111.24 & 67.57 \\
\hline C7 & 83.67 & 94.38 \\
\hline C2 & 47.90 & 129.16 \\
\hline C6 & 49.34 & 127.76 \\
\hline C5 & 60.29 & 117.14 \\
\hline C11 & 10.57 & 165.46 \\
\hline C13 & 9.48 & 166.52 \\
\hline
\end{tabular}

Table S17. Selected calculated absolute chemical shielding $\sigma$ vs. predicted ${ }^{13} \mathrm{C}$ NMR chemical shifts $\delta$ of carbo- $[\mathrm{NMI}(\mathrm{H})]^{-}$in benzene- $d_{6}(\mathrm{ppm})$.

\begin{tabular}{|l|c|c|}
\hline Entry & Calculated Shielding $(\sigma)$ & Predicted $(\delta)$ \\
\hline C11 & 71.41 & 106.30 \\
\hline C4 & 56.54 & 120.76 \\
\hline C2 & 54.97 & 122.29 \\
\hline C6 & 54.32 & 122.92 \\
\hline C7 & 53.10 & 124.11 \\
\hline C3 & 52.50 & 124.69 \\
\hline C5 & 49.56 & 127.55 \\
\hline C13 & 13.13 & 162.97 \\
\hline
\end{tabular}

\section{G.3. Analysis of the Experimental NMR Spectra Based upon ${ }^{1} \mathrm{H}$ and ${ }^{13} \mathrm{C}$ NMR Calculations}

Addition of a hydride anion to $\mathrm{NMI}$ is predicted to make 4 possible isomers, designated ortho$[\mathrm{NMI}(\mathrm{H})]^{-}$, meta- $[\mathrm{NMI}(\mathrm{H})]^{-}$, para- $[\mathrm{NMI}(\mathrm{H})]^{-}$, or carbo-[NMI $\left.(\mathrm{H})\right]^{-}$. = Based upon known $\mathrm{S}_{N} \mathrm{Ar}$ chemistry, it would be expected that the most likely outcome of the reaction of NMI with a hydride equivalent is the formation of either the ortho- $[\mathrm{NMI}(\mathrm{H})]^{-}$, para- $[\mathrm{NMI}(\mathrm{H})]^{-}$, or carbo- $[\mathrm{NMI}(\mathrm{H})]^{-}$ species. To assist in the identification of the species present in Figure S10, ${ }^{1} \mathrm{H}$ and ${ }^{13} \mathrm{C} \mathrm{NMR}$ calculations were utilized to predict the NMR spectra of the possible isomers for comparison. The structures of the four isomers were optimized using the B3LYP functional and the $6311 G+(d, p)$ 
basis set with an IEFPCM benzene solvation shell to arrive at equilibrium structures. From these calculations, key ${ }^{1} \mathrm{H}$ and ${ }^{13} \mathrm{C}$ NMR chemical shifts were compared with the experimental spectra, shown below:

Table S18. ${ }^{1} \mathrm{H}$ and ${ }^{13} \mathrm{C}$ calculated chemical shifts of the relevant hydride protons or carbon atom which is directly bonded to the hydride equivalent.

\begin{tabular}{|c|c|}
\hline Species & Prediction (ppm) \\
\hline ortho-[NMI(H)]- $\left(\mathrm{H}_{2}\right)$ & 3.85 \\
\hline ortho-[NMI(H)]- (C) & 31.26 \\
\hline meta-[NMI(H)]- $\left(\mathrm{H}_{2}\right)$ & 5.73 \\
\hline meta-[NMI(H)]-(C) & 40.91 \\
\hline para-[NMI(H)]- $\left(\mathrm{H}_{2}\right)$ & 4.05 \\
\hline para- $[\mathrm{NMI}(\mathrm{H})]^{-}(\mathrm{C})$ & 33.48 \\
\hline carbo-[NMI(H)]- $(\mathrm{H})$ & 6.81 \\
\hline carbo-[NMI(H)]- $(\mathrm{C})$ & 106.30 \\
\hline
\end{tabular}

Table S19. Diagnostic experimental ${ }^{1} \mathrm{H}$ and ${ }^{13} \mathrm{C}$ resonances of the product of treating $\mathrm{NMI}$ with a hydride equivalent (ppm, benzene- $\left.d_{6}\right)$.

\begin{tabular}{|l|c|}
\hline Entry & Chemical Shift (ppm) \\
\hline Experimental ${ }^{1} \mathrm{H}$ resonance of the hydride product & 4.10 \\
\hline Experimental ${ }^{1} \mathrm{H}$ resonance of the hydride product & 4.18 \\
\hline Experimental ${ }^{13} \mathrm{C}$ resonance of the hydride product & 27.7 \\
\hline Experimental ${ }^{13} \mathrm{C}$ resonance of the hydride product & 30.2 \\
\hline
\end{tabular}

Comparison of the calculated values in Table S12 with the experimental values obtained in Table S13 clearly implicate ortho- $[\mathrm{NMI}(\mathrm{H})]^{-}$and para- $[\mathrm{NMI}(\mathrm{H})]^{-}$as the likely products of the reaction of $\mathrm{NMI}$ with a hydride source or electrochemical $2 \mathrm{e}^{-}$reduction concomitant with protonation. While conclusive assignment of the resonances in Table S13 cannot be made from these calculations alone, the predicted $\mathrm{CH}_{2}{ }^{1} \mathrm{H}$ and ${ }^{13} \mathrm{C}$ resonances of the ortho isomer are calculated to be further upfield relative to the para isomer, leading to the following tentative assignment below: 


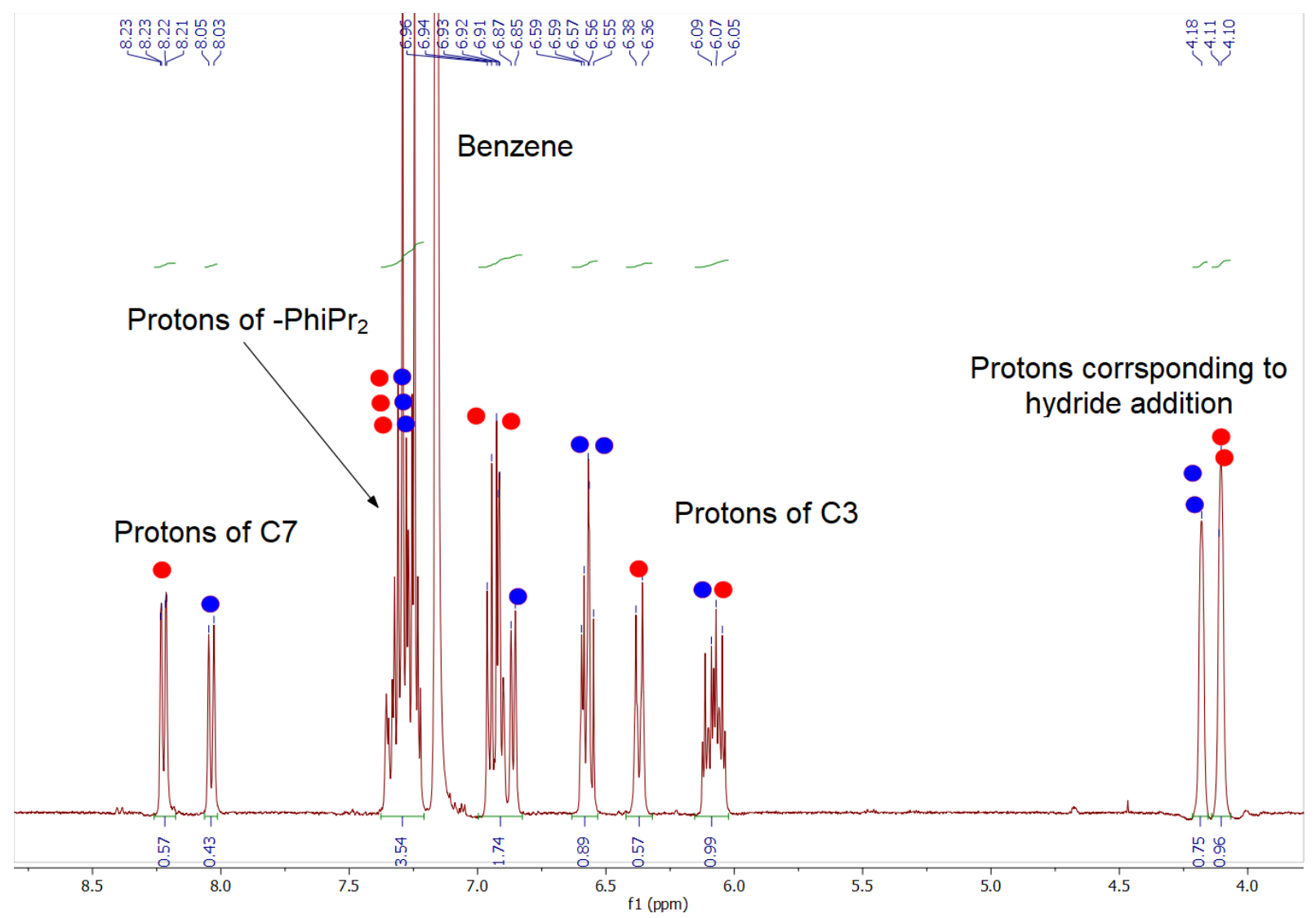

Figure S20. Tentative assignment of the ${ }^{1} \mathrm{H}$ spectrum in Figure S10 considering the calculated NMR predictions. The red dots correspond to ortho- $[\mathrm{NMI}(\mathrm{H})]^{-}$while the blue dots correspond to para- $[\mathrm{NMI}(\mathrm{H})]^{-}$. Each dot represents a proton. There is an apparent $~ 57: 43$ ratio of ortho:para $[\mathrm{NMI}(\mathrm{H})]^{-}$isomers. 


\section{H. HOMO and LUMO Energy Levels and Latimer Diagram of [NMI(H)] $]^{-}$}

A

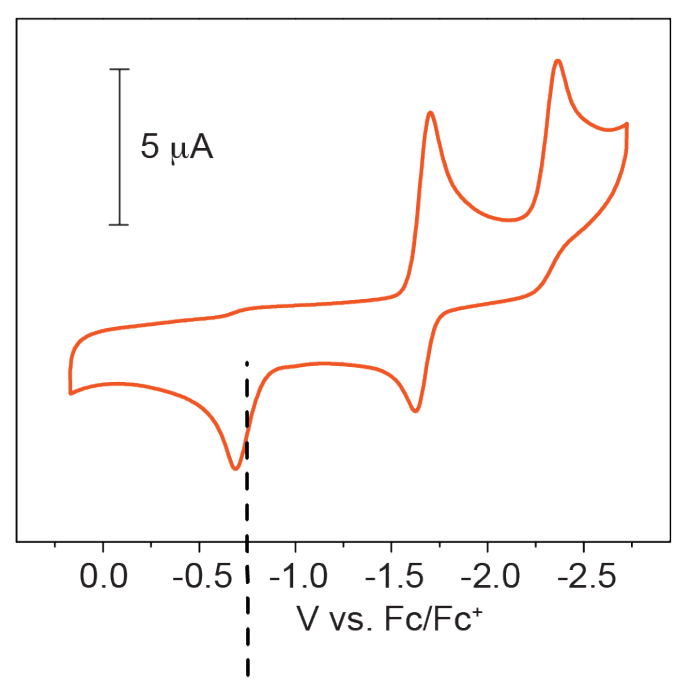

$\mathrm{HOMO}=-0.75 \mathrm{Vvs} . \mathrm{Fc} / \mathrm{Fc}^{+}$ inflection point of reoxidation wave

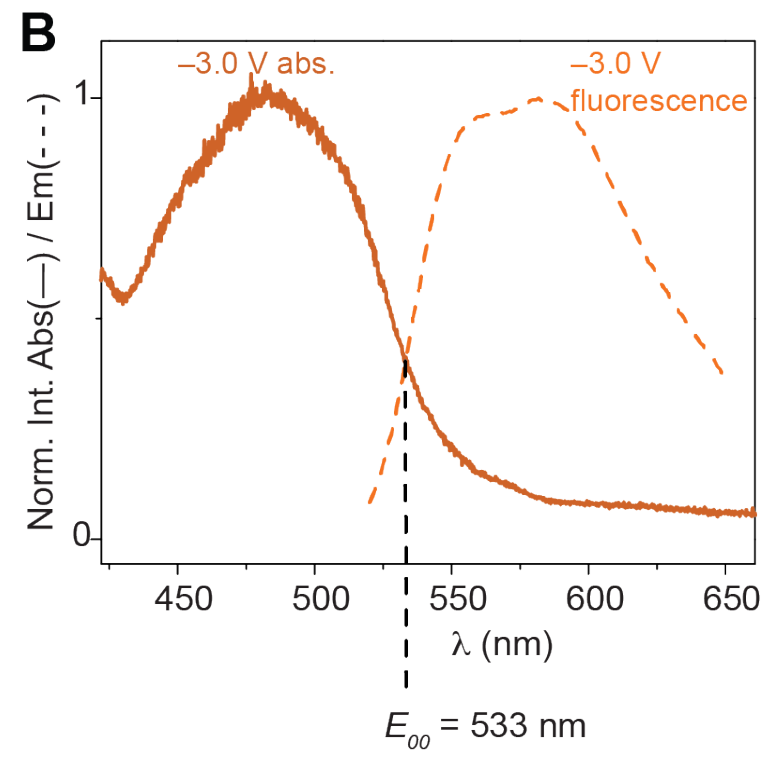

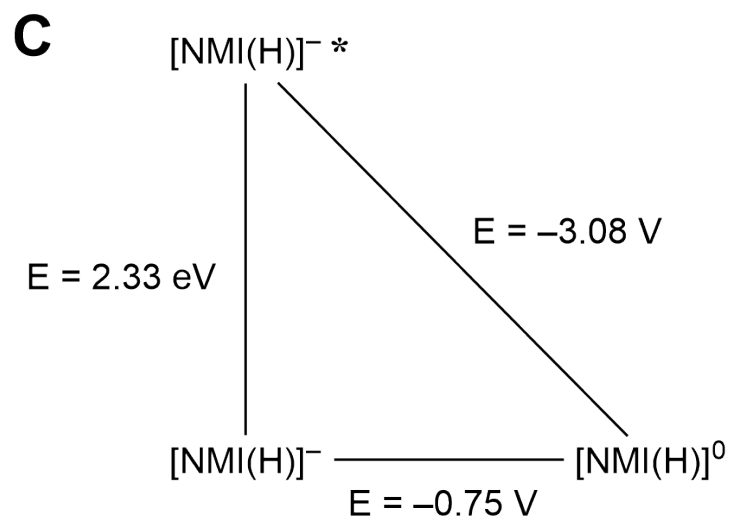

Figure S21. (A) Cyclic voltammogram of $1 \mathrm{mM} \mathrm{NMI}$ in $100 \mathrm{mM} \mathrm{TBAPF}_{6}$ propylene carbonate solution. The scan rate was $100 \mathrm{mV} / \mathrm{s}$. A $1 \mathrm{~cm}^{2}$ glassy carbon working electrode, leak-free $\mathrm{Ag} / \mathrm{AgCl}$ reference electrode, and Pt mesh counter electrode were used. The HOMO energy level is approximated by the $[\mathrm{NMI}(\mathrm{H})]^{0 /-}$ reduction potential at $-0.75 \mathrm{~V}$ vs. $\mathrm{Fc} / \mathrm{Fc}^{+}$. (B) Overlay of the normalized absorbance (solid) and emission (dashed) spectra of $1 \mathrm{mM} \mathrm{NMI} \mathrm{in} 100$ mM 100 mM TBAPF $_{6}$ dimethyl acetamide solution after applying $3.0 \mathrm{~V}$ vs. $\mathrm{Fc} / \mathrm{Fc}^{+}$. The $E_{00}$ excited state energy of $[\mathrm{NMI}(\mathrm{H})]^{-*}$ is assigned as the overlap of the normalized absorption and emission spectra: $E_{00}=533 \mathrm{~nm}, 2.33 \mathrm{eV}$. (C) Latimer diagram of $[\mathrm{NMI}(\mathrm{H})]^{-}$to furnish the $[\mathrm{NMI}(\mathrm{H})]^{0 /-*}$ reduction potential of $-3.08 \mathrm{~V}$ vs. $\mathrm{Fc} / \mathrm{Fc}^{+}$. The energies of $\mathrm{NMI}[\mathrm{H}\}^{-}$are summarized on the energy level diagram of Figure 4 in main text. 


\section{Photoreactivity of [NMI(H)]-[TBA]+ with Methyl-4-Chlorobenzoate}

Inside a $\mathrm{N}_{2}$-filled glovebox, a stock solution consisting of [NMI(H)] $]^{-}[\mathrm{TBA}]^{+}$(30 $\mathrm{mg}, 0.051 \mathrm{mmol}$ ) and methyl-4-chlorobenzoate $\left(9 \mathrm{mg}, 0.051 \mathrm{mmol}\right.$ ) dissolved in $2.25 \mathrm{~mL} \mathrm{C}_{6} \mathrm{D}_{6}$ was prepared. To $3 \mathrm{~J}$ Young NMR tubes, $0.75 \mathrm{~mL}$ of the stock solution were added. One tube was sealed. To the second tube was added $0.075 \mathrm{~mL}$ (50 eq.) N-methyl pyrrole, and the tube was then sealed. To the third tube was added $0.014 \mathrm{~mL}$ (5 equiv) triethylphosphite, and the tube was then sealed. Solutions in sealed J-Young tubes were brought out of the glovebox and allowed to sit for $2 \mathrm{~h}$ in the dark, then NMR spectra were acquired. Solutions were then illuminated with two $440 \mathrm{~nm}$ Kessil LED lamps while cooled by a fan. Post-reaction NMR spectra were then acquired after two hours of illumination.

Scheme 1: Photoreactivity of $[\mathrm{NMI}(\mathrm{H})]^{-}[\mathrm{TBA}]^{+}$with methyl-4-chlorobenzoate, and with radical traps $\mathrm{N}$ methylpyrrole or triethylphosphite.

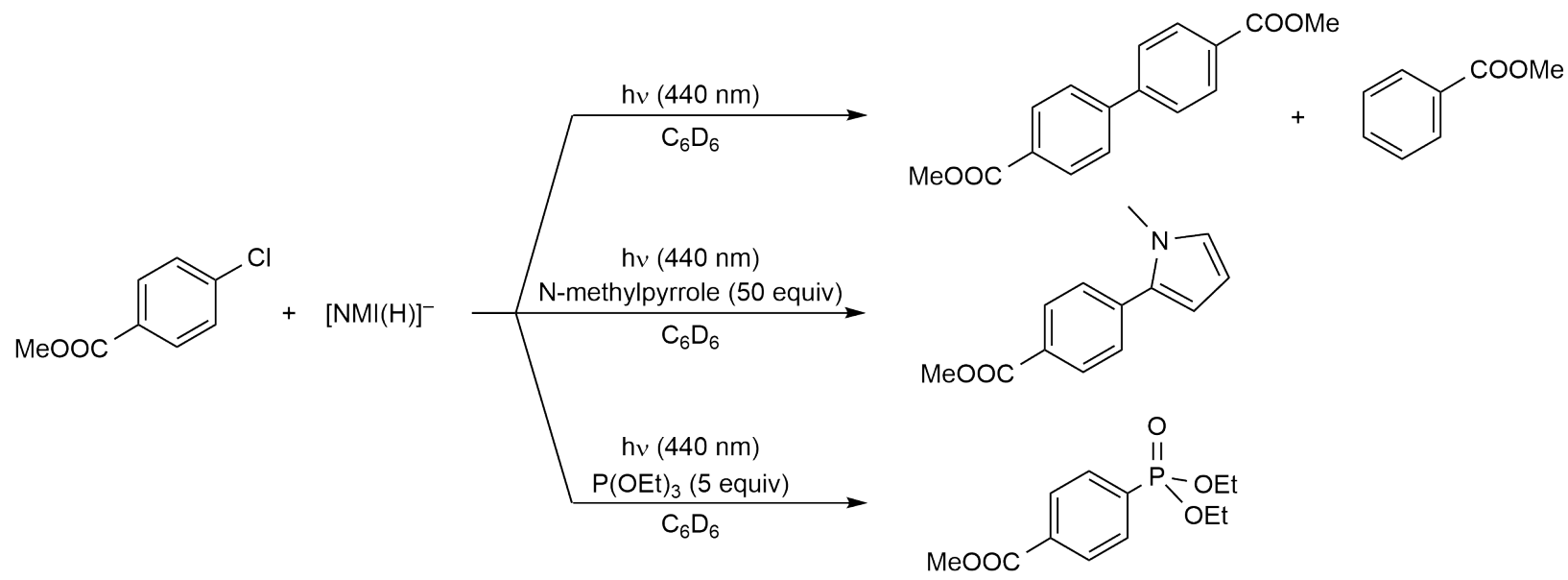



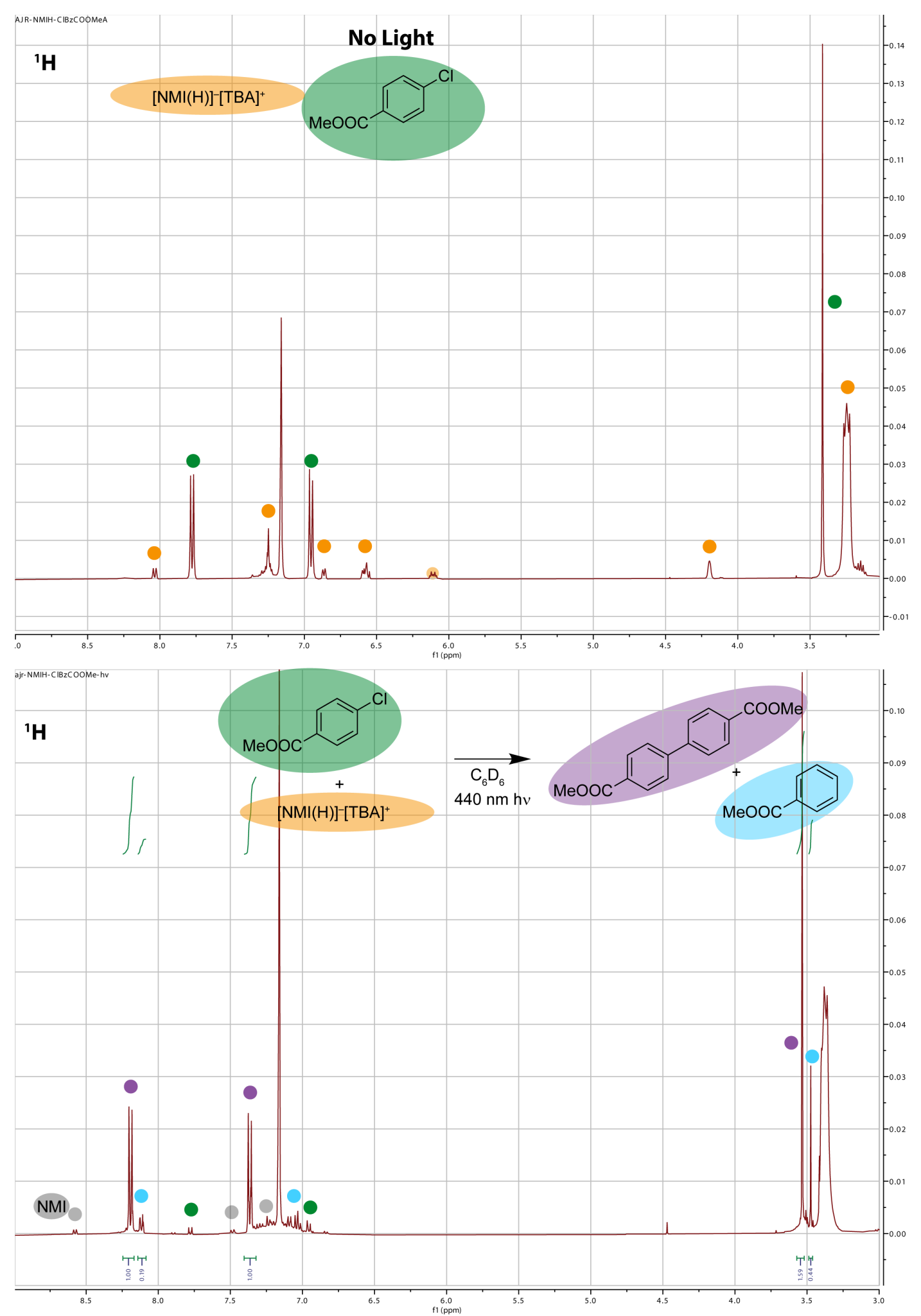

Figure S22. Top: NMR spectrum $\left({ }^{1} \mathrm{H}, 400 \mathrm{MHz}\right)$ of $[\mathrm{NMI}(\mathrm{H})]^{-}[\mathrm{TBA}]^{+}$and methyl-4-chlorobenzoate dissolved $\mathrm{C}_{6} \mathrm{D}_{6}$, after sitting in the dark for $2 \mathrm{~h}$ in a J-Young NMR tube. Bottom: NMR spectrum $\left({ }^{1} \mathrm{H}, 400 \mathrm{MHz}\right)$ of the same sample after illumination $(440 \mathrm{~nm})$ for $2 \mathrm{~h}$. 

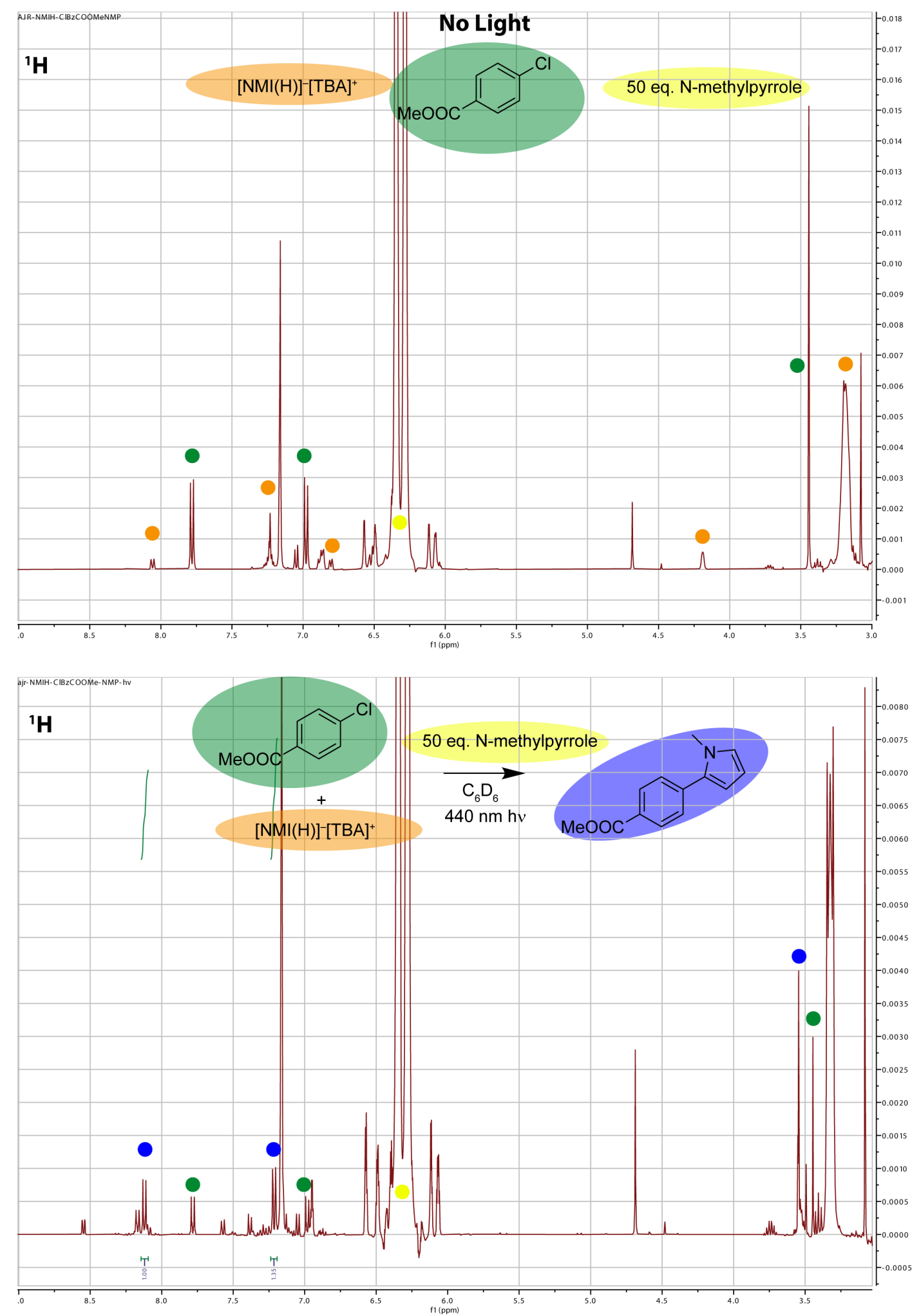

Figure S23. Top: NMR spectrum $\left({ }^{1} \mathrm{H}, 400 \mathrm{MHz}\right)$ of $[\mathrm{NMI}(\mathrm{H})]^{-}[\mathrm{TBA}]^{+}$, methyl-4-chlorobenzoate and $\mathrm{N}$-methyl pyrrole dissolved $\mathrm{C}_{6} \mathrm{D}_{6}$, after sitting in the dark for $2 \mathrm{~h}$ in a J-Young NMR tube. Bottom: NMR spectrum $\left({ }^{1} \mathrm{H}\right.$, $400 \mathrm{MHz}$ ) of the same sample after illumination (440 $\mathrm{nm})$ for $2 \mathrm{~h}$. 

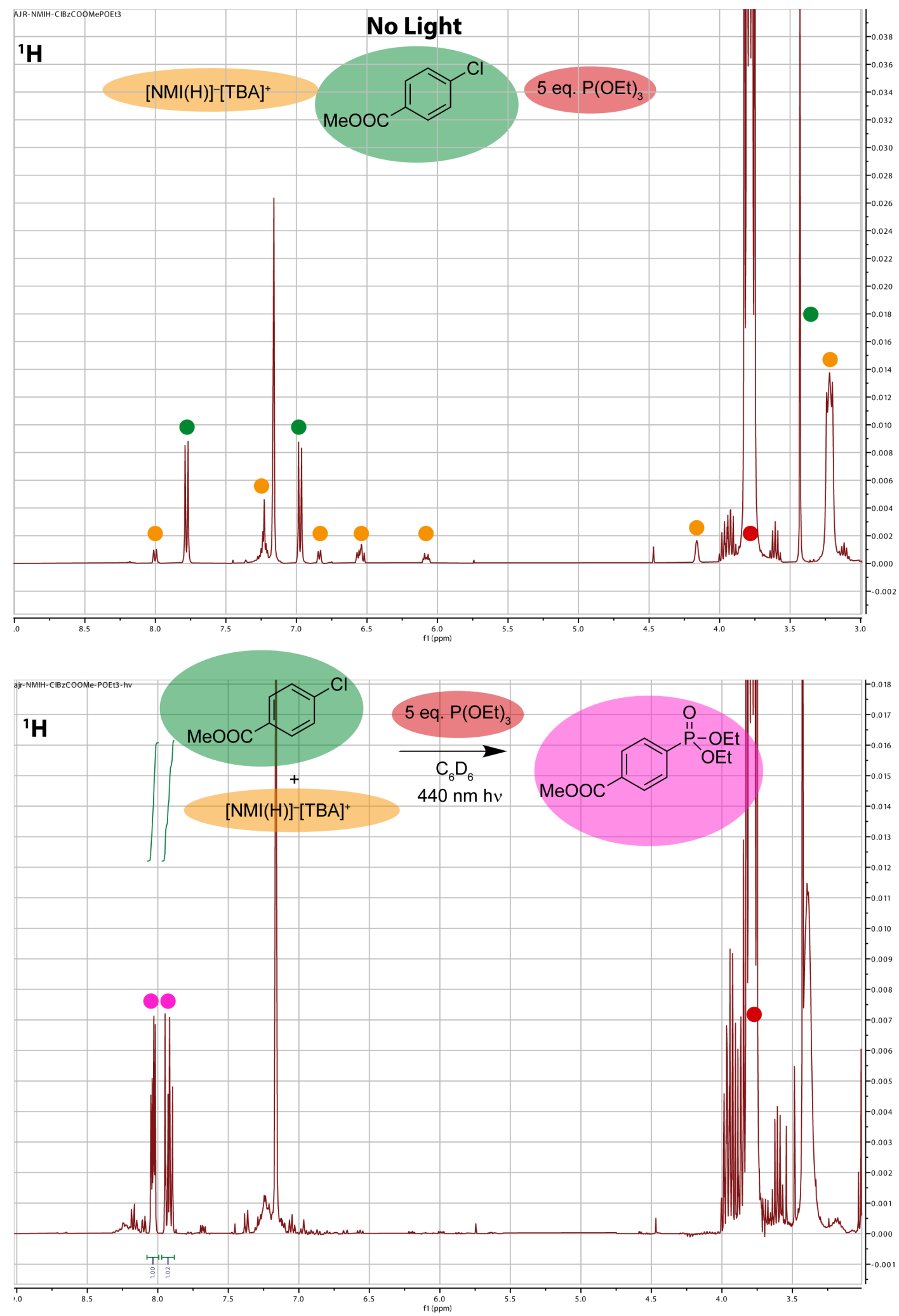

Figure S24. Top: NMR spectrum $\left({ }^{1} \mathrm{H}, 400 \mathrm{MHz}\right)$ of $[\mathrm{NMI}(\mathrm{H})]^{-}[\mathrm{TBA}]^{+}$, methyl-4-chlorobenzoate and $\mathrm{P}(\mathrm{OEt})_{3}$ dissolved $\mathrm{C}_{6} \mathrm{D}_{6}$, after sitting in the dark for $2 \mathrm{~h}$ in a J-Young NMR tube. Bottom: NMR spectrum $\left({ }^{1} \mathrm{H}, 400 \mathrm{MHz}\right)$ of the same sample after illumination $(440 \mathrm{~nm})$ for $2 \mathrm{~h}$. 

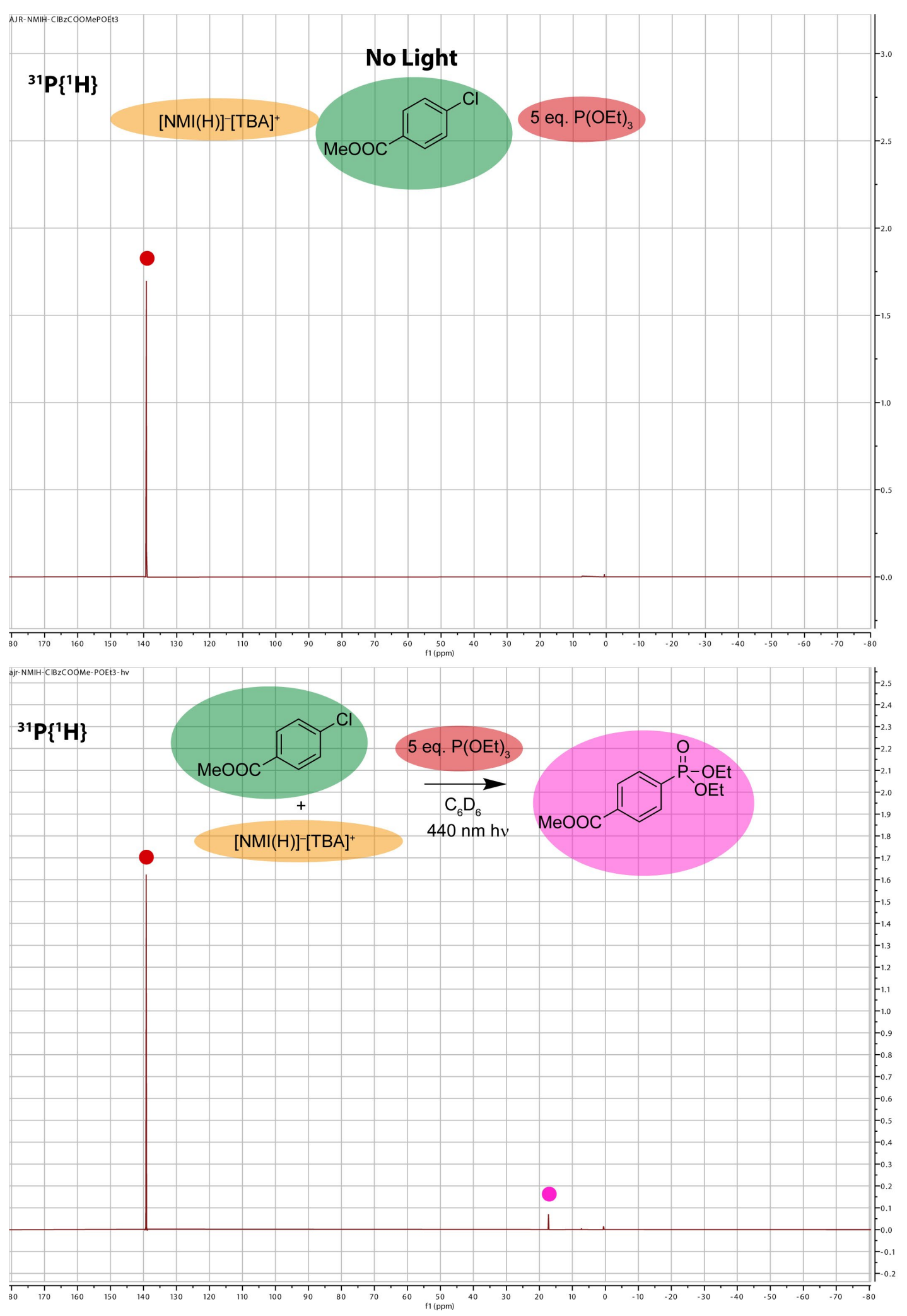

Figure S25. Top: NMR spectrum $\left({ }^{31} \mathrm{P}\left\{{ }^{1} \mathrm{H}\right\}, 400 \mathrm{MHz}\right)$ of $[\mathrm{NMI}(\mathrm{H})]^{-}[\mathrm{TBA}]^{+}$, methyl-4-chlorobenzoate and $\mathrm{P}(\mathrm{OEt})_{3}$ dissolved $\mathrm{C}_{6} \mathrm{D}_{6}$, after sitting in the dark for $2 \mathrm{~h}$ in a J-Young NMR tube. Bottom: NMR spectrum $\left({ }^{31} \mathrm{P}\left\{{ }^{1} \mathrm{H}\right\}, 400 \mathrm{MHz}\right)$ of the same sample after illumination $(440 \mathrm{~nm})$ for $2 \mathrm{~h}$. 


\section{J. References}

1. Cowper, N. G. W.; Chernowsky, C. P.; Williams, O. P.; Wickens, Z. K. Potent Reductants via ElectronPrimed Photoredox Catalysis: Unlocking Aryl Chlorides for Radical Coupling. J. Am. Chem. Soc. 2020, 142, 2093-2099.

2. Bradler, M.; Riedle, E. Temporal and Spectral Correlations in Bulk Continua and Improved Use in Transient Spectroscopy. J. Opt. Soc. Am. B 2014, 31, 1465-1475.

3. SAINT and APEX 2 Software for CCD Diffractometers; Bruker Analytical X-ray Systems: Madison, WI, 2000.

4. Sheldrick, G. M. SADABS; Bruker Analytical X-ray Systems: Madison, WI, 2014.

5. Sheldrick, G. M. SHELXT - Integrated Space-Group and Crystal-Structure Determination. Acta Cryst. A 2015, A71, 3-8.

6. Sheldrick, G. M. SHELXL; University of Göttingen: Germany, 2014.

7. Dolomanov, O. V.; Bourhis, L. J.; Gildea, R. J.; Howard, J. A. K.; Puschmann, H. OLEX2: A Complete Structure Solution, Refinement and Analysis Program. J. Appl. Cryst. 2009, 42, 339-341.

8. Frisch, M. J. et al. Gaussian09 Revision D.01. Gaussian Inc. Wallingford CT 2009.

9. Lee, C.; Yang, W.; Parr, R. G. Development of the Colle-Salvetti correlation-energy formula into a functional of the electron density. Phys. Rev. B 1988, 37, 785-789.

10. Perdew, J. P.; Burke, K.; Ernzerhof, M. Generalized Gradient Approximation Made Simple. Phys. Rev. Lett. 1996, 77, 3865-3868.

11. McLean, A. D.; Chandler, G. S. Contracted Gaussian basis sets for molecular calculations. I. Second row atoms, Z=11-18. J. Chem. Phys. 1980; 72: 5639-48.

12. Krishnan, R.; Binkley, J. S.; Seeger, R.; Pople, J. A. Self-consistent molecular orbital methods. XX. A basis set for correlated wave functions. J. Chem. Phys. 1980, 72, 650-654.

13. Clark, T.; Chandrasekhar, J.; Spitznagel, G. W.; Schleyer, P. V. R. Efficient diffuse function-augmented basis sets for anion calculations. III. The 3-21+G basis set for first-row elements, Li-F. J. Comp. Chem. 1983, 4, 294-301. 
14. Cheeseman, J. R.; Trucks, G. W.; Keith, T. A.; Frisch, M. J. A comparison of models for calculating nuclear magnetic resonance shielding tensors. J. Chem. Phys. 1996, 104, 5497- 5509.

15. Wolinski, K.; Hinton J. F.; Pulay, P. Efficient implementation of the gauge-independent atomic orbital method for NMR chemical shift calculations. J. Am. Chem. Soc. 1990, 112, 8251-8260.

16. Ditchfield, R. Self-consistent perturbation theory of diamagnetism. Mol. Phys. 1974, 27, 789-807.

17. McWeeny, R. Perturbation Theory for the Fock-Dirac Density Matrix. Phys. Rev. 1962, 126, 1028-1034.

18. London, F. Theorie quantique des courants interatomiques dans les combinaisons aromatiques. J. Phys. Radium 1937, 8, 397-409. 